\title{
Isolation, synthesis and complement inhibiting activity of the naturally occurring K-76, its analogues and derivatives
}

\author{
Enrique L. Larghi and Teodoro S. Kaufman* \\ Instituto de Química Rosario (IQUIR, CONICET-UNR) and \\ Facultad de Ciencias Bioquímicas y Farmacéuticas, Universidad Nacional de Rosario, \\ Suipacha 531, S2002LRK Rosario, República Argentina \\ E-mail: kaufman@iquir-conicet.gov.ar
}

Dedicated to Professor Manuel González Sierra on the occasion of his $65^{\text {th }}$ birthday

DOI: http://dx.doi.org/10.3998/ark.5550190.0012.708

\begin{abstract}
The Complement inhibitor K-76 was isolated from the supernatant of the culture broth of the fungus Stachybotrys complementi, nov. sp. K-76. The natural product is a sesquiterpenic dialdehyde which can be partially oxidized to the monocarboxylic acid derivative ( $\mathrm{K}-76 \mathrm{COOH}$, MX-1), the sodium salt of which is more soluble and less toxic than the natural product. Both, $\mathrm{K}$ 76 and $\mathrm{K}-76 \mathrm{COOH}$ inhibit Complement activation by the classical and alternative pathways, mainly at the C5 level. Reviewed here are the isolation and total syntheses of the natural product as well as aspects of its Complement inhibitory activity. Approaches to the synthesis of grisan, which bears the BCD skeleton of the natural product, as well as the synthesis of CD-, BCD- and ACD-ring structural analogues of K-76, including the use of natural products as starting materials, and evaluation of their biological activity as Complement inhibitors, are also discussed.
\end{abstract}

Keywords: K-76, Complement inhibitors, filifolinol, structural analogues, chemical synthesis, bioactive natural products

\section{Table of Contents}

1. The Complement system. Structure and activity in health and disease

2. Complement inhibitors

2.1. Synthetic non-peptidic low molecular weight compounds as Complement inhibitors

2.2. Natural products and semi-synthetic compounds as Complement inhibitors

3. Isolation of K-76. Simple modifications of the natural product. Activity as Complement 
inhibitor

3.1. Stachybotrys $s p$. derived natural products structurally related to K-76

4. Chemical syntheses of K-76

4.1. The K-76 synthesis of Corey and Das

4.2. The K-76 synthesis of McMurry and Erion

4.3. The K-76 synthesis of Mori and Komatsu

4.4. Enantioselective syntheses of diastereomeric compounds closely related to K-76

5. Syntheses of Grisan, the tricycle embodying the BCD ring system of K-76

5.1. Synthesis of grisan by Antus and co-workers

5.2. Synthesis of grisan by Kaufman and Sindelar

5.3. Synthesis of grisan by Snider and co-workers

6. Synthesis of K-76 analogues and related compounds for biological testing

6.1. Synthesis and evaluation of CD-ring analogues

6.2. Synthesis and evaluation of BCD-ring analogues

6.3. Synthesis and evaluation of ACD-ring analogues

6.4. Semi-synthetic filifolinol derivatives as $\mathrm{K}-76 \mathrm{COOH}$ analogues. Biological evaluation

7. Conclusions

\section{The Complement system. Structure and activity in health and disease}

The Complement system is a phylogenetically conserved element which emerged about 600-700 million years ago, preceding the emergence of vertebrates and antibody development, and evolved as a sophisticated, distinct and important part of the innate immune system, reflecting its relevance in protection against non-self. Even sea urchins, which evolved some 700 millon years ago, have a functioning Complement system. ${ }^{1}$ Humans born with highly defective Complement systems do not live long before succumbing to infection. The system is composed of about thirty plasma and membrane components, factors, regulators and receptors, which are linked in biochemical cascades, known as the classical, alternative and lectin pathways. ${ }^{2}$

The Complement system is designed to allow unimpeded and rapid activation on a target, with strict limitation of such activation in time and space. It plays a critical role in host-defence response against infectious pathogens, through its participation in the elimination of potentially damaging substances from the body, including self-antigens and apoptotic cells, ${ }^{3}$ in the modulation of the antigen-specific immune response as well as in the initiation of the inflammatory response, ${ }^{4}$ tissue regeneration and interference with tumour growth. ${ }^{5}$

Activation of the Complement system most often can take place through the classical, the lectin (mannose-binding) or the alternative pathway. Initiation of these cascades is mainly based on the detection of surface structures by pattern-recognition proteins. As shown in Figure 1, these three proximal pathways converge on Complement component C3. Cleavage of this key component yields $\mathrm{C} 3 \mathrm{a}$ and $\mathrm{C} 3 \mathrm{~b}$, which in turn leads to $\mathrm{C} 5$ cleavage with production of $\mathrm{C} 5 \mathrm{a}$ and 
$\mathrm{C} 5 \mathrm{~b}$; the latter precedes the assembly of the membrane attack complex (C5b-9), capable of causing cell lysis, including those of foreign microorganisms. The peptides C3a and C5a (produced and released during Complement activation) are anaphylatoxins, powerful chemo attractants for leukocytes, which may cause important tissue damage.

The three pathways are triggered by different initiators. The classical pathway is activated through $\mathrm{Clq}$ binding to immune complexes; this induces $\mathrm{C} 1 \mathrm{q}$ association with the serine proteases $\mathrm{C} 1 \mathrm{r}$ and $\mathrm{C} 1 \mathrm{~s}$ in a large enzymatic complex which is able to cleave $\mathrm{C} 4$ and $\mathrm{C} 2$, producing $\mathrm{C} 4 \mathrm{~b}$ and $\mathrm{C} 2 \mathrm{a}$, respectively, which assemble to form the classical $\mathrm{C} 3$ convertase.

The alternative pathway is spontaneously activated by hydrolysis of the internal thioester bond of $\mathrm{C} 3$ generating $\mathrm{C} 3\left(\mathrm{H}_{2} \mathrm{O}\right){ }^{6}$ this slow but permanent activation is markedly enhanced by contact with various exposed factors found on foreign surfaces, including microorganisms. The $\mathrm{C} 3\left(\mathrm{H}_{2} \mathrm{O}\right)$ generated by the spontaneous "tick-over" is capable of binding and cleaving factor B into $\mathrm{Ba}$ and $\mathrm{Bb}$ by the protease known as factor $\mathrm{D}$. This process generates $\mathrm{C} 3\left(\mathrm{H}_{2} \mathrm{O}\right) \mathrm{Bb}$, which is able to cleave additional $\mathrm{C} 3$ molecules into $\mathrm{C} 3 \mathrm{a}$ and $\mathrm{C} 3 \mathrm{~b}$. The $\mathrm{C} 3 \mathrm{~b}$ fragment generated by any of the three proximal pathway $\mathrm{C} 3$ convertases may also bind factor $\mathrm{B}$, allowing further propagation of $\mathrm{C} 3$ activation through a sort of 'amplification loop'.

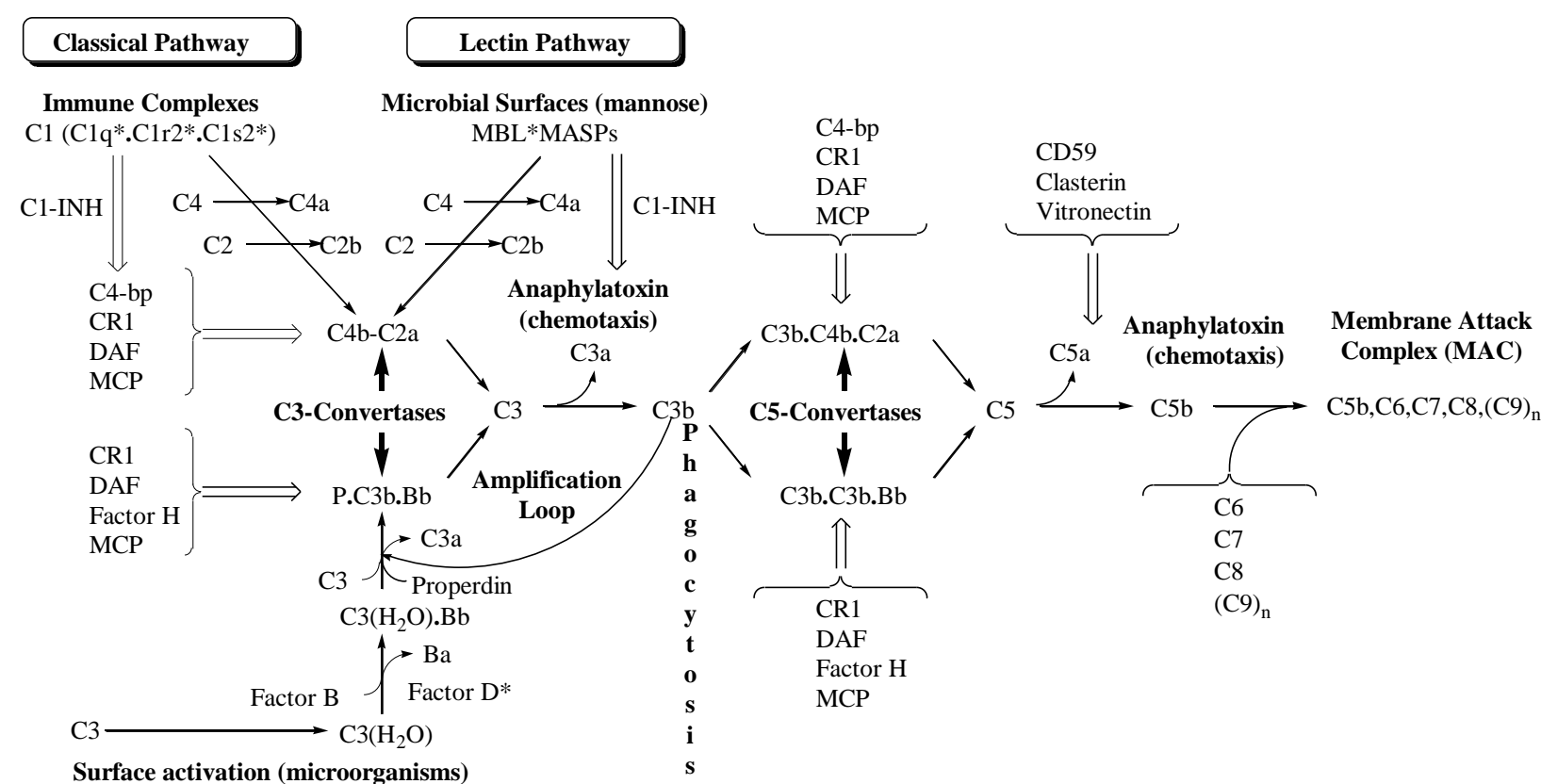

Figure 1. Schematics of the components, activation pathways and regulation points within the Complement system.

Finally, the mannose binding lectin (MBL) pathway is triggered by the binding of MBL to repeating carbohydrate residues exposed on target cells. This pathway has been described in cases of ischemia and reperfusion of systemic organs, a situation which leads to self-antigens 
exposure, which bind MBL. Then, the mannose-associated serine protease 2 (MASP-2), assists cleavage of $\mathrm{C} 4$ and $\mathrm{C} 2$, leading to the assembly of a $\mathrm{C} 3$ convertase. $^{8}$ In addition, several other proteases such as thrombin, the coagulation cascade serine protease, have been described as able to serve as independent or parallel pathway $\mathrm{C} 3$ and/or $\mathrm{C} 5$ convertases, both in vitro and in vivo. ${ }^{9}$ Under normal conditions, this complex mission is accomplished employing different strategies, depending upon the nature of the triggering agent: (a) Tagging pathogen cells and promoting their phagocytosis; (b) Generating anaphylatoxic responses which lead to local inflammatory responses; (c) Promoting membrane attack on pathogenic cells, which results in their lysis; (d) Assisting the solubilization and clearance of immune complexes from circulation; (e) Promoting an antibody response by helping the immune system to select the appropriate antigens, and (f) Helping the body to eliminate self-reactive B cells. Therefore, the Complement system is ubiquitous within living species and remains in constant activation. Main Complement effects and their corresponding Complement mediators are depicted in Table 1.

Table 1. Main Complement effects and their corresponding Complement mediators

\begin{tabular}{ll}
\hline Effect & Complement product(s) involved \\
\hline Cell lysis & C5b-9 \\
& (MAC, membrane attack complex) \\
$\begin{array}{l}\text { Inflammatory response } \\
\text { Chemotaxis and extravasation of white cells (leukocytes) at the }\end{array}$ & C3a, C5a, C5b-7 \\
inflammation site & \\
Degranulation of eosinophiles & C3a, C5a \\
Degranulation of mast cells and basophils & C3a. C4a, C5a (anaphylatoxins) \\
Inhibition of monocyte/macrophage migration and spreading & Bb \\
Release of neutrophils from bone marrow & C3c \\
Release of hydrolytic enzymes from neutrophils & C5a \\
Increased expression of Complement Receptors CR1 and CR3 on & C5a \\
neutrophils & \\
Opsonization of particulate antigens & C3b, C4b, iC3b \\
Neutralization of virus & C3b, C5b-9 (MAC) \\
Solubilization and clearance of immune complexes & C3b \\
\hline
\end{tabular}

The architecture of the Complement system yields an aggressive proteolytic cascade which is not able to discriminate between the self and the non-self; consequently, activation of Complement entails the potential to destroy harmful as well as harmless cells, including those of the host. Therefore, the Complement system is tightly regulated at different levels by a complex family of functionally related membrane-bound and soluble proteins. However, deficiencies of these regulatory components or excessive activation of Complement in response to certain pathological conditions can overwhelm this protective mechanism. Such unbalanced activation has been associated with a number of diseases, pathological disorders and situations taking place 
during medical interventions, ${ }^{10}$ some of which are shown in Table 2.

Controlled activation of this system is critical for a proper response. On the contrary, the autologous activation of the Complement may lead to disease complications, resulting in significant tissue damage with devastating effects. This is often a result from incomplete biocompatibility of materials during haemodialysis, use of artificial hearts and the like.

Table 2. Diseases and interventions in which the Complement system is implicated

\begin{tabular}{|c|c|c|}
\hline Disease/Intervention & Process & Evidence of Complement involvement \\
\hline $\begin{array}{l}\text { Immune-mediated } \\
\text { diseases }\end{array}$ & Rheumatoid arthritis & $\begin{array}{l}\text { Consumption of Complement in acute disease; activation } \\
\text { products in synovial fluid and on synovial membrane; } \\
\text { systemic Complement inhibition suppresses disease in animal } \\
\text { models; Complement deficiency suppresses disease in mouse } \\
\text { models. }\end{array}$ \\
\hline \multirow[t]{3}{*}{$\begin{array}{l}\text { Membranoproliferative } \\
\text { diseases }\end{array}$} & Glomerulonephritis & $\begin{array}{l}\text { Abundant deposits of Complement activation products, } \\
\text { including membrane attack complexes, in glomeruli; } \\
\text { Complement inhibition suppresses disease in models; } \\
\text { intrarenal administration of Complement regulators suppresses } \\
\text { disease in models. }\end{array}$ \\
\hline & Multiple sclerosis & $\begin{array}{l}\text { Activation products found in CSF and around areas of } \\
\text { demyelination in CNS; Complement inhibition suppresses } \\
\text { disease in animal models; Complement deficiency suppresses } \\
\text { disease in rodent models. }\end{array}$ \\
\hline & Myasthenia gravis & $\begin{array}{l}\text { Abundant activation products at motor end plate during } \\
\text { attacks; Complement deficiency or depletion abrogates disease } \\
\text { in rodent models; Complement inhibition (cobra venom factor; } \\
\text { soluble recombinant human CR1) suppresses disease in } \\
\text { models. }\end{array}$ \\
\hline Degenerative diseases & Alzheimer's disease & $\begin{array}{l}\text { Complement activation products in and around plaques in the } \\
\text { central nervous system; anti-inflammatory therapy appears to } \\
\text { slow progression. }\end{array}$ \\
\hline $\begin{array}{l}\text { Ischemia-reperfusion } \\
\text { injuries }\end{array}$ & $\begin{array}{l}\text { Myocardial infarct } \\
\text { Stroke }\end{array}$ & $\begin{array}{l}\text { Reperfusion associated with activation in ischemic area; } \\
\text { abundant deposits of activation products in and around infarct; } \\
\text { Complement inhibition at time of reperfusion in models } \\
\text { reduces size of infarct. }\end{array}$ \\
\hline Interventional activation & $\begin{array}{l}\text { Cardiopulmonary } \\
\text { bypass } \\
\text { Hemodialysis }\end{array}$ & $\begin{array}{l}\text { Complement activation products in plasma; "coating" circuits } \\
\text { to reduce Complement activation improves outcome. }\end{array}$ \\
\hline
\end{tabular}

Unregulated Complement activation leading to acute inflammation and tissue damage has been implicated in the pathology of many disease states. ${ }^{11}$ Activation of the classical pathway 
has been implicated in humorally mediated graft rejection, ${ }^{12}$ ischemia-reperfusion injury, ${ }^{13}$ hereditary angioedema, ${ }^{14}$ vascular leak syndrome, ${ }^{15}$ and acute respiratory distress syndrome. ${ }^{16}$ Complement activation is also an important event during allograft rejection, making the use of Complement inhibitors a requirement for long-term graft survival in allotransplantology. ${ }^{17}$

These and other often life-threatening effects, including hyperacute rejection of xenografts, ${ }^{18}$ necrosis of infarcted heart tissue, brain damage and autoimmune tissue lesions, ${ }^{19}$ can be ameliorated by Complement inhibition. ${ }^{20}$ Several autoimmune conditions where the Complement system is a rational therapeutic target have been listed. ${ }^{21}$ Surprisingly, only very recently the first therapeutic Complement inhibitor has been approved for routine clinical use in specific cases. ${ }^{22}$ In addition, the involvement of the Complement system in the early phases of the inflammatory response and the wide array of pro-inflammatory consequences of Complement activation, ${ }^{23}$ have made this system an attractive target for therapeutic intervention. This has resulted in the isolation and synthesis of a host of Complement inhibitors, ${ }^{24}$ as well as the design of new and useful bioactive structures. ${ }^{25}$

\section{Complement inhibitors}

During the last two decades, the Complement system has been the focus of drug research and still remains as a highly active area for drug discovery and lead optimization. Moreover, in recent years, the growing understanding of its role in the pathogenesis of various diseases has seeded a renaissance of the interest on the development of Complement inhibitors for clinical use. ${ }^{26}$ Different aspects of therapeutic Complement inhibition, ${ }^{27}$ including the most promising Complement inhibitors and their structural requirements for inhibition ${ }^{28}$ have been the subject of several review articles. ${ }^{29}$

The search for Complement inhibitors has lead to the discovery and development of several new chemical entities, including monoclonal antibodies (eculizumab), recombinant Complement regulatory proteins, small peptides and others. ${ }^{30}$ Examples of these are the small cyclic peptides compstatin $^{31}$ and 'peptide 2j', a soluble version of recombinant human CR1 (sCR1) lacking the transmembrane and cytoplasmic domains ${ }^{32}$ and sulphated polymers, like carrageenine, dextran sulphate, chondroitin sulphate, polyvinyl sulphate and others such as heparin. ${ }^{33}$

During this search, a host of active compounds were found to be useless due to chemical instability, low potency, poor selectivity, high toxicity and short half-life. All the currently available Complement-inhibiting drugs in clinical use and most of those being clinically tested are high molecular weight biotherapeutics. ${ }^{34}$ Peptidic, ${ }^{35}$ polysaccharide and protein-based Complement inhibitors seem to be highly efficacious and to possess some interesting advantages; some of them are highly specific and act at low molar doses. However, they also display some serious drawbacks; their production is usually expensive, their formulation is difficult and they are potentially immunogenic; in addition, their bioavailability ${ }^{36}$ and tissue penetration are often very limited and some of them cannot be given orally. These inconveniencies constitute serious 
limits to the full potential of these inhibitors. ${ }^{37}$

Many low molecular weight compounds ${ }^{38}$ and pharmaceutically active ingredients belonging to different classes of therapeutic agents, have been found to inhibit Complement; among them antiarrhythmics (practolol and procainamide), antibacterials (clofazimine, dapsone and isoniazid), antihypertensives (cadralazine, captopril, hydralazine, nifedipine and pindolol), antirheumatics (penicillamine), non-steroidal anti-inflammatory agents (acetylsalicylic acid, flufenamic acid, indomethacin, niflumic acid, oxyphenbutazone, phenylbutazone and sulindac), steroidal anti-inflammatory agents (prednisolone) and tranquilizers (chlorpromazine). This prompted Becker as early as in 1972 to note that a list of all compounds capable to inhibit Complement would become 'a catalogue of a chemical supply house'. ${ }^{39}$

However, none of them is clinically useful as Complement inhibitor. Therefore, there is an urgent need for the development of low molecular weight therapeutically effective Complement inhibitors. These therapeutics have been proposed as inexpensive, orally and topically active, more tissue-penetrating and patient-preferred alternatives to their labile proteinaceous counterparts. Such advantages become more important when the drug must be administered over a long period of time, such as during the management of chronic autoimmune disorders. ${ }^{40}$

Small-molecule Complement inhibitors have yet to enter the marketplace. Their search and design has remained an active area of research during the last 20 years. Compstatin, a synthetic 13 amino acid cyclic peptide that blocks all three known Complement activation pathways, is currently undergoing clinical development for the treatment of age-related macular degeneration. ${ }^{41}$ On the other hand, polysubstituted amidines have been developed to block the serine protease activity of $\mathrm{C} 1 \mathrm{~s}$. However, therapeutic intervention at more central levels such as on the C3 and C5 convertases constitute attractive strategies because this approach can more effectively modulate the production of all the critical Complement mediators. Most of the regulatory components of the Complement system itself act at this level. Among naturally occurring compounds showing Complement inhibitory properties, the biopolymers, including polysaccharides, polynucleotides, polypeptides, and proteins appear to be the most actives. Low molecular weight compounds, such as flavonoids (rutin and quercetin) and terpenoids, including betulinic acid ${ }^{42}$ and rosmarinic acid, ${ }^{43}$ also have shown to display anticomplement activity.

\subsection{Synthetic non-peptidic low molecular weight compounds as complement inhibitors}

A brief survey of the recent literature indicates that several low molecular weight compounds have been shown to possess Complement inhibiting properties. Among the non-peptidic chemical entities that have exhibited this activity, the amidino-guanidino type serine protease inhibitor FUT-175 (futhan, nafamostat, 1) ${ }^{44}$ is perhaps the best known (Figure 2).

Amidine type inhibitors include the Complement inhibitor BCX 14702 and compounds 3-5 carrying a 5-methylthiophene motif. The former was initially discovered in 1997 as a Factor D inhibitor with an $\mathrm{IC}_{50}$ of $96 \mathrm{nM}$, but turned out to be a very potent $\mathrm{C} 1 \mathrm{~s}$ inhibitor $\left(\mathrm{IC}_{50}=1.6\right.$ $\mathrm{nM}) .{ }^{45}$ The latter two are new scaffolds, resulting from a structure-based design of inhibitors of factor D, a serine protease of the alternative Complement pathway. These molecules showed a 
highly specific inhibitory profile ( $\mathrm{IC}_{50}=0.096-0.0016 \mu \mathrm{M}$ ). Compound $\mathbf{5}$ is considered as one of the most promising inhibitors of Complement activation. ${ }^{46}$
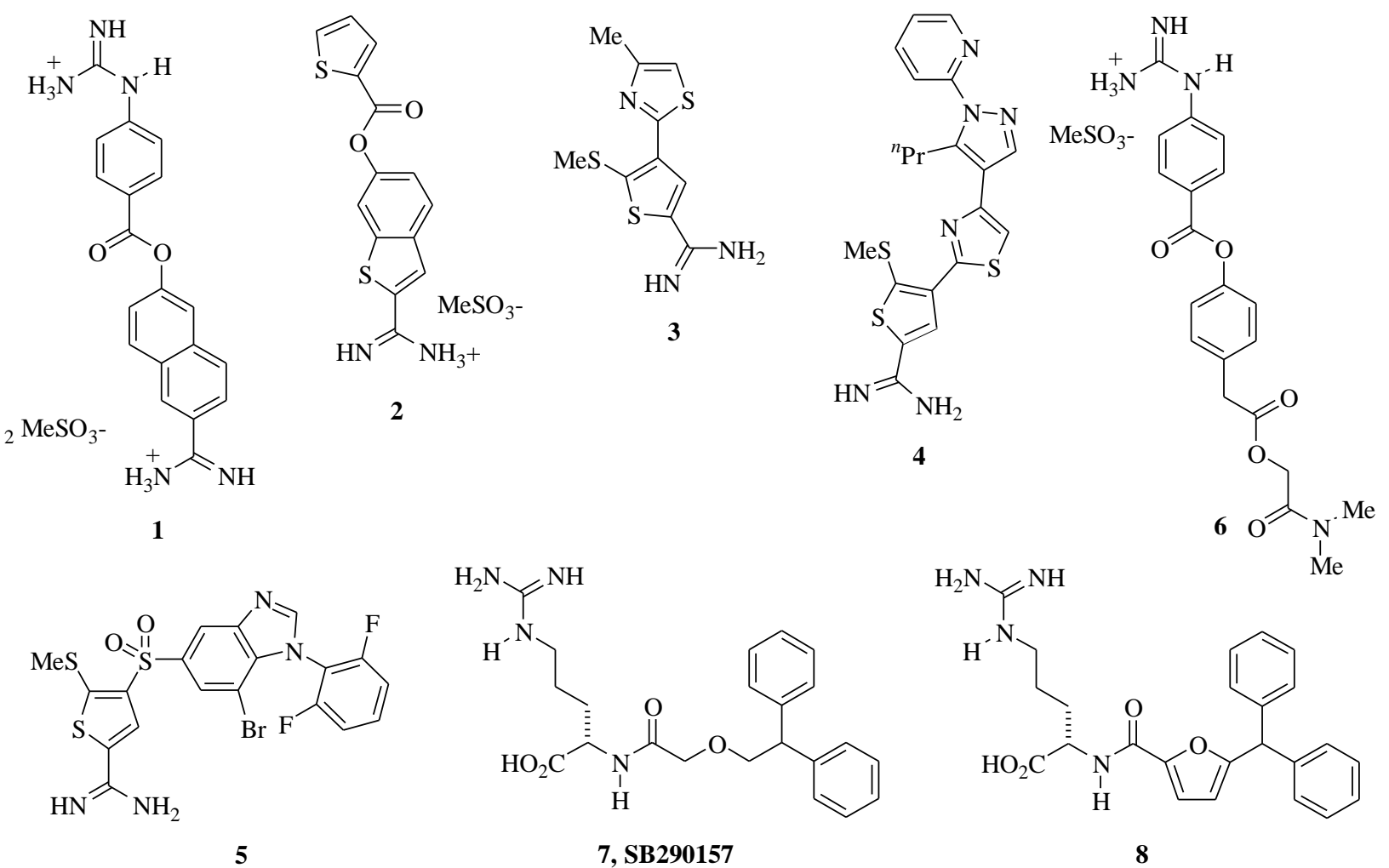

Figure 2. Representative synthetic inhibitors of the Complement system.

The proteinase inhibitor FOY-305 (camostat, 6) has shown to possess some Complement inhibitory activity. ${ }^{47}$ On the other hand, compounds 7 (SB290157) and its conformationally restricted analog $\mathbf{8}$, which embody the guanidine moiety as part of an arginine residue, act as potent $\mathrm{C} 3$ a receptor antagonists. ${ }^{48}$ Additionally, carboxylic acids $\mathbf{9}, \mathbf{1 0}^{49}$ and $\mathbf{1 1},{ }^{50}$ the disodium disuccinate derivative astaxanthin (cardax, 12) and amino acid-related carbamoylphosphinic acids such as $\mathbf{1 3},{ }^{51}$ have also shown Complement inhibiting activity (Figure 3).

On the other hand, Complement inhibitory properties have also been associated to nitrogen heterocycles, including pyrazolo[3,4-d] pyridazine 14 (Figure 4), ${ }^{52}$ derivatives of orlistat $15^{53}$ and benzylpyridinium salts 16. These novel structures were discovered as a result of structureactivity relationship studies of several classes of compounds displaying Complement-inhibiting activity. ${ }^{54} \mathrm{~A}$ good correlation between substituent lipophilicity and electronic properties, expressed by Hammett's constant, was established..$^{55}$

Very recently, the group of Bureeva applied this approach in an analogous fashion to bisphenol A 17 derivatives (Figure 5), correlating their biological activity with structural descriptors as hydrophobicity, polarizability and partial charges. ${ }^{56}$ Based on their findings, the authors concluded that the activity increased with introduction of two anionic groups (sulfate or 
phosphate) and also with bulky hydrophobic substituents, rendering sulfonic acid structure $\mathbf{1 8}$ as the most active compound of this series. On the other hand, epigallocatechin $19^{57}$ is another example of polyphenolics which have been reported as Complement inhibitors.<smiles>C=C1C(=O)OC(CCCCCCCC)C1C(=O)O</smiles>

9<smiles>CC=CC1=C(C)C(=O)[C@@H](OC(=O)CCC(=O)O)CC1(C)C</smiles><smiles>O=C(O)/C=C/c1cccc(Oc2ccccc2)c1</smiles>

10<smiles>CCCCCCCCC(=O)O</smiles>

11

Figure 3. Carboxylic 9-12 and carbamoylphosphinic 13 acid derivatives as Complement inhibitors.

Dyestuffs, many of which have been commonly used as medicines during the early 1900s, constitute an interesting family of compounds unexpectedly capable to exert anticomplement activity. Some examples with proven activity as Complement inhibitors are suramin, trypan blue 20 and chlorazol fast pink. They share a common structural arrangement of negatively charged groups, which may determinate their property to inhibit Complement activation. ${ }^{58}$<smiles>C=CCn1nc(N)c2cc(-c3c(-c4ccccc4)nn4ccccc34)nnc21</smiles>

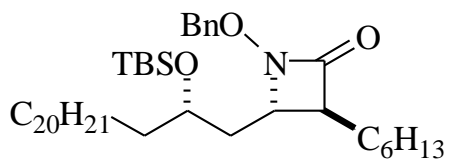

15<smiles>[Y]1=CC=[N+](Cc2cc[Y]cc2)CC=1</smiles>

16

14

Figure 4. Complement inhibitors exhibiting various nitrogen-based heterocyclic structures. 


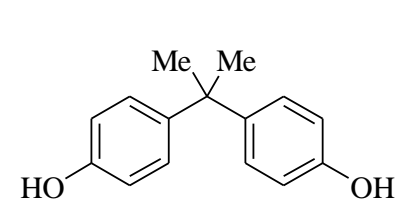

17

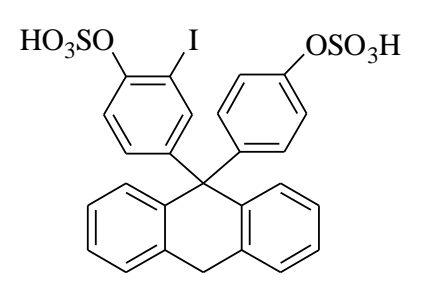

18<smiles>O=C(OC1Cc2ccccc2O[C@H]1c1cc(O)c(O)c(O)c1)c1cc(O)c(O)c(O)c1</smiles><smiles>Cc1cc(-c2ccc(N=Nc3c([N+](=O)[O-])cc4cc([N+]([O-])([O-])[O-])cc(N)c4c3O)c([N+](=O)[O-])c2)ccc1N=Nc1c([N+](=O)[O-])cc2cc(S(N)(=O)=O)cc(N)c2c1O</smiles>

19

Figure 5. Polyphenolics and sulfonic acid derivatives as Complement inhibitors.

\subsection{Natural products and semi-synthetic compounds as complement inhibitors}

Natural products remain as the richest source of Complement system inhibitors. Among naturally occurring compounds, biopolymers, including polysaccharides (heparin), polynucleotides, polypeptides, and proteins appear to be the most active. However, many low molecular weight compounds also have shown to display Complement inhibiting properties, among them flavonoids such as rutin and quercetin, terpenoids, including betulinic acid (21, Figure 6), oleanolic acid $\mathbf{2 2}^{42}$ and rosmarinic acid. ${ }^{43}$

An elegant and useful approach to discover new lead compounds is based on the development of semi-synthetic derivatives of natural products. Usually, the modification of the original structure conducts to an improvement on physicochemical and therapeutic profiles (solubility, bioavailability, increased bioactivity, minimal toxicity), when compared with its natural precursor. Several research groups have been exploiting this approach to discover new active steroids and terpenoids derivatives, from natural products with known Complementinhibiting properties. Packard and Weiler found a set of steroid sulfates and phosphates capable of inhibiting activation of the alternate Complement pathway at relatively high concentrations $(0.6 \mathrm{mg} / \mathrm{mL}) .{ }^{59}$ In a similar approach, Bureeva and co-workers devoted their efforts to find selective inhibitors of the reaction of $\mathrm{C}_{1 \mathrm{q}}$ with immunoglobulins and of the classical Complement pathway, studying polysulfates derived from triterpenoids and steroids. ${ }^{60}$ Assefa et al. focused their study on the classical Complement pathway-inhibiting properties of betulinic acid $\left(\mathrm{IC}_{50}=\right.$ $577 \mu \mathrm{M}$ ), oleanolic acid $\left(\mathrm{IC}_{50}=72.3 \mu \mathrm{M}\right)$, and some of their negatively charged derivatives, finding oleanolic acid ester $\mathbf{2 3}$ as the most active compound of this series $\left(\mathrm{IC}_{50}=31.4 \mu \mathrm{M}\right){ }^{42} \mathrm{In}$ addition, they also prepared A/B-ring partial analogues of oleanolic acid. ${ }^{61}$ 


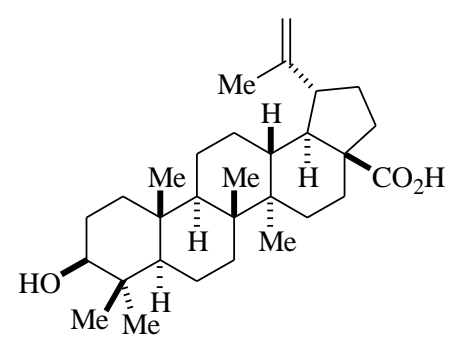

21, Betulinic acid

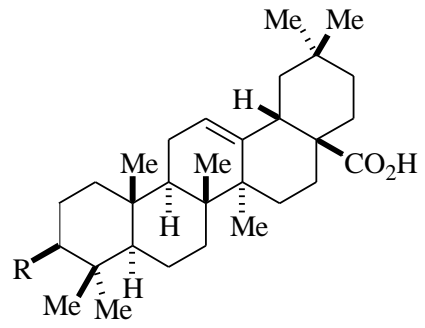

22, $\mathrm{R}=\mathrm{OH}$, Oleanolic acid 23, $\mathrm{R}=\mathrm{OC}(\mathrm{O}) \mathrm{CH}_{2} \mathrm{OCH}_{2} \mathrm{CO}_{2} \mathrm{H}$

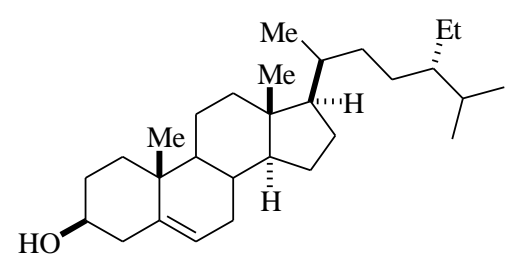

24, Clionasterol

Figure 6. Natural products and derivatives as Complement inhibitors.

On the other hand, ursolic acid was evaluated by Master, showing good profile for the inhibition of the classical Complement pathway $\left(\mathrm{IC}_{50}=54.7 \mu \mathrm{M}\right),{ }^{62}$ while Cerqueira and coworkers found in clionasterol 24 a potent Complement inhibitor $\left(\mathrm{IC}_{50}=4.1 \mu \mathrm{M}\right){ }^{63}$ However, the most prominent naturally-occurring product found to act as an anticomplementary agent is the drimanic terpenoid K-76 25, which was extensively studied and employed in numerous investigations, as detailed below.

\section{Isolation of K-76. Simple modifications of the natural product. Activity as complement inhibitor}

The isolation of K-76 was first reported in 1978 by the group of Inoue, from the culture broth of Stachybotrys complementi, nov. sp. K-76, as the result of a massive effort involving the screening of over 3000 strains of actinomycetes and fungi. The fungal strain which yielded the natural product was isolated from soil obtained from Ishigaki Island, in Okinawa, Japan. ${ }^{64}$

K-76 has a drimanic skeleton associated to a polysubstituted benzene ring through a spirofuran moiety (Figure 7). Its structure was determined as $\mathbf{2 5}$ by various methods including X-ray diffraction analysis, ${ }^{65}$ where the absolute configuration was established by the dibenzoate chirality method. ${ }^{66}$ Silver(I) oxide partial oxidation of the natural product gave K-76 COOH (28, also known as MX-1). This compound is able to form a lactol between the adjacent carboxylic acid and formyl groups, thus becoming insoluble in water; however, treatment of $\mathrm{K}-76 \mathrm{COOH}$ with sodium hydroxide gives the mono-sodium salt $\mathbf{2 6}$, readily soluble in water. Interestingly, initial studies attributed structure 27 to $\mathrm{K}-76 \mathrm{COOH}{ }^{65,67}$

The tricyclic skeleton of the BCD ring system of K-76, known as grisan 29 is shared with other polycyclic natural products, including the clinically relevant antifungal griseofulvin (30, from Penicillium griseo-fulvum Dierckx $)^{68}$ and filifolinol 31, an antioxidant, antiviral, antifungal and antibacterial terpenoid recently isolated from Heliotropium filifolium (Miers) Reiche, $H$. Sclerocarpum Phil. and H. taltalense (Phil.) Johnst (Heliotropiaceae). ${ }^{69}$ 


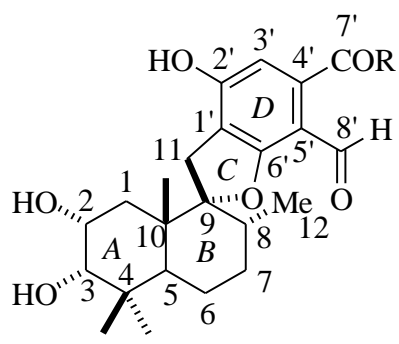

25, $\mathrm{R}=\mathrm{H}, \mathrm{K}-76$

26, $\mathrm{R}=\mathrm{ONa}, \mathrm{K}-76 \mathrm{CO}_{2} \mathrm{Na}$

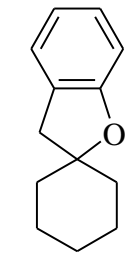

29, Grisan

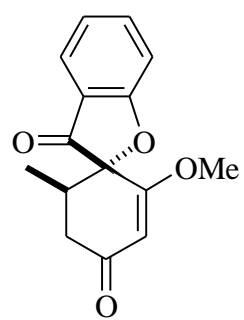

30, Grisofulvin

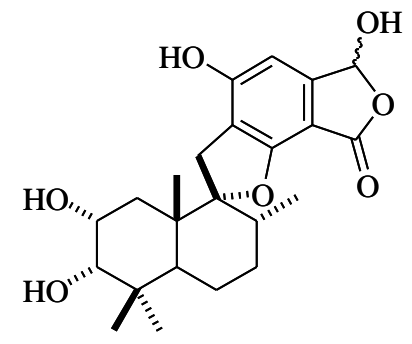

27

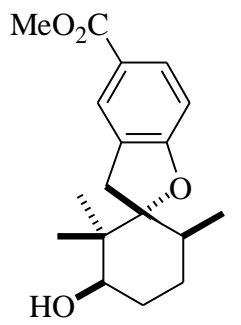

31, Filifolinol

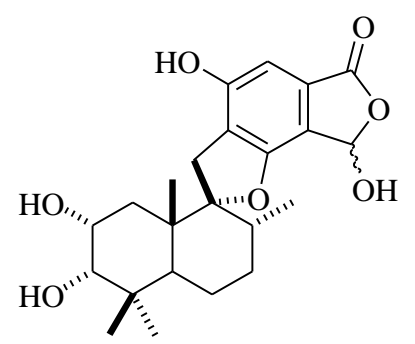

28, $\mathrm{K}-76 \mathrm{COOH}$

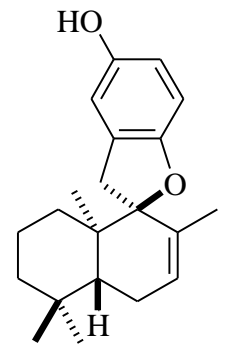

32, Isochromazonarol

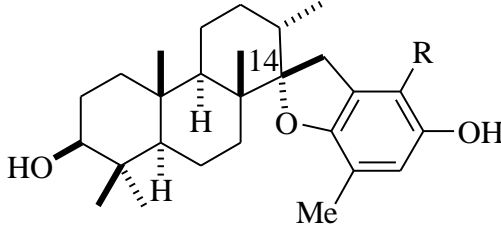

33, $\mathrm{R}=\mathrm{H}$, Stypodiol

34, $\mathrm{R}=\mathrm{OH}$, Stypotriol

Figure 7. Chemical structures of K-76 (25), K-76 COONa (26), K-76 COOH (28) and related compounds bearing the grisan (29) skeleton.

The tetracyclic ichtiotoxic algal metabolite isochromazonarol 32 from Dictyopteris undulata, ${ }^{70}$ as well as the pentacyclic stypodiol 33, its C14 epimer epistypodiol and stypotriol (34), secondary diterpene metabolites excreted by the tropical brown algae Stypopodium zonale (Lamouroux) Papenfuss, also share this motif. ${ }^{71,72}$ These terpenoids display diverse biological properties, being particularly toxic and producing strong narcotic and hyperactive effects upon the reef-dwelling fish Eupomacentrus leucostictus.

K-76 demonstrated to be extremely toxic, with $\mathrm{LD}_{50}=40 \mathrm{mg} / \mathrm{Kg}$ body weight, and when injected intravenously to mice, dead took place within 48 h. However, K-76 COONa 26 proved to be less toxic, with $\mathrm{LD}_{50}=500 \mathrm{mg} / \mathrm{Kg}$ in mice. Given daily intravenous or intraperitoneal $\mathrm{K}-76$ COONa injections of $100 \mathrm{mg} / \mathrm{Kg}$ for 3 weeks, rats were able to gain weight normally. Dogs also gained weight normally when treated orally with $2 \mathrm{~g} / \mathrm{Kg}$ /day during 3 weeks.

It was also observed that K-76 caused hemolysis of sheep and rabbit red blood cells at millimolar concentrations; on the other side, K-76 COONa had no hemolytic activity even at concentrations of one order of magnitude higher. Neither of both compounds displayed direct cytotoxic activity on leukocytes according to the trypan blue test. It was concluded that the natural product and $\mathrm{K}-76 \mathrm{COOH}$ have a unique Complement inhibitory activity, due to their ability to inhibit the generation of anaphylatoxin $\mathrm{C} 5 \mathrm{a}\left(\mathrm{IC}_{50}=3 \mathrm{mM}\right)$ a peptide released upon Complement activation. Under these conditions, little inhibition of $\mathrm{C} 3$ a production was observed. In laboratory experiments, $\mathrm{K}-76 \mathrm{COOH}$ has demonstrated to play an important role in diminishing gastric mucosal damage induced by ischemia-reperfusion in rats, ${ }^{73}$ and on the 
survival of discordant cardiac xenografts from guinea pig to rat and from pig to human. ${ }^{74}$

In addition, the natural product derivative $\mathbf{2 8}$ has been employed, among other situations, for the development of a new treatment for the ulcerative colitis,${ }^{75}$ for blocking human lymphocyte cell-mediated cytotoxicity and antibody-dependent natural cytotoxicity, ${ }^{76}$ and as a noncompetitive inhibitor of the enzyme inositol monophosphatase. ${ }^{77}$ Furthermore, K-76 COOH protected MDP-primed $\mathrm{C} 3 \mathrm{H} / \mathrm{HeJ}$ mice from mortality in the anaphylactoid reaction induced by Prevotella intermedia and Salmonella typhimurium lipopolysaccharides, respectively. It also inhibited platelet degradation, but not their accumulation induced by $P$. intermedia ${ }^{78}$ and protected $\mathrm{BALB} / \mathrm{c}$ mice from mortality in the anaphylactoid reaction. ${ }^{79}$

\subsection{Stachybotrys sp. derived natural products structurally related to K-76}

The unique skeleton of K-76 is also shared with other novel bioactive compounds which have been isolated from different strains of Stachybotrys (and the closely related Memnoniella) species (Figure 8). These include, among others, stachybotrylactam (35, from Stachybotrys chartarum or S. atra), stachybotrin A $\mathbf{3 6}$ and stachybotrin 37 (from Stachybotrys alternans), stachybotrilactone (38, stachybotrolide) and congeners 39-40, ${ }^{80}$ and the dimeric stachybocins 4143, isolated from Stachybotrys sp. M6222, which are active as antagonists of endothelin and inhibit HIV-1 protease. ${ }^{81}$

Other members of this family are the inhibitor of inositol monophosphatase L-671,776 (44 from S. chartarum and Memnoniella echinata), ${ }^{82}$ the antiviral and enzyme inhibitor stachybotrydial (45, from Stachybotrys sp. F-1839 and S. cylindrospora), ${ }^{83}$ as well as the pancreatic cholesterol esterase inhibitors F-1839-A, F-1839-B, F-1839-E and F-1839-F (46-49, respectively, from Stachybotrys sp. F-1839) ${ }^{84}$ and the structurally simpler triprenylphenols $\mathbf{5 0}$ and $\mathbf{5 1}$ (from Stachybotrys chartarum), which act as tyrosine kinase receptor inhibitors. ${ }^{85}$

The staplabins (formerly included among the stachybotrins) such as SMTP 0 (47, also known as stachybotrin B, from Stachybotrys microspora) ${ }^{86}$ and the related $\mathbf{5 3}$ and $\mathbf{5 4}$, also display simplified versions of the basic skeleton; on the other hand, the stachyflins ( $\mathbf{5 5}$ and $\mathbf{5 6}$, from Stachybotrys sp. RF-7260), the first of which is a potent and novel anti-influenza A virus agent, are examples of structurally modified compounds, which include skeletal rearrangements. ${ }^{87}$

\section{Chemical syntheses of K-76}

\subsection{The K-76 synthesis of Corey and Das}

To date, there are three reported total syntheses of K-76. The first synthesis of the natural product and derivatives was carried out by Corey and Das, ${ }^{88}$ who took advantage of the ready availability of bicyclic $\beta$-ketoester $\mathbf{5 8}$ in five steps from geranyl bromide (57). ${ }^{89}$ 


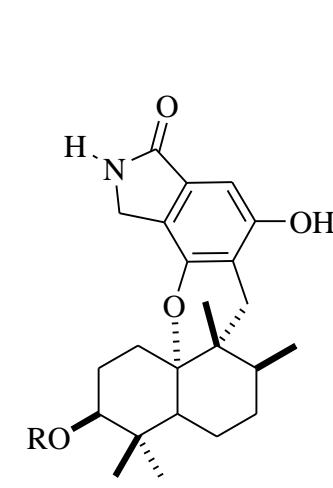

55, R= H, Stachyflin 56, $R=$ Ac, Acetyl stachyflin

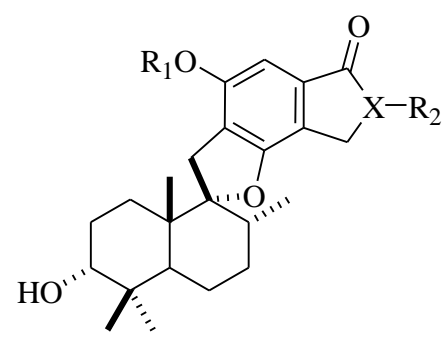

35, $X=N, R_{1}=R_{2}=H$, Stachybotrylactam 36, $\mathrm{X}=\mathrm{N}, \mathrm{R}_{1}=\mathrm{Me}, \mathrm{R}_{2}=\left(\mathrm{CH}_{2}\right)_{2} \mathrm{OH}$, Stachybotrin A 37, $\mathrm{X}=\mathrm{N}, \mathrm{R}_{1}=\mathrm{H}, \mathrm{R}_{2}=\left(\mathrm{CH}_{2}\right)_{2} \mathrm{OH}$, Stachybotrin 38, $\mathrm{X}=\mathrm{O}, \mathrm{R}_{1}=\mathrm{H}$, Stachybotrilactone 39, $\mathrm{X}=\mathrm{N}, \mathrm{R}_{1}=\mathrm{H}, \mathrm{R}_{2}=\mathrm{CH}\left(\mathrm{CO}_{2} \mathrm{H}\right)\left(\mathrm{CH}_{2}\right)_{2} \mathrm{CO}_{2} \mathrm{H}$ 40, $\mathrm{X}=\mathrm{N}, \mathrm{R}_{1}=\mathrm{H}, \mathrm{R}_{2}=\mathrm{CH}\left(\mathrm{CO}_{2} \mathrm{H}\right) \mathrm{CH}(\mathrm{OH}) \mathrm{Me}$

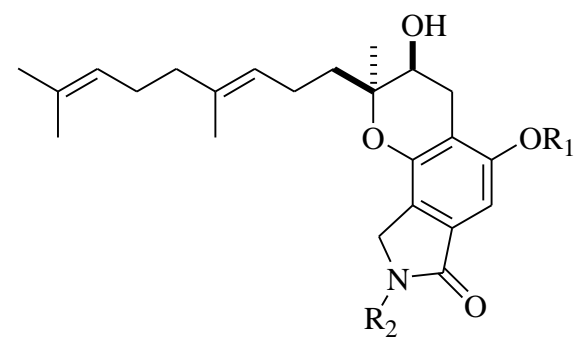

52, $\mathrm{R}_{1}=\mathrm{R}_{2}=\mathrm{H}$, SMTP 0

53, $\mathrm{R}_{1}=\mathrm{H}, \mathrm{R}_{2}=\left(\mathrm{CH}_{2}\right)_{2} \mathrm{OH}$, SMTP 1

54, $\mathrm{R}_{1}=\mathrm{H}, \mathrm{R}_{2}=\left(\mathrm{CH}_{2}\right)_{4} \mathrm{CO}_{2} \mathrm{H}$, Staplabin

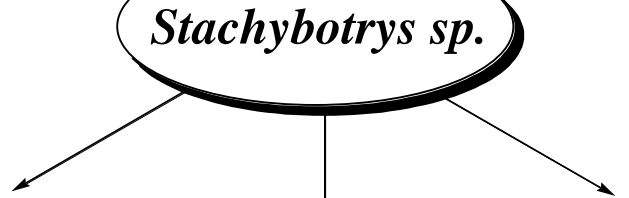

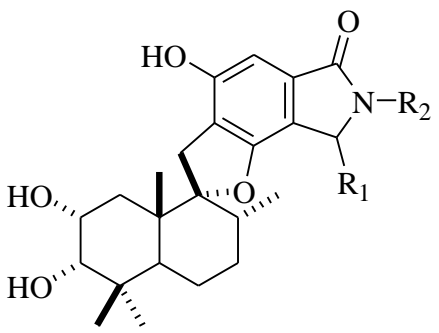

46, $\mathrm{R}_{1}=\mathrm{R}_{2}=\mathrm{H}, \mathrm{F}-1839-\mathrm{A}$ 47, $\mathrm{R}_{1}=\mathrm{OMe}, \mathrm{R}_{2}=\mathrm{H}, \mathrm{F}-1839-\mathrm{B}$ 48, $\mathrm{R}_{1}=\mathrm{H}, \mathrm{R}_{2}=\left(\mathrm{CH}_{2}\right)_{2} \mathrm{OH}, \mathrm{F}-1839-\mathrm{E}$ 49, $\mathrm{R}_{1}=\mathrm{H}, \mathrm{R}_{2}=\left(\mathrm{CH}_{2}\right)_{3} \mathrm{CO}_{2} \mathrm{H}, \mathrm{F}-1839-\mathrm{F}$ 50, $\mathrm{R}_{1}=\mathrm{H}, \mathrm{R}_{2}=\left(\mathrm{CH}_{2}\right)_{3} \mathrm{CHMe}_{2}$ 51, $\mathrm{R}_{1}=\mathrm{H}, \mathrm{R}_{2}=\mathrm{CH}\left(\mathrm{CO}_{2} \mathrm{H}\right) \mathrm{CHMe}_{2}$<smiles></smiles>

44, $\mathrm{R}=\mathrm{CH}_{2} \mathrm{OH}, \mathrm{L}-671,776$

45, R= CHO, Stachybotrydial

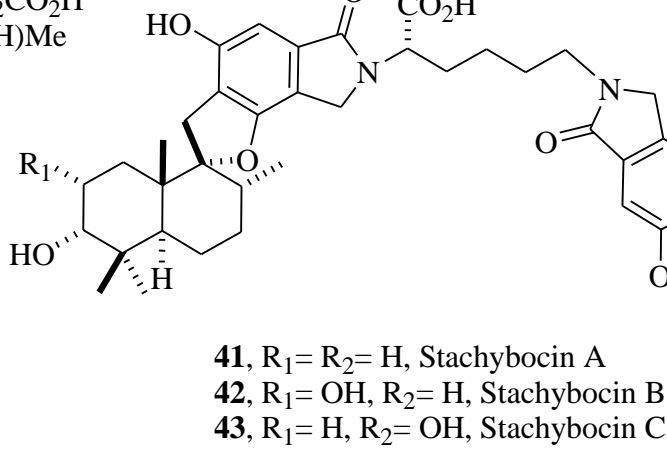

Figure 8. Stachybotrys-derived natural products related to K-76.

Enolization of $\mathbf{5 8}$ followed by treatment with triflic anhydride afforded enol triflate $\mathbf{5 9}$ (Scheme 1), which was reacted with $\mathrm{LiMe}_{2} \mathrm{Cu}$, yielding the $\beta$-methyl $\alpha, \beta$-unsaturated ester $\mathbf{6 0}$. $\mathrm{LiAlH}_{4}$ reduction of the ester and conversion of the resulting alcohol to the allylic bromide $\mathbf{6 1}$ through the related mesylate, was followed by coupling with $\mathbf{6 2 a}$, the lithium derivative of acetal 62, to give $75 \%$ of the tricyclic acetal 63. 

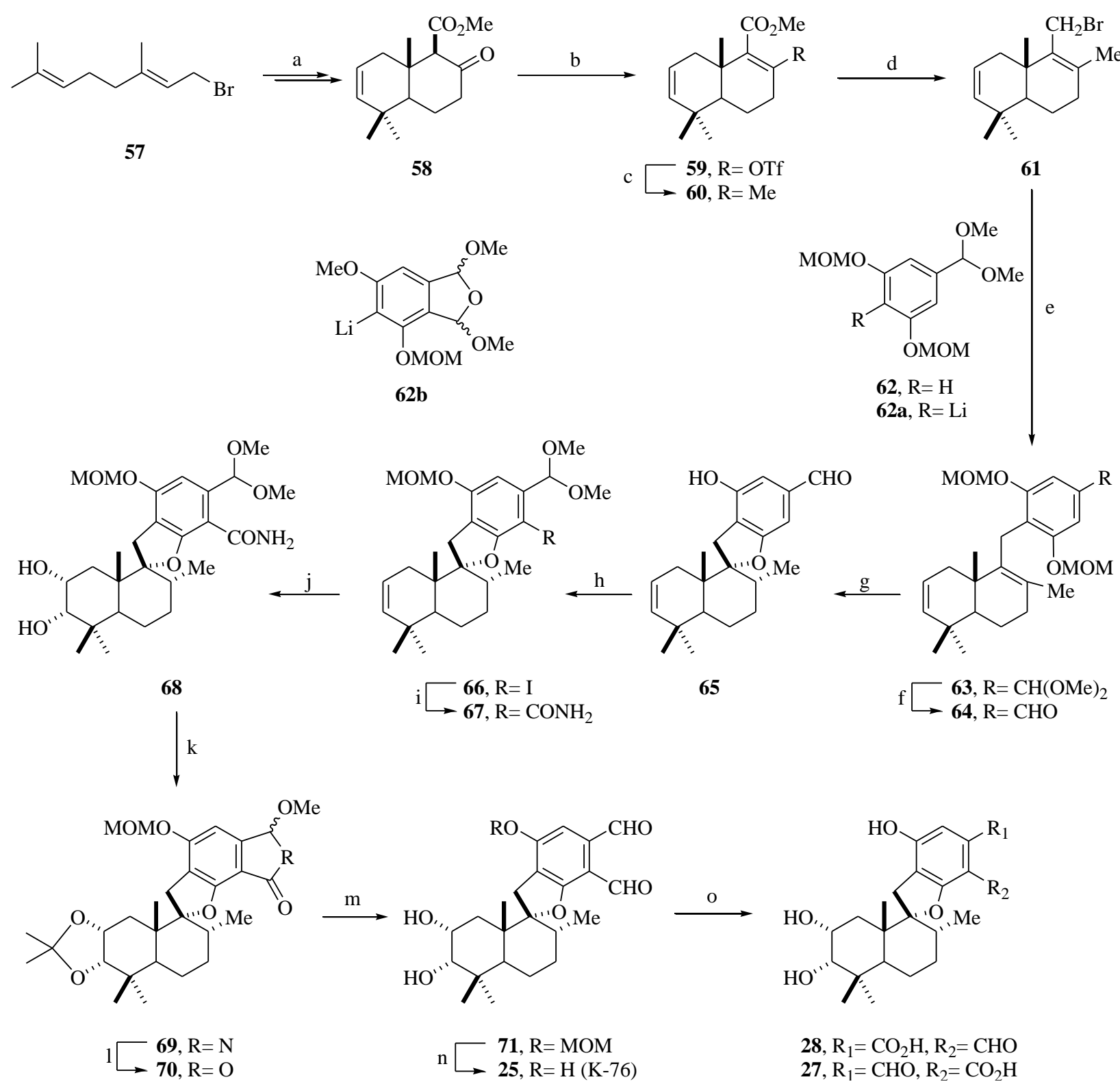

Scheme 1. Reagents and conditions: a) $1 . \mathrm{NaH}, \mathrm{MeC}(\mathrm{O}) \mathrm{CH}_{2} \mathrm{CO}_{2} \mathrm{Et},{ }^{n} \mathrm{BuLi}, \mathrm{Et}_{2} \mathrm{O}, 0^{\circ} \mathrm{C}, 1 \mathrm{~h}(95 \%)$; 2. $\mathrm{NaH}, \mathrm{ClP}(\mathrm{O})(\mathrm{OEt})_{2}, \mathrm{Et}_{2} \mathrm{O}, \mathrm{rt}, 2 \mathrm{~h} ; 3 . \mathrm{Hg}(\mathrm{TFA})_{2}, \mathrm{MeNO}_{2},-20^{\circ} \mathrm{C} \rightarrow 0^{\circ} \mathrm{C} ; \mathrm{NaCl}(60 \%) ; 4 . \mathrm{KI}_{3}$, Dioxane; 5. LiCl, DMF, rt, 48h (70\% overall); b) 1. NaH; 2. $\mathrm{Tf}_{2} \mathrm{O}$ (90\%); c) $\mathrm{LiMe}_{2} \mathrm{Cu}, \mathrm{Et}_{2} \mathrm{O}$, $78^{\circ} \mathrm{C}$ to $-30^{\circ} \mathrm{C}, 2 \mathrm{~h}(90 \%)$; d) $1 . \mathrm{LiAlH}_{4}, \mathrm{Et}_{2} \mathrm{O}, 4 \mathrm{~h} ; 2 . \mathrm{MsCl}, \mathrm{Et}_{3} \mathrm{~N}, \mathrm{CH}_{2} \mathrm{Cl}_{2},-50^{\circ} \mathrm{C}, 10$ min.; 3. $\mathrm{LiBr}$, THF, $-50^{\circ} \mathrm{C} \rightarrow 0^{\circ} \mathrm{C}, 1 \mathrm{~h}$; e) $62,{ }^{n} \mathrm{BuLi}$, THF-TMEDA, HMPA, $-78^{\circ} \mathrm{C} \rightarrow 0^{\circ} \mathrm{C}, 1 \mathrm{~h}(75 \%)$; f) $1 \mathrm{~N}$ $\mathrm{HCl}-\mathrm{THF}(1: 3)$, rt, $1 \mathrm{~h}$ (93\%); g) 2N HCl, $\mathrm{HOCH}_{2} \mathrm{CH}_{2} \mathrm{OH}-\mathrm{THF}$ (2:1:4), rt, 48h (50-70\%); h) 1. TsOH, $\mathrm{MeOH}$, rt, $1 \mathrm{~h}(97 \%)$; 2. $\mathrm{Bu}_{4} \mathrm{NI}_{3}, \mathrm{CH}_{2} \mathrm{Cl}_{2}, \mathrm{rt}, 10 \mathrm{~min}$; 3. $\mathrm{ClCH}_{2} \mathrm{OMe}, 0^{\circ} \mathrm{C}, 15 \mathrm{~min}(85 \%)$; i) 1. $\mathrm{CuCN}, \mathrm{HMPA}, 85^{\circ} \mathrm{C}, 24 \mathrm{~h}(90 \%)$; 2 . $\mathrm{KOH},{ }^{t} \mathrm{BuOH}$, reflux, 48h (92\%); j) $\mathrm{OsO}_{4}, \mathrm{Py}, \mathrm{rt}, 16 \mathrm{~h}$ (80\%, $1: 1$ mixture of $2 \alpha, 3 \alpha$ and $2 \beta, 3 \beta$ diols); k) $1.1 \mathrm{~N} \mathrm{HCl}$, THF, rt, $1 \mathrm{~h}(99 \%) ; 2 . \mathrm{MeOH}, \mathrm{TsOH}$, rt, 1h; 3. $\mathrm{Me}_{2} \mathrm{CO}, 2$,2-DMP, TsOH, rt, $1 \mathrm{~h}(90 \%)$; 1) $\mathrm{N}_{2} \mathrm{O}_{4}, \mathrm{NaOAc}, \mathrm{CCl}_{4}, 0^{\circ} \mathrm{C}, 30$ min.; m) DIBAL-H, PhMe, $-78^{\circ} \mathrm{C}, 10 \mathrm{~min}$; 2. $\left.1 \mathrm{~N} \mathrm{HCl-THF} \mathrm{(1:5),} \mathrm{rt,} 30 \mathrm{~min} ; \mathrm{n}\right) 6 \mathrm{~N} \operatorname{HCl}-\mathrm{THF}$ (1:1), rt, 4h (87\%); o) $\mathrm{Ag}_{2} \mathrm{O}, 1 \mathrm{~N} \mathrm{NaOH}, \mathrm{rt}, 30 \mathrm{~min}$. 
The symmetric acetal 62 was prepared in $63 \%$ overall yield from the commercially available methyl 3,5-dihydroxybenzoate by a four-step sequence which included transformation to the bis(methoxymethyl) ether (MOM) derivative, followed by reduction of the ester to the primary alcohol with lithium aluminium hydride, oxidation of the latter to the aldehyde and final acetalization with $\mathrm{MeOH}$ under $\mathrm{TsOH}$ catalysis.

Mild acid hydrolysis of 63 gave aldehyde 64, which upon submission for two days to $2 \mathrm{~N} \mathrm{HCl}$ in a THF-ethylene glycol mixture, resulted in MOM hydrolysis and cyclization yielding phenol 65. The trans-diaxial addition to the double bond which took place established the desired geometry of both, the dihydrofuran ring and the neighbouring methyl group. The authors discovered that the use of acetal $\mathbf{6 2} \mathbf{b}$ instead of its congener 62a furnished poor yields (26\%) of cyclized material.

Reacetalization of 65 with $\mathrm{TsOH}$ in $\mathrm{MeOH}$ was followed by iodination with ${ }^{n} \mathrm{Bu}_{4} \mathrm{NI}$ to the iodide and further transformation in situ to the corresponding methoxymethyl ether 66. Replacement of the iodine with a cyano moiety and subsequent basic hydrolysis of the resulting nitrile furnished the amide $\mathbf{6 7}$ in over $80 \%$ yield from the iodide $\mathbf{6 6}$.

Next, installation of the cis-diol moiety was taken care of. Unfortunately, dihydroxylation of 67 yielded a 1:1 mixture of both possible cis-diols. However, the synthesis went ahead and the cis-diol 68 was transformed into methoxy lactam 69 by acid hydrolysis of the acetal moiety followed by lactamization and acetalization of the resulting lactam-hemiacetal with $\mathrm{TsOH}$ in $\mathrm{MeOH}$ and final acetalization of the diol moiety with acetone, 2,2-dimethoxypropane and tosic acid. Treatment of $\mathbf{6 9}$ with dinitrogen tetraoxide gave the diastereomeric methoxy lactones 70, while reduction of the lactone carbonyl of $\mathbf{7 0}$ with DIBAL followed by acid deketalization furnished dialdehyde 71. Hydrolysis of the MOM ether moiety finally yielded K-76. Oxidation of synthetic K-76 with silver(I) oxide in $1 \mathrm{~N} \mathrm{NaOH}$ yielded $\mathrm{K}-76 \mathrm{COOH}$, which the authors demonstrated to possess structure 28, contrary to the previously assigned isomeric structure 27.

Interestingly, the poor yields and stereochemical problems associated to the cisdihydroxylation of the 2,3-double bond of the A-ring, initially found by Corey and Das would plague the other syntheses of the natural product, becoming more than once their Achilles' heel.

\subsection{The K-76 synthesis of McMurry and Erion}

Three years later, McMurry and Erion also reported a total synthesis of K-76. ${ }^{90}$ In their first attempt involving the coupling of allyl bromide $\mathbf{6 1}$ with acetal 82, the strategy exhibited several broad analogies with the original route devised by Corey and Das.

For the synthesis of 61, ethyl farnesate (72) was cyclized with mercury(II) triflate, yielding the chloromercurial bicyclic ester $\mathbf{7 3}$, which was transformed into selenium derivative $\mathbf{7 4}$ with $(\mathrm{PhSe})_{2}$ under (sun)light promotion (Scheme 2). Sodium periodate-mediated oxidation of the phenyl selenide followed by elimination of the resulting selenoxide, efficiently ( $82 \%$ yield) installed the 2,3-double bond (75), while addition of tert-butanol to the reaction medium resulted in the potassium tert-butoxide mediated isomerization of the double bond of ring $\mathrm{B}$ to furnish $\alpha, \beta$-unsaturated ester 76, analogous to one of Corey's intermediates. Reduction of the ester to the 
corresponding allylic alcohol 77 and treatment of the latter with $\mathrm{PBr}_{3}$ yielded the required allyl bromide intermediate $\mathbf{6 1}$ (previously prepared by Corey and Das) in $44 \%$ overall yield.

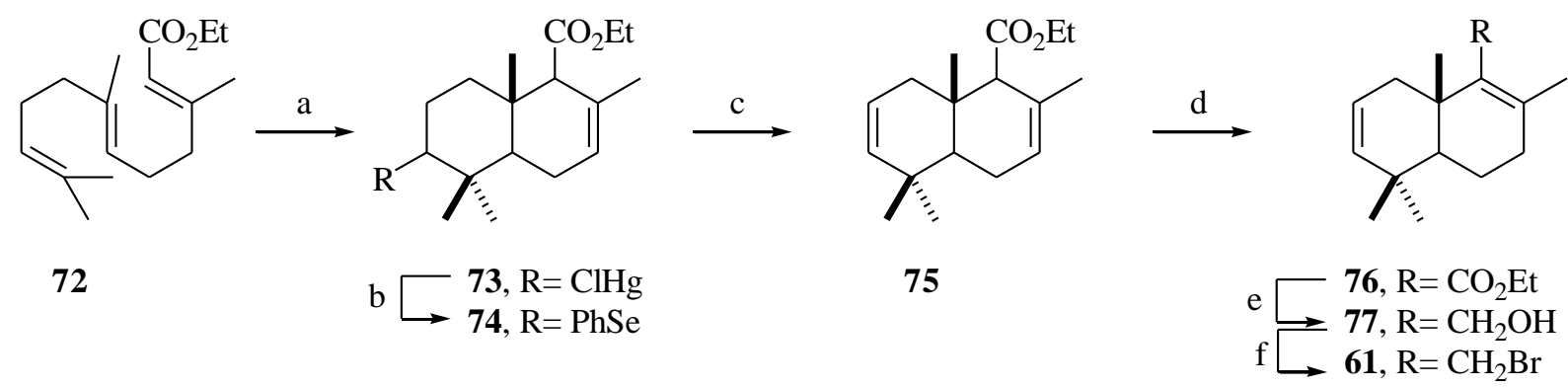

Scheme 2. Reagents and conditions: a) $1 . \mathrm{Hg}(\mathrm{OTf})_{2}, \mathrm{MeNO}_{2} ; 2 . \mathrm{NaCl}(71 \%)$; b) 1. (PhSe) $\mathrm{PhH}$, hv (sunlamp); c) $\mathrm{NaIO}_{4}, \mathrm{THF}-\mathrm{H}_{2} \mathrm{O}, 0^{\circ} \mathrm{C}, 12 \mathrm{~h}$ (83\%); d) 1. KH, DME, $60^{\circ} \mathrm{C}, 30 \mathrm{~min} ; 2$. ${ }^{t} \mathrm{BuOH}, 5 \mathrm{~min}(90 \%)$; e) $\mathrm{LiAIH}_{4}, \mathrm{Et}_{2} \mathrm{O}, 0^{\circ} \mathrm{C} \rightarrow \mathrm{rt}, 15 \mathrm{~h}(74 \%)$; f) $\mathrm{PBr}_{3}, \mathrm{Et}_{2} \mathrm{O}, 0^{\circ} \mathrm{C}, 10 \mathrm{~min}(99 \%)$.

On the other hand, bis-TBDMS ether $\mathbf{8 2}$ was synthesized from the methyl enol-ether of 1,3cyclohexanedione (78) employing a multi-step sequence (Scheme 3). First, the enone was converted into a 1,3-diene by a $\mathrm{KH}$-mediated enolization, following by TMSCl trapping of the enolate; subsequent Diels-Alder reaction with dimehyl acetylene dicarboxylate gave an intermediate which upon heating at $120^{\circ} \mathrm{C}$ followed by exposure to silica gel during chromatography underwent a retro-Diels-Alder reaction with loss of ethylene, and further acidpromoted desilylation, furnishing phenolic derivative $\mathbf{7 9}$ in $71 \%$ overall yield. Protection of the phenol as the tetrahydropyranyl ether $(\mathbf{8 0})$, followed by reduction of both ester groups and transformation of the resulting diol $\mathbf{8 1}$ to the bis-TBDMS ether (82) completed the synthesis.

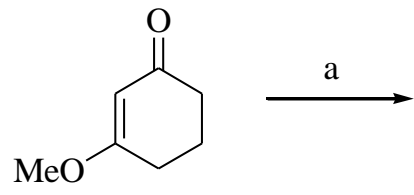

78<smiles>COC(=O)c1c(O)cc(OC)cc1C(C)=O</smiles>

79
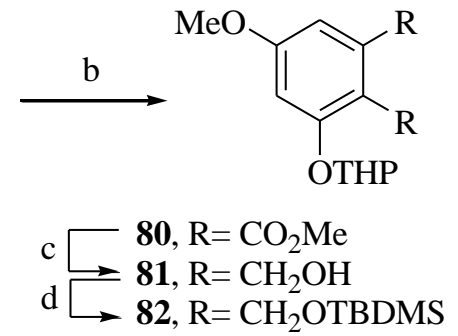

Scheme 3. Reagents and conditions: a) 1. $\mathrm{KH}$, TMSCl, THF; 2. DMAD; 3. $\Delta\left(120^{\circ} \mathrm{C}\right) ; 4 . \mathrm{SiO}_{2}$ (chromatography) (71\%); b) DHP, TsOH, $\mathrm{CH}_{2} \mathrm{Cl}_{2}(82 \%)$; c) $\mathrm{LiAIH}_{4}, \mathrm{Et}_{2} \mathrm{O}-\mathrm{PhH}$ (99\%); d) TBDMSCl, Imidazole, rt, 24h (93\%).

Fragment coupling was performed by ${ }^{n} \mathrm{BuLi}$-TMEDA lithiation of $\mathbf{8 2}$, followed by alkylation with the allyl bromide 61. Next, TBAF-mediated removal of the silicon-based protecting groups and Swern oxidation of the benzylic alcohols yielded the dialdehyde 83, which upon acid hydrolysis furnished the free phenol $\mathbf{8 4}$ ready for cyclization (Scheme 4). This was performed by treatment of $\mathbf{8 4}$ with the strong acid ion-exchange resin Amberlyst-15, which afforded 56\% of 
the desired tetracyclic product (85). However, at this point the synthesis met a serious obstacle. Attempts to dihydroxylate $\mathbf{8 5}$ to $\mathbf{8 6}$ met with failure, as other experiments intending to introduce the diol moiety at early stages of the sequence. It was concluded that severe 1,3-diaxial interactions between the axial methyl groups supported on the cyclohexene ring A (87) were responsible of holding the A-ring in a boat-like conformation during the reaction with $\mathrm{OsO}_{4}$, hiding the $\alpha$-face from attack and hindering the reaction.

An alternative strategy was then devised, based on the information given by molecular models, which suggested that masking the gem-dimethyl moiety as a spiro-fused cyclopropane ring would allow proper changes in the geometry of ring A, which would facilitate the dihydroxylation. The strategy, which hinged upon the use of an alkylidenecyclopropane derivative as initiator for an electrophile-induced polyene cyclization, also took into account that hydrogenolytic ring opening of the cyclopropane ring could easily generate the required gemdimethyl groups, and also included an early introduction of the 2,3-diol moiety.

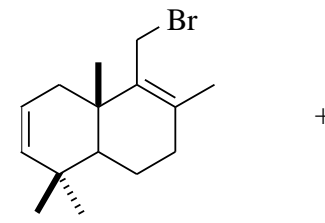

61

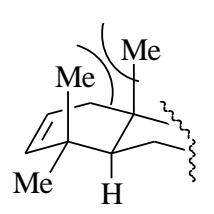

87<smiles>CCOc1c(COc2ccccc2)cc(OC)cc1OC</smiles>

OTHP
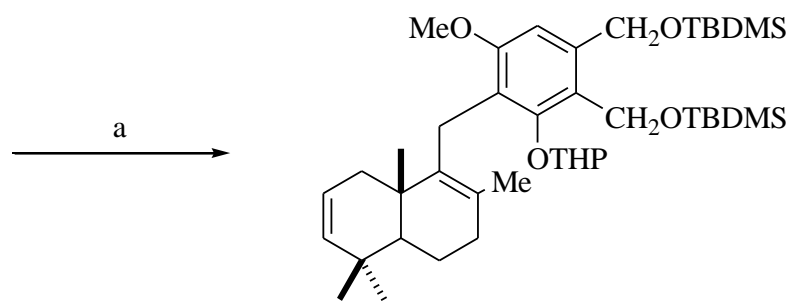

82

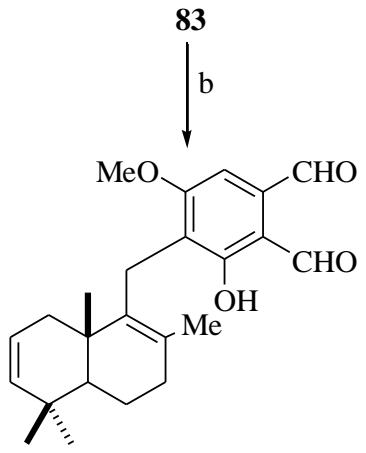

84

Scheme 4. Reagents and conditions: a) ${ }^{n} \mathrm{BuLi}$, TMEDA, hexane, $0^{\circ} \mathrm{C}(65 \%)$; b) 1. TBAF, THF, rt, 30 min (100\%); 2. $(\mathrm{COCl})_{2}$, DMSO, Et 3 N, $\mathrm{CH}_{2} \mathrm{Cl}_{2}$ (Swern [O]); 3. AcOH, THF-H $\mathrm{H}_{2} \mathrm{O}$, rt, 13h (86\%, overall); c) Amberlyst-15; $\mathrm{CH}_{2} \mathrm{Cl}_{2}, 8.5 \mathrm{~h}(56 \%)$.

Therefore, the key allylic bromide intermediate 101 was prepared from aldehyde 88, in turn easily available in $61 \%$ yield as a product of the selective ozonolysis of geranyl acetate (Scheme 5). Wittig reaction of $\mathbf{8 8}$ with cyclopropylidene triphenylphosphorane furnished the alkylidenecyclopropane derivative $\mathbf{8 9}$, which was transformed into the related allylic bromide $\mathbf{9 1}$ through basic hydrolysis of the acetate moiety and treatment of the resulting alcohol (90) with $\mathrm{PBr}_{3}$. Next, alkylation of bromide 91 with the dianion of methyl acetoacetate furnished $\beta$ - 
ketoester 92, which was converted into cyclization substrates 93 and 94 by trapping the corresponding enolates with $\mathrm{ClP}(\mathrm{O})(\mathrm{OEt})_{2}$ and $\mathrm{TBDMSCl}$, respectively.

However, treatment of alkylidenecyclopropane 93 with mercury(II) trifluoroacetate, followed by hydrolysis and anion exchange with $\mathrm{NaCl}$, gave poor yields of the sought tricyclic product. On the contrary, reaction of the more nucleophilic enol silyl ether 94 under the same conditions, furnished an organomercurial polysubstituted decaline in $57 \%$ isolated yield.

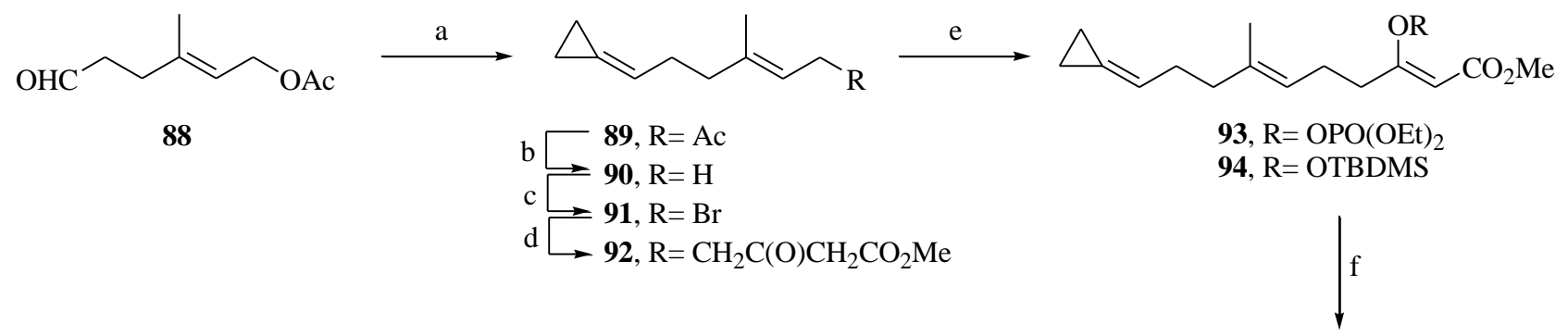

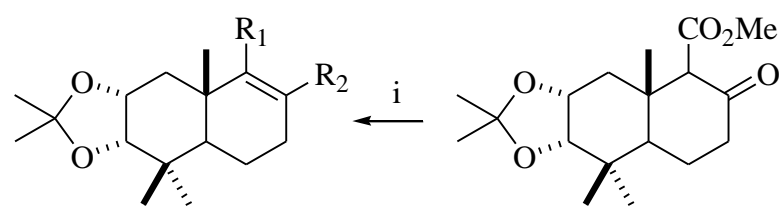

$\mathrm{j}-\mathbf{9 8}, \mathrm{R}_{1}=\mathrm{CO}_{2} \mathrm{Me}, \mathrm{R}_{2}=\mathrm{OPO}(\mathrm{OEt})_{2}$

$\longrightarrow$ 99, $\mathrm{R}_{1}=\mathrm{CO}_{2} \mathrm{Me}, \mathrm{R}_{2}=\mathrm{Me}$

$\mathrm{k} \longrightarrow \mathbf{1 0 0}, \mathrm{R}_{1}=\mathrm{CH}_{2} \mathrm{OH}, \mathrm{R}_{2}=\mathrm{Me}$

$1 \longrightarrow 101, \mathrm{R}_{1}=\mathrm{CH}_{2} \mathrm{Br}, \mathrm{R}_{2}=\mathrm{Me}$

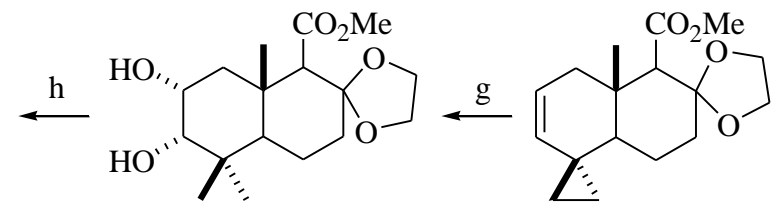

96

95

Scheme 5. Reagents and conditions: a) $\mathrm{NaH}$, cyclopropyl- $\mathrm{PPh}_{3}{ }^{+} \mathrm{Br}^{-}, \mathrm{DME}, 60^{\circ} \mathrm{C}, 12 \mathrm{~h}$; b) $\mathrm{K}_{2} \mathrm{CO}_{3}$, $\mathrm{MeOH}$, rt, $1 \mathrm{~h}\left(66 \%\right.$ from 88); c) $\mathrm{PBr}_{3}$, Hexane, $0^{\circ} \mathrm{C}, 20 \mathrm{~min}(100 \%)$; $)$ 1. $\mathrm{NaH}$, $\mathrm{MeC}(\mathrm{O}) \mathrm{CH}_{2} \mathrm{CO}_{2} \mathrm{Me}$, THF; 2. ${ }^{n} \mathrm{BuLi}(75 \%)$; e) $\mathrm{ClP}(\mathrm{O})(\mathrm{OEt})_{2}$ (93) or Imidazole, TBDMSCl, DMF, rt, 24h (94, 90\%); f) 1. $\mathrm{Hg}\left(\mathrm{O}_{2} \mathrm{CCF}_{3}\right)_{2}, \quad \mathrm{MeNO}_{2}, \quad-5^{\circ} \mathrm{C}, \quad \mathrm{NaCl} \quad(57 \%) ; \quad 2$. TBDMSOCH${ }_{2} \mathrm{CH}_{2} \mathrm{OTBDMS}$, TMSOTf, $\mathrm{CH}_{2} \mathrm{Cl}_{2}, 0^{\circ} \mathrm{C}$, 7h (85\%); 3. (PhSe) 2 , $\mathrm{PhH}$, hv (sunlamp), 1.5h (93\%); 4. $\mathrm{H}_{2} \mathrm{O}_{2}$, THF, $0^{\circ} \mathrm{C} \rightarrow \mathrm{rt}, 15 \mathrm{~h}\left(91 \%\right.$ overall); g) $1 . \mathrm{OsO}_{4}, \mathrm{NMO},{ }^{t} \mathrm{BuOH}-\mathrm{H}_{2} \mathrm{O}, \mathrm{rt}, 12 \mathrm{~h}$ $\left.(2 \alpha, 3 \alpha / 2 \beta, 3 \beta=12: 1,88 \%) ; 2 . \mathrm{H}_{2}(520 \mathrm{psi}), \mathrm{PtO}_{2}, \mathrm{AcOH}, \mathrm{rt}, 48 \mathrm{~h}(99 \%) ; \mathrm{h}\right) 1$. $2 \mathrm{~N} \mathrm{HCl}-\mathrm{THF}(1: 1)$, rt, 26h; 2. $\mathrm{Me}_{2} \mathrm{CO}$, Aberlyst, rt, 2h (85\%); i) NaH, DME, ClP(O)(OEt) 2 ; j) MeLi, CuI, Et ${ }_{2} \mathrm{O}$, $\left.78^{\circ} \mathrm{C} \rightarrow-23^{\circ} \mathrm{C}, 2.5 \mathrm{~h} ; \mathrm{k}\right) \mathrm{LiAlH}_{4}, \mathrm{Et}_{2} \mathrm{O}, 0^{\circ} \mathrm{C}, 4 \mathrm{~h}$ (71\% overall); 1) $1 . \mathrm{MsCl}_{2} \mathrm{Et}_{3} \mathrm{~N}, \mathrm{CH}_{2} \mathrm{Cl}_{2},-50^{\circ} \mathrm{C}, 45$ $\min ; 2$. $\mathrm{LiBr}, \mathrm{THF},-20^{\circ} \mathrm{C}, 1 \mathrm{~h}(>90 \%)$.

This was followed by protection of the ketone as ethylene ketal with ethyleneglycol bisTBDMS ether and TMSOTf in $85 \%$ yield, conversion of the organomercurial moiety into the related phenylselenide under sunlamp irradiation and a final hydrogen peroxide-mediated oxidation-elimination reaction, which furnished the spiro-cyclohexene ketal $\mathbf{9 5}$ in $91 \%$ overall yield.

The next pair of critical steps included the osmium tetraoxide-mediated dihydroxylation of 95, which the authors were able to carry out in a catalytic fashion, yielding the desired $\alpha, \alpha$-diol 
as the main diastereomer product, and the hydrogenolytic cleavage of the cyclopropyl moiety, which was accomplished with Adams catalyst in $\mathrm{AcOH}$, to provide 96 in quantitative yield.

Acid hydrolysis of the ketal moiety of $\mathbf{9 6}$ and protection of the diol as the acetonide under Amberlyst-15 catalysis furnished $85 \%$ of $\beta$-ketoester 97, which was next subjected to transformation into the $\beta$-methyl $\alpha, \beta$-unsaturated ester 99 via the enol-phosphate intermediate 98. In turn, this was reduced to the related alcohol (100) and converted to the required allyl bromide 101 by bromide ion displacement of the mesylate intermediate, which was not isolated.

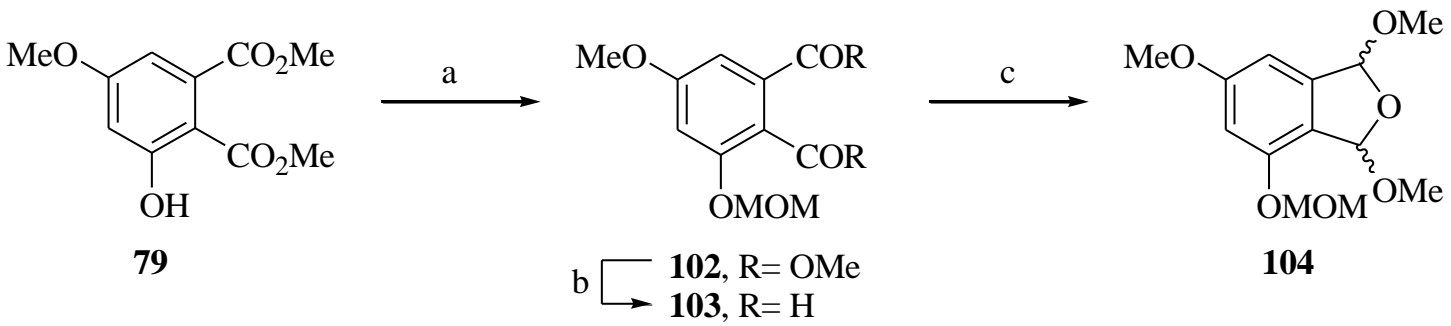

Scheme 6. Reagents and conditions: a) $\mathrm{MOMCl}, \mathrm{K}_{2} \mathrm{CO}_{3}, \mathrm{Me}_{2} \mathrm{CO}, 0^{\circ} \mathrm{C} \rightarrow \mathrm{rt}, 15 \mathrm{~h}(99 \%)$; b) $\mathrm{LiAlH}_{4}, \mathrm{Et}_{2} \mathrm{O}, 0^{\circ} \mathrm{C} \rightarrow \mathrm{rt}, 2 \mathrm{~h} ; 2$. $(\mathrm{COCl})_{2}, \mathrm{DMSO}_{2} \mathrm{Et}_{3} \mathrm{~N}, \mathrm{CH}_{2} \mathrm{Cl}_{2}$ (Swern [O]) (89\%); c) TsOH, $\mathrm{MeOH}, \mathrm{CH}_{2} \mathrm{Cl}_{2}, 0^{\circ} \mathrm{C}, 20 \mathrm{~min}(91 \%)$.

A new aromatic coupling component (104) was also prepared from the previously synthesized 79. As shown in Scheme 6, this was accomplished through protection of the phenol moiety as MOM-ether, followed by reduction of the esters to the corresponding alcohols with $\mathrm{LiAlH}_{4}$, partial reoxidation of the diol under Swern conditions to phthaldehyde derivative $\mathbf{1 0 3}$ and final bis-acetalization with $\mathrm{TsOH}$ in $\mathrm{MeOH}$.

Coupling of acetal 104 with bromide 101 took place to furnish intermediate 105. The coupling strategy employed the organocopper derivative of 104, because the original aryl-lithium mediated coupling strategy proved unsuccessful (Scheme 7). Aqueous acid hydrolysis simultaneously effected acetonide, acetal and MOM-ether cleavage, furnishing advanced intermediate 106 in 59\% overall yield and setting the stage for culmination of the sequence.

However, application of the originally developed cyclization conditions met with failure, being 106 either reluctant to cyclize under other acidic conditions, furnishing six-membered ether derivatives or resulting in complete destruction of the starting phenol. On comparison with the cyclization of $\mathbf{8 4}$, this reluctance was attributed to the presence of the $2 \alpha, 3 \alpha$-diol moiety. It was conjectured that the basicity of these hydroxyl groups could hinder protonation of the B-ring double bond, turning compound $\mathbf{1 0 6}$ more labile to acid-catalyzed decomposition. In order to mitigate this unwanted effect, diol $\mathbf{1 0 6}$ was protected by treatment with phenylboronic acid, quantitatively giving phenyl boronate $\mathbf{1 0 7}$.

The protective group was chosen on the assumption that overlapping of the oxygen lone-pair of electrons with the vacant boron orbital should be effective in deactivating the oxygens toward protonation. This effect was observed as a large downfield shift for the $\mathrm{C} 2$ and $\mathrm{C} 3$ protons of 
boronate 107 relative to those of diol 106, presumably due to the expected lower electron density on the $\mathrm{C} 2$ and $\mathrm{C} 3$ oxygens.<smiles>COc1cc(OC)c2c(c1)C(OC)OC2OC</smiles>

104<smiles>CC1=C(CBr)C2(C)C[C@H]3OC(C)(C)O[C@H]3C(C)(C)C2CC1</smiles>

101

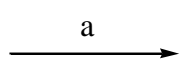<smiles>COC1=C(Cc2c(OC)cc3c(c2OC)C[C@@H]2OC(C)(C)O[C@@H]32)C2(C)C(CC1)[C@H](OC)O[C@@H]2OC</smiles>

105

b

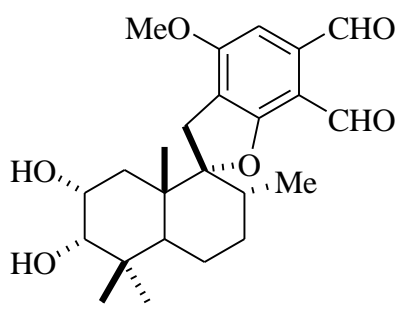

87

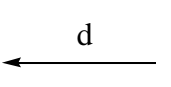<smiles>COc1cc(C=O)c(C=O)c(O)c1CC1=C(C)CCC2C1(C)C[C@@H]1OB(c3ccccc3)O[C@@H]1C2(C)C</smiles>

107

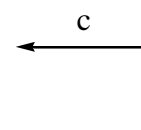<smiles>CC=CC=C(O)CCC1=C(C)CCC2C(C)(C)[C@H](O)[C@H](O)C[C@]12C</smiles>

106

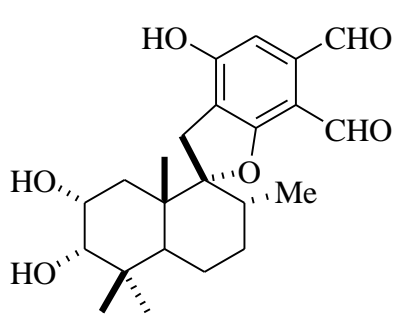

25<smiles>COc1cc(C=O)c(C=O)c2c1CC1C3(C)C[C@@H]4OB(c5ccccc5)O[C@H]4C(C)(C)[C@H]3CC[C@]1(C)O2</smiles>

108

Scheme 7. Reagents and conditions: a) ${ }^{t} \mathrm{BuLi}$, TMEDA, THF, $\mathrm{CuCN},-78^{\circ} \mathrm{C} \rightarrow-15^{\circ} \mathrm{C}, 8 \mathrm{~h}$; b) $2 \mathrm{~N}$ $\mathrm{HCl}, 2-\mathrm{PrOH}-\mathrm{THF}(10: 10: 1)$, 15h, rt (59\% overall); c) $\mathrm{PhB}(\mathrm{OH})_{2}, \mathrm{MgSO}_{4}, \mathrm{PhH}, \mathrm{rt}, 15 \mathrm{~h}(100 \%)$; d) Amberlyst-15, PhH, rt, 37h (45\%); e) ${ }^{t} \mathrm{BuSLi}$, HMPA, rt, 7h (75\%).

As expected, 107 was smoothly cyclized in the presence of excess Amberlyst-15 in benzene to furnish $O$-methyl K-76 (87), together with pyranic diastereomeric derivatives $\mathbf{1 0 8}$ in a 1.7:1 ratio and $72 \%$ overall yield. Final cleavage of the methyl ether was accomplished with in situ generated lithium tert-butyl mercaptide ( ${ }^{t} \mathrm{BuSH}$ and $\left.{ }^{n} \mathrm{BuLi}\right)$, providing $\mathrm{K}-76(\mathbf{2 5})$ in $75 \%$ yield.

Interestingly, the kampanols A-C (109a-c) are drimanic benzopyran derivatives (Figure 9) tightly resembling the structure of 108; they have been recently isolated from Stachybotrys kampalensis Hansf (MF 6199, ATCC 74357), ${ }^{91}$ obtained from leaf litter, collected at the Palo Verde National Park, in the Guanacaste Province of Costa Rica. 


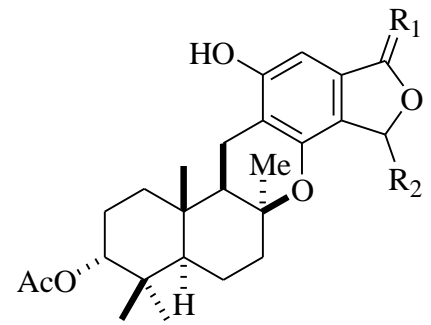

109a, $\mathrm{R}_{1}=\mathrm{O} ; \mathrm{R}_{2}=\mathrm{H}$, Kampanol A 109b, $\mathrm{R}_{1}=\mathrm{H}, \mathrm{OMe} ; \mathrm{R}_{2}=\mathrm{OMe}$, Kampanol B

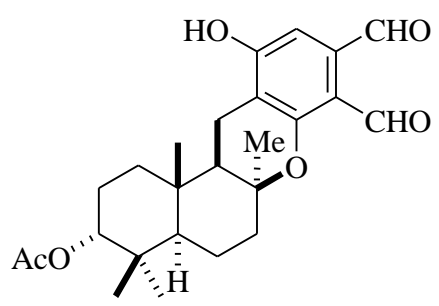

109c, Kampanol C

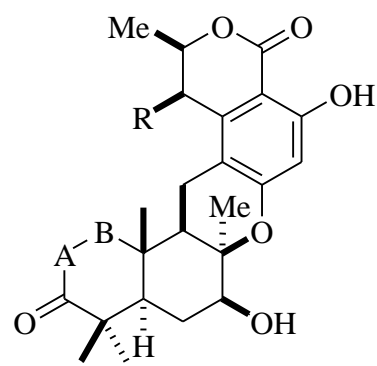

109d, $\mathrm{AB}=\mathrm{CH}_{2}-\mathrm{CH}_{2}, \mathrm{R}=\mathrm{H}$, Thailandolide $\mathrm{A}$ 109e, $\mathrm{AB}=\mathrm{CH}=\mathrm{CH}, \mathrm{R}=\mathrm{OAc}$,Thailandolide $\mathrm{B}$

Figure 9. Examples of naturally occurring drimanic derivatives carrying benzopyran skeletons.

These compounds have demonstrated to possess interesting inhibitory activity on the farnesyl-protein transferase $\left(\mathrm{IC}_{50}=7-13 \mu \mathrm{M}\right)$, having the potential of being novel anticancer agents for tumours in which the ras oncogene is found mutated and contributes to cell transformation. ${ }^{92}$ They also resemble the thailandolides A and B (109d,e), recently reported merodrimanes isolated from the previously undescribed fungus Talaromyces thailandiasis. ${ }^{93}$

\subsection{The K-76 synthesis of Mori and Komatsu}

Taking advantage of McMurry's synthesis, which employed $\alpha, \beta$-unsaturated ester 99 as key intermediate, Mori ${ }^{94}$ expected to accomplish an enantioselective synthesis of K-76 by preparing this intermediate in optically active form, from $(S)$ - $\beta$-hydroxy ketone 111. This starting material is easily available through a biotransformation which involves the baker's yeast-assisted reductive desymmetrization of 1,3-diketone $\mathbf{1 1 0} .{ }^{95}$

Initially, 111 was converted into bicyclic ketol 112 in seven steps (Scheme 8). ${ }^{96}$ Next, dehydration of the alcohol was performed in $89 \%$ yield via the corresponding triflate, and the resulting olefin was cis-dihydroxylated with stoichiometric amounts of $\mathrm{OsO}_{4}$, yielding a mixture of cis-diols from which the desired 113 could be isolated in $36 \%$ yield. This was uneventfully transformed into acetonide 114, which after some experimentation was converted to the $\alpha, \beta$ unsaturated ketone $\mathbf{1 1 5}$ in $37 \%$ overall yield by the Reich sequence, involving $\alpha$-selenenylation with LDA and $\mathrm{BnSeCl}$, followed by ozonation and elimination of the resulting selenoxide. ${ }^{97}$

The required conjugate addition-alkylation stage could not be performed as a one-pot process. Therefore, the enolate resulting from lithium divinyl cuprate was trapped as a TMS enol ether, which was subsequently treated with $\mathrm{LiNH}_{2}$ to effect lithiation, prior to alkylation with methyl iodide. However, the attained yields of $\mathbf{1 1 6}$ were $16 \%$ at best, being 117 the major product. Therefore, the sequence was abandoned in favour of an alternative strategy, designed to overcome the difficulties found during the introduction of the $\mathrm{C} 8$ and $\mathrm{C} 9$ substituents.

Thus, these functionalities were built at early stages of the synthesis, as shown in Scheme 9. For that purpose, 111 was protected as the TBDMS ether and this was subjected to addition of acetylene, followed by $\mathrm{CuSO}_{4}$-mediated dehydration and partial hydrogenation with $\mathrm{Pd}-\mathrm{CaCO}_{3}$ in the presence of quinoline, which provided diene 119 in $50 \%$ overall yield. ${ }^{98}$ In turn, this was 
heated with dimethyl acetylene dicarboxylate to furnish, after deprotection, 1,4-diene $\mathbf{1 2 1}$ (29\%) along with its $\mathrm{C} 10$ diastereomer $\mathbf{1 2 0}(32 \%)$ and $15 \%$ of the bicycle carrying fully aromatized ring $\mathrm{B}$, as result of a Diels-Alder reaction. Chromatographic separation of the diastereomers afforded key intermediates for the synthesis of the natural (-)-K-76 and the methyl ether of the unnatural enantiomer, $O$-methyl (+)-K-76 (128c).

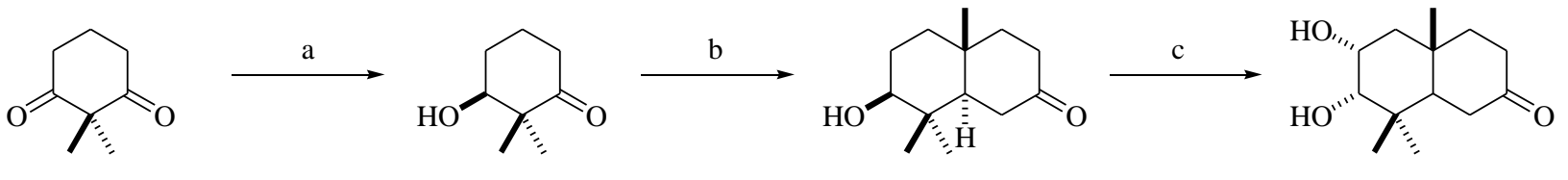

110

111

112

113
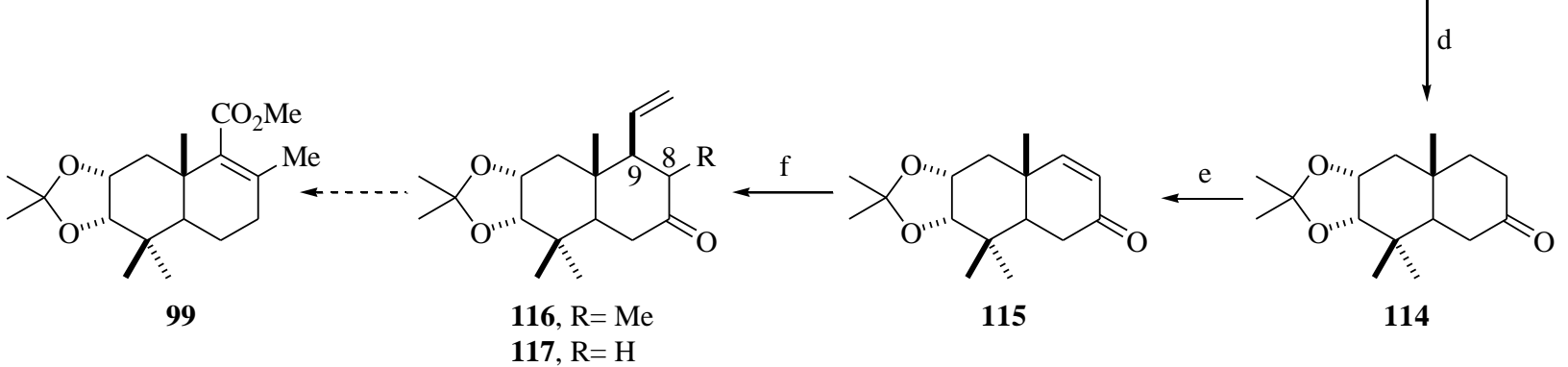

Scheme 8. Reagents and conditions: a) Baker's yeast, sucrose, water, $30^{\circ} \mathrm{C}, 48 \mathrm{~h}(79 \%, 99 \%$ ee); b) 1. DHP, TsOH, $\mathrm{CH}_{2} \mathrm{Cl}_{2}$ (100\%); 2. LDA, $\mathrm{H}_{2} \mathrm{C}=\mathrm{CHCH}_{2} \mathrm{CH}_{2} \mathrm{I}$, THF-HMPA (92\%); 3. LDA, MeI, THF-HMPA (93\%); 4. $\mathrm{PdCl}_{2}, \mathrm{CuCl}, \mathrm{O}_{2}, \mathrm{DMF}-\mathrm{H}_{2} \mathrm{O}$ (77\%); 5. Pyrrolidine, $\mathrm{PhH}(89 \%) ; 6$. $\mathrm{MeOH}$, TsOH (84\%); 7. $\mathrm{H}_{2}, \mathrm{Pd} / \mathrm{C}, \mathrm{MeOH}$ (96\%); c) 1. TfCl, DMAP, $\mathrm{CH}_{2} \mathrm{Cl}_{2},-10^{\circ} \mathrm{C} \rightarrow 0^{\circ} \mathrm{C}$, 4h (89\%); 2. $\mathrm{OsO}_{4}$, Pyridine, THF, rt, 88h (36\%); d) $\mathrm{Me}_{2} \mathrm{CO}$, TsOH, rt, 5h (98\%); e) 1. BnSeCl; 2. $\mathrm{O}_{3}(37 \%)$; f) 1. $\left(\mathrm{H}_{2} \mathrm{C}=\mathrm{CH}\right)_{2} \mathrm{CuLi} ; 2$. TMSCl; 3. $\mathrm{LiNH}_{2}, \mathrm{MeI}(\mathbf{1 1 6}, 16 \%)$.

Partial hydrogenation of the non-conjugated double bond of diester $\mathbf{1 2 0}$ furnished $80 \%$ of 122, which was quantitatively protected as the TBDMS ether $\mathbf{1 2 3}$. Selective reduction of the C8supported methyl ester with DIBAL-H gave $63 \%$ of primary allylic alcohol 124, which was hydrogenolytically deoxygenated (93\%), ${ }^{99}$ and subsequently deprotected with $\mathrm{HF}$ in $\mathrm{MeCN}$ to yield $87 \%$ of $\mathbf{1 2 5}$.

Generation of the required double bond in ring A and conjugation of the double bond of ring B were next undertaken. This was accomplished by tosylation of $\mathbf{1 2 5}$, followed by treatment of the resulting tosylate with the DBU-tetrabutylammonium bromide reagent in DMF, ${ }^{100}$ which simultaneously effected elimination of $\mathrm{TsOH}$ and double bond isomerization, furnishing $\mathbf{5 S - 6 0}$ (the racemic ethyl ester of which was previously prepared by McMurry and Erion), in 77\% overall yield. Osmium tetraoxide-mediated dihydroxylation of $\mathbf{5 S - 6 0}$ finally gave a 1:2 mixture of both possible cis-diols 126a and 126b, in $67 \%$ overall yield.

The total synthesis of (-)-K-76 was then completed, employing McMurry and Erion's protocols and starting from $\mathbf{5 S - 9 9}$, the optically active acetonide of 126a. The overall yield of the synthesis was $0.021 \%$, in 25 steps from $\boldsymbol{S}$-111. The synthetic compound was compared with the natural 
product, exhibiting similar specific optical rotation data and no melting point depression when mixed with the natural K-76.

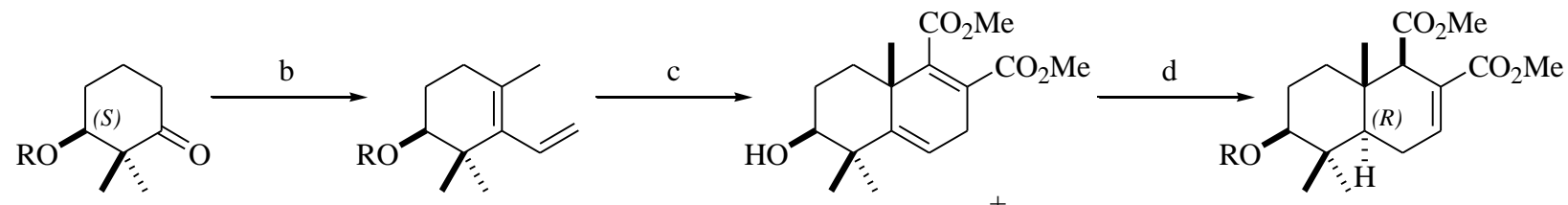

$\square$ 111, $R=\mathrm{H}$
$\longrightarrow \mathbf{1 1 8}, \mathrm{R}=\mathrm{TBDMS}$

119

120<smiles>[CH2+]C(=O)OC</smiles>

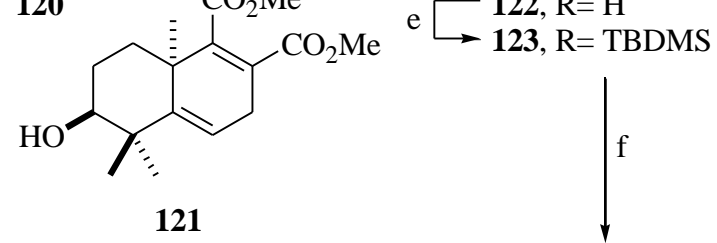<smiles>[R]C1C[C@]2(C)C(C(C)=O)=C(C)CC[C@H]2[C@H](C)C([R])C1C</smiles>

126a, $\mathrm{R}=2 \alpha, 3 \alpha$-diol 126b, $R=2 \beta, 3 \beta$-diol

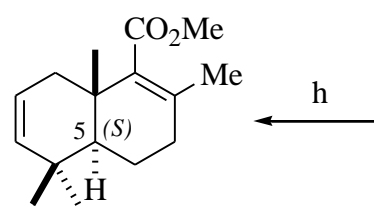

60

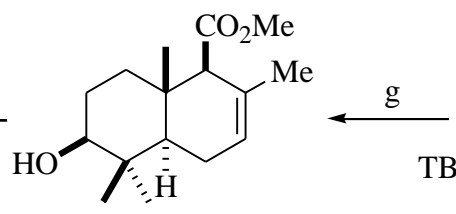

125<smiles>CC(=O)C1C(CO)=CC[C@H]2[C@@H](C)[C@H](OS(C)(C)C)CCC12C</smiles>

124

Scheme 9. Reagents and conditions: a) TBDMSCl, Imidazole, DMF, 40 ${ }^{\circ} \mathrm{C}, 18 \mathrm{~h}(81 \%)$; b) 1. LDA, THF-HMPA, MeI, $78^{\circ} \mathrm{C} \rightarrow 0^{\circ} \mathrm{C}, 30 \min (72 \%) ; 2 . \quad \mathrm{NaC} \equiv \mathrm{CH}, \mathrm{Et}_{2} \mathrm{O}-\mathrm{NH}_{3}$ (liq.) (99\%); 3. $\mathrm{CuSO}_{4}$, Xylene, reflux (51\%); 4. $\mathrm{H}_{2}, \mathrm{Pd} / \mathrm{CaCO}_{3}$, Quinoline (100\%); c) $1 . \mathrm{MeO}_{2} \mathrm{C}-\mathrm{C} \equiv \mathrm{C}-\mathrm{CO}_{2} \mathrm{Me}$, $100-105^{\circ} \mathrm{C}$ (sealed tube), 32h; 2. HF, MeCN, rt, 3h (120, 32\%; 121, 36\%); d) $\mathrm{H}_{2}, 10 \% \mathrm{Pd} / \mathrm{C}$, $\mathrm{MeOH}(80 \%)$; e) TBDMSCl, Imidazole, DMF, rt, 20h (100\%); f) DIBAL-H, PhMe, $-65^{\circ} \mathrm{C}, 30$ $\left.\min (63 \%) ; \mathrm{g}) 1 . \mathrm{H}_{2}, 10 \% \mathrm{Pd} / \mathrm{C}, \operatorname{EtOAc}(93 \%) ; 2.46 \% \mathrm{HF}, \mathrm{MeCN}(1: 60), \mathrm{rt}, 2 \mathrm{~h}(87 \%) ; \mathrm{h}\right) 1$. TsCl, Pyridine, rt, 41h (97\%); 2. DBU, Bu 4 NBr, DMF, $90^{\circ} \mathrm{C}, 44 \mathrm{~h}(77 \%)$; i) $\mathrm{OsO}_{4}$, Pyridine-THF (126a, 21\%; 126b, 46\%).

\subsection{Enantioselective syntheses of diastereomeric compounds closely related to K-76}

Mori and Komatsu also synthesized 128a employing the $2 \beta, 3 \beta$-diol 126b, resulting from the $\beta$ dihydroxylation of 5S-60, through the intermediacy of acetonide 127a, as shown in Scheme 10. Similarly, using 130 as starting material and resorting to a very similar strategy, allyl bromides $\mathbf{1 2 7 b}$ and 127c were prepared. These were then employed for the syntheses of $\mathbf{1 2 8 b}$ and $\mathbf{1 2 8 c}$ [(+)-O-methyl K-76]. Interestingly, cyclization leading to the $\beta$-diol analogue of $\mathrm{K}-76 \mathbf{1 2 8 a}$, which was accomplished in $16 \%$ yield, furnished the related benzopyran isomer 129 as the major reaction product $(25 \%)$. 


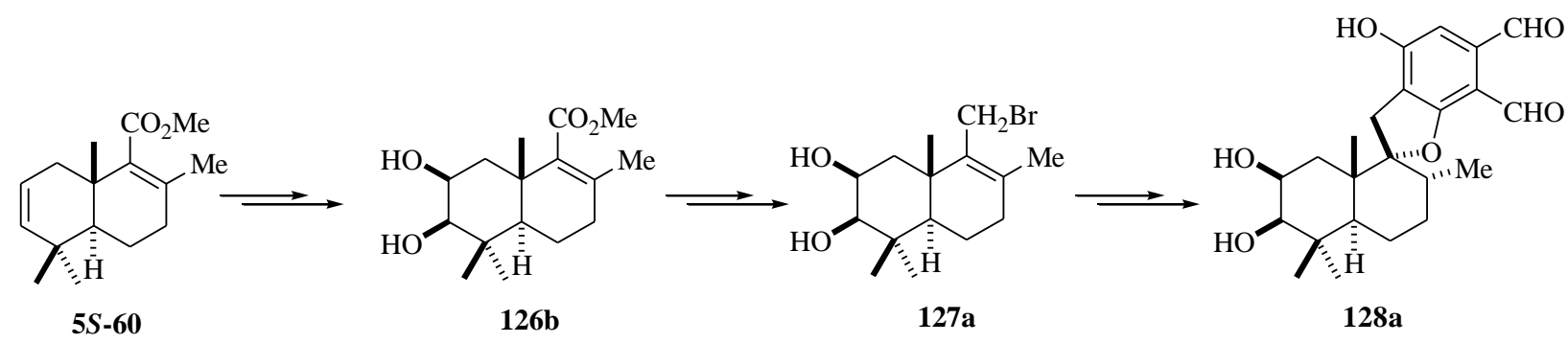<smiles></smiles>

129<smiles>C=CC=CC</smiles>

130

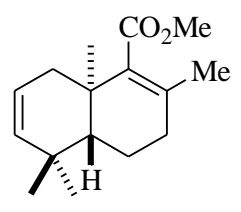

$5 R-58$

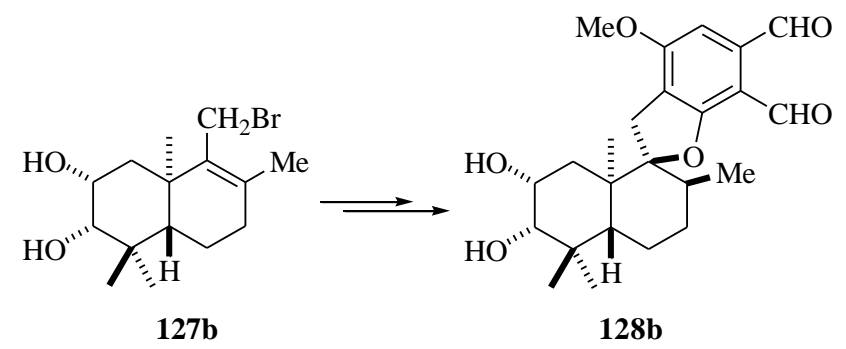

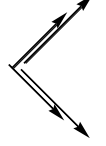

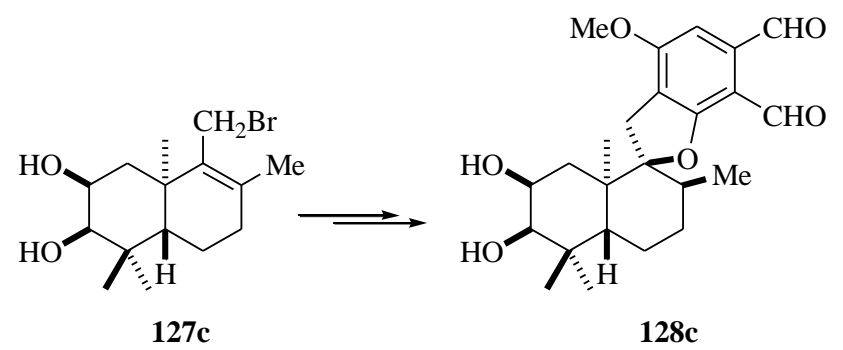

Scheme 10. Enantioselective syntheses of diastereomeric compounds 128a-c, closely related to K-76.

\section{Syntheses of Grisan, the tricycle embodying the BCD ring system of K-76}

\subsection{Synthesis of grisan by Antus and co-workers}

Grisan (29) was the name originally given by the group of Grove ${ }^{101}$ to the spiro[benzofuran2(3H)-1'-cyclohexane] skeleton characteristic of griseofulvin (30). The synthesis of griseofulvin has received much attention during the 1960's and the 1970's, ${ }^{102}$ but its basic skeleton (29) was first synthesized by chance, by Antus and co-workers in 1986 during their attempt of preparing hexahydroxanthenes (Scheme 11). ${ }^{103}$

These authors condensed cyclohexanone (131) with salicylaldehyde benzyl ether (132) under piperidine catalysis to obtain $51 \%$ of $\alpha, \beta$-unsaturated ketone $\mathbf{1 3 3}$, which was reduced to the allylic alcohol 134 with $\mathrm{NaBH}_{4}$ or DIBAL-H (90-92\% yield) and then catalytically hydrogenated with $\mathrm{Pd} / \mathrm{C}$ to yield a mixture of cis and trans alcohols $\mathbf{1 3 5}$ and $\mathbf{1 3 6}$ in 52\% overall yield. 
Treatment of the cis alcohol with $\mathrm{BF}_{3} \cdot \mathrm{Et}_{2} \mathrm{O}$ or $\mathrm{TsOH}$ gave $80 \%$ of the spiro-tricyclic compound 29 through the intermediacy of $\mathbf{1 4 0}$, while the trans alcohol remained reluctant to cyclize under $\mathrm{BF}_{3} . \mathrm{Et}_{2} \mathrm{O}$ promotion, yielding a 6:1 mixture of cis and trans hexahydroxanthenes 138 and 139 in $54 \%$ combined yield upon prolonged treatment with $\mathrm{TsOH}$ in refluxing benzene.

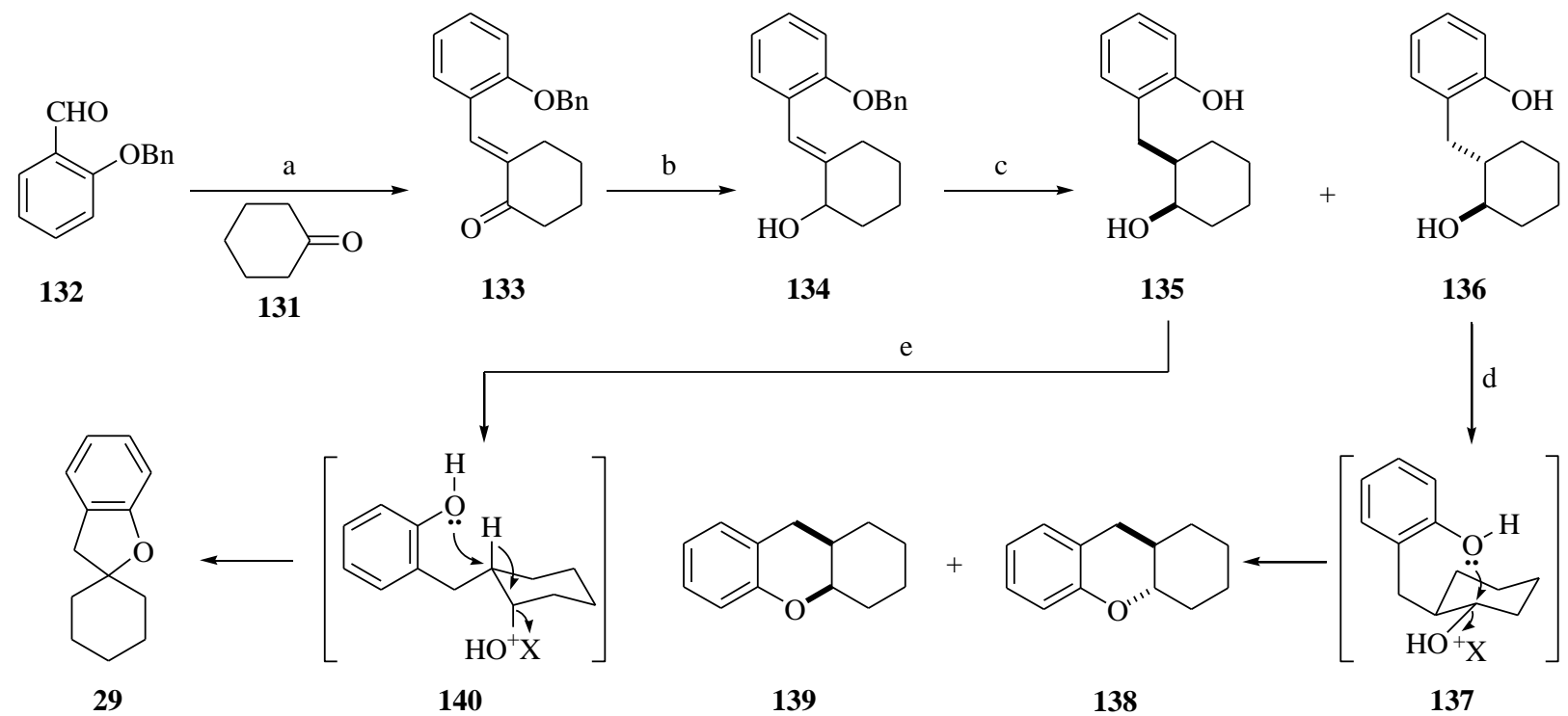

Scheme 11. Reagents and conditions: a) EtOH, Piperidine, reflux, 48h (51\%); b) $\mathrm{NaBH}_{4}, \mathrm{EtOH}$, $15 \min (92 \%)$ or DIBAL-H, PhMe, $-65^{\circ} \mathrm{C}, 30 \mathrm{~min}(90 \%)$; c) $\mathrm{H}_{2}, \mathrm{Pd} / \mathrm{C}, \mathrm{MeOH}(\mathbf{1 3 5}, 40 \%$; 136, $12 \%)$; d) TsOH, $\mathrm{PhH}$, reflux, $160 \mathrm{~h}(139,46 \%$; 138, $8 \%)$; e) $\mathrm{BF}_{3} . \mathrm{Et}_{2} \mathrm{O}, \mathrm{CH}_{2} \mathrm{Cl}_{2}, \mathrm{rt}, 100 \mathrm{~h}(80 \%)$.

Cyclization of deuterium labelled precursors revealed that formation of the spiro-derivative 29 involved a 1,2-hydrogen shift. It was concluded that during the formal elimination of water the oxygen and the neighbouring tertiary hydrogen atom can adopt anti-periplanar positions only in the case of the cis diastereomer 135. This hydrogen atom can thus undergo the observed hydride shift upon concomitant attack of the phenolic $\mathrm{OH}$ at the tertiary centre. However, the diastereomer $\mathbf{1 3 6}$ is unable to adopt this conformation, necessary for such a hydride migration; therefore, only xanthene derivatives 138 and 139 result from the acid-catalyzed cyclization. The main product (139) is formed under $\mathrm{SN}_{2}$-conditions by inversion leading to the thermodynamically less stable cis-compound. However, since the $\mathrm{SN}_{\mathrm{l}}$-type reaction is a competitive path, minor amounts of the trans-diastereomer $\mathbf{1 3 8}$ are also formed.

\subsection{Synthesis of grisan by Kaufman and Sindelar}

Shortly after Antus findings, Kaufman and Sindelar reported a short and more efficient synthesis of grisan. ${ }^{104 a}$ In their three-step sequence, the easily available MOM-ether derivative $\mathbf{1 4 1}$ was ortho-metallated ${ }^{104 b, c}$ with ${ }^{n} \mathrm{BuLi}$-TMEDA in THF and subjected to a copper(I)-assisted coupling with 1-chloromethyl cyclohexene (142), furnishing 95\% of 143 (Scheme 12). Careful acid hydrolysis of the acetalic protecting group with $3 \mathrm{~N} \mathrm{HCl}$ cleanly afforded cyclohexenyl phenol 
144 in $94 \%$ yield, which furnished $94 \%$ of grisan (29) upon treatment with an excess of Amberlyst-15 in methylene chloride. ${ }^{105}$

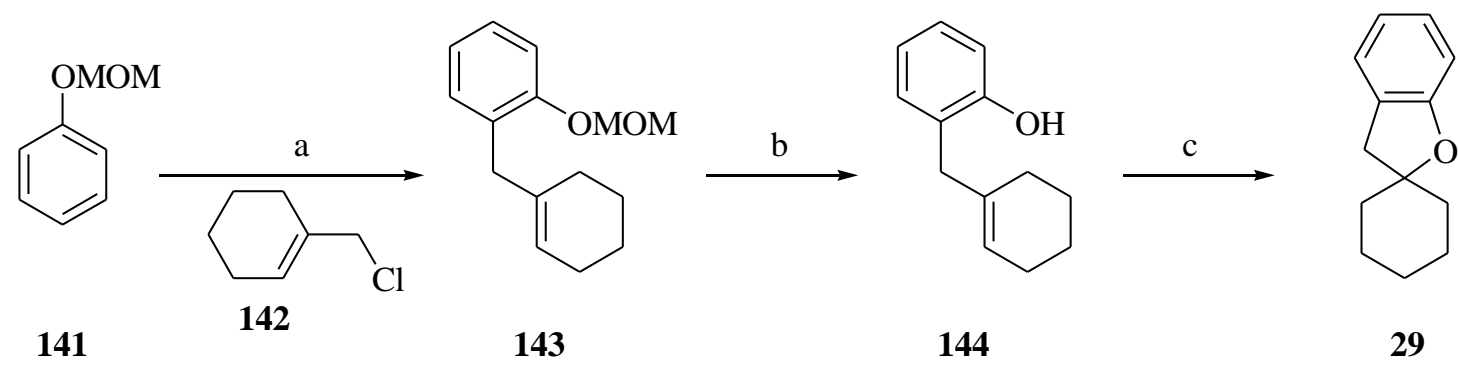

Scheme 12. Reagents and conditions: a) $1 .{ }^{n} \mathrm{BuLi}-\mathrm{TMEDA}, \mathrm{THF}, 0^{\circ} \mathrm{C} \rightarrow \mathrm{RT}, 1.75 \mathrm{~h} ; 2$. CuI, $45^{\circ} \mathrm{C}, 1 \mathrm{~h}$; 3. 1-chloromethyl-cyclohexene (142), overnight (95\%); b) $3 \mathrm{~N} \mathrm{HCl}, 2-\mathrm{PrOH}, \mathrm{H}_{2} \mathrm{O}$, rt, overnight (94\%); c) Amberlist-15, $\mathrm{CH}_{2} \mathrm{Cl}_{2}$, rt, overnight (94\%).

\subsection{Synthesis of grisan by Snider and co-workers}

Following Watt's initial report on the $\alpha$ '-acetoxylation of 2-cyclohexenone (145) with $\mathrm{P}_{2} \mathrm{O}_{5}$ dried $\mathrm{Mn}(\mathrm{OAc})_{3}$ in refluxing benzene, ${ }^{106}$ the group of Snider found that intramolecular trapping of the $\alpha$ '-keto radicals obtained from cyclohexenones by suitably located olefins takes place much faster than $\alpha^{\prime}$-acetoxylation, furnishing bicyclic dienones in good yields. ${ }^{107}$

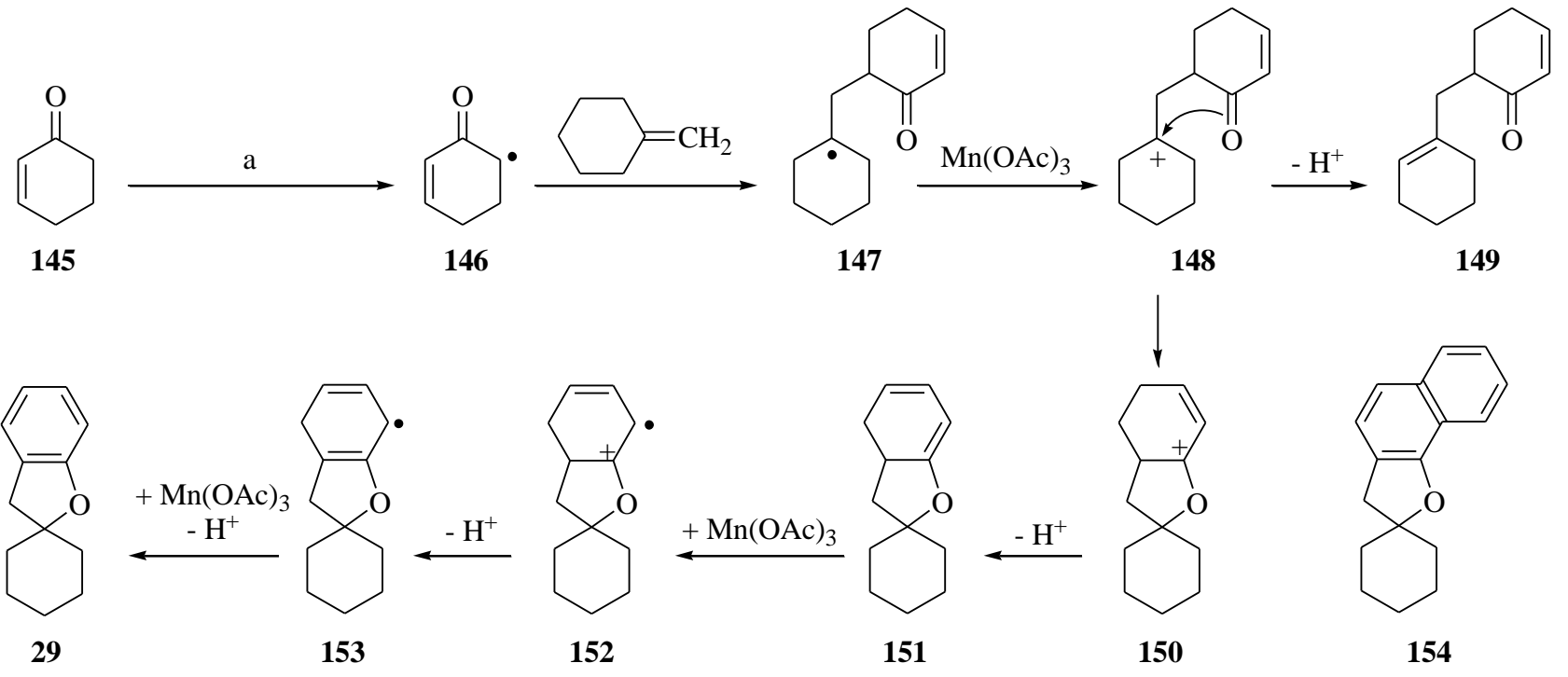

Scheme 13. Reagents and conditions: a) $\mathrm{Mn}(\mathrm{OAc})_{3}\left(\geq 4\right.$ equiv.), $\mathrm{PhH}, \geq 80^{\circ} \mathrm{C}, 3$ days.

When studying the intermolecular version of this transformation, they found that the $\mathrm{Mn}(\mathrm{OAc})_{3}$-mediated oxidative addition of 2-cyclohexenones with methylenecyclohexane in refluxing benzene gave $25-42 \%$ of dihydrobenzofuran derivatives and up to $18 \%$ of 6-(1cyclohexenylmethyl)-2-cyclohexenones. In this way, grisan (29) was made available in $42 \%$ 
overall yield, in a one pot process (Scheme 13), together with $18 \%$ of cyclohexenylmethyl derivative 149. In a similar fashion, even complex compounds such as 154 (from $\alpha$-tetralone) bearing the same motif, where made easily available in reasonable yields. ${ }^{108}$

Mechanistically, oxidation of the cyclohexenone 145 forms $\alpha$-keto radical 146, the addition of which to the olefin furnishes radical 147; being tertiary, 147 is readily oxidized by $\mathrm{Mn}(\mathrm{OAc})_{3}$ to cation $\mathbf{1 4 8},{ }^{109}$ which may lose a proton to give the 2 -alkenyl-2-cyclohexenone side product 149. However, cyclization of $\mathbf{1 4 8}$ to the bicyclic cation $\mathbf{1 5 0}$ is also a viable alternative; in such case, loss of a proton will give tetrahydrobenzofuran $\mathbf{1 5 1}$ or a double bond positional isomer. Taking into account that electron-rich double bonds are easily oxidized to radical cations by $\mathrm{Mn}(\mathrm{OAc})_{3}{ }^{110}$ dienyl ether $\mathbf{1 5 1}$ may become oxidized to grisan through the intermediacy of cation radical 152. In fact, after losing a proton, 152 would yield radical 153 , the final oxidation of which would give a cation, that after losing a proton should afford grisan (29).

\section{Synthesis of K-76 analogues and related compounds for biological testing}

\subsection{Synthesis and evaluation of CD-ring analogues}

In search for the pharmacophore of K-76, and after some in vitro results suggesting that the lipophilic moiety of K-76 analogues may be causing unwanted lytic activity, Srivastava and coworkers prepared a series of CD-ring analogues of K-76 (Scheme 14), featuring different substituents on $\mathrm{C} 6$ (formyl, carboxylic acid, tetrazole) and $\mathrm{C} 4(\mathrm{OH}, \mathrm{OMe}, \mathrm{OPh}){ }^{111}$

In their synthesis, bis-MOM derivative 155 was subjected to lithiation and coupled with methallyl chloride employing organocopper chemistry (156). Fluoro-desilylation of the silyl ether moiety was followed by PCC-mediated partial oxidation of the benzylic alcohol (157) to the aldehyde (158), which in turn was deprotected and cyclized under acidic conditions, furnishing bicycle $\mathbf{1 5 9}$ in $65 \%$ overall yield. Methylation and phenylation of the free phenol group yielded congeners 160 and 161, which together with 159 were subjected to a silver(I)mediated oxidation to the corresponding carboxylic acids (162-164) in good yields.

The protected intermediate aldehydes $\mathbf{1 6 0}$ and $\mathbf{1 6 1}$ were also transformed into the corresponding tetrazoles 167 and 168, bio-isosteric with the corresponding carboxylic acids $\mathbf{1 6 3}$ and 164, ${ }^{112}$ in three step processes which involved formation of the oximes by treatment with hydroxylamine, oxime dehydration to form the corresponding benzonitriles 165 and 166 in 85 and $91 \%$ yield, respectively, and final treatment of the latter with $\mathrm{NaN}_{3}$ and $\mathrm{NH}_{4} \mathrm{Cl}$ in refluxing DMF to which $\mathrm{LiCl}$ has been added.

The target compounds were analyzed for their ability to inhibit the classical pathway activation of human Complement (Table 3 ) $;{ }^{113}$ their lytic activity was also tested, by incubation with sensitized sheep erythrocytes in the absence of Complement. None of the CD-ring analogues exhibited lytic activity, except phenyl ether 167. 


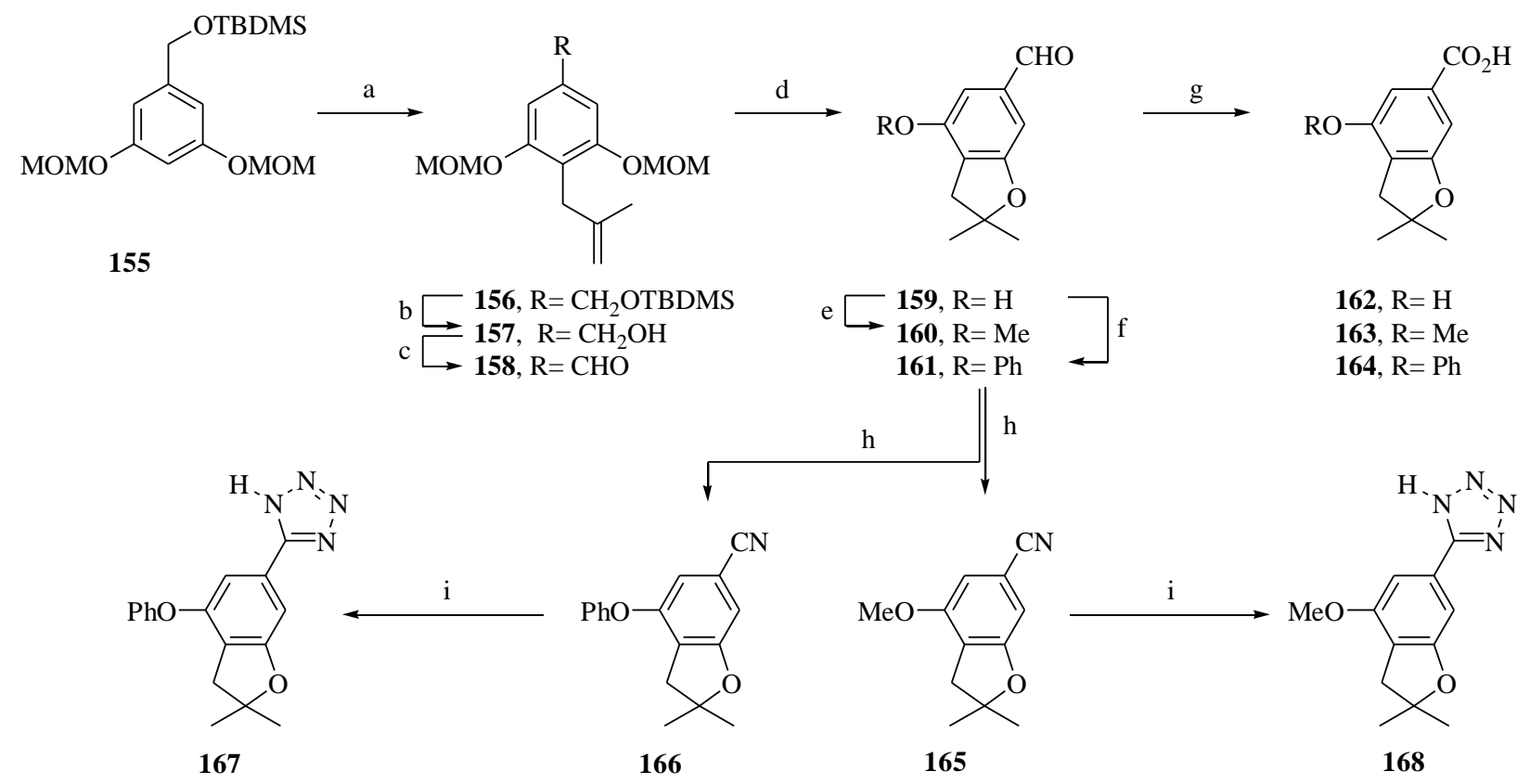

Scheme 14. Reagents and conditions: a) ${ }^{n} \mathrm{BuLi}$, TMEDA, $\mathrm{CuI}, \mathrm{H}_{2} \mathrm{C}=\mathrm{C}\left(\mathrm{CH}_{3}\right) \mathrm{CH}_{2} \mathrm{Cl}$ (83\%); b) TBAF, THF; c) PCC, $\mathrm{CH}_{2} \mathrm{Cl}_{2}$ (89\%, overall) d) 3N HCI, 2-PrOH, rt, 8h (92\%); e) $\mathrm{CH}_{3} \mathrm{I}, \mathrm{Ag}_{2} \mathrm{O}$, $\mathrm{CHCl}_{3}$ (68\%); f) $\mathrm{Ph}_{3} \mathrm{Bi}(\mathrm{OAc})_{2}, \mathrm{Cu}^{\circ}, \mathrm{CH}_{2} \mathrm{Cl}_{2}$ (61\%); g) $\mathrm{AgNO}_{3}, \mathrm{KOH}, \mathrm{EtOH}, \mathrm{H}_{2} \mathrm{O}$ (162, 64\%); h) $1 . \mathrm{NH}_{2} \mathrm{OH} . \mathrm{HCl}, \mathrm{NaOAc}, \mathrm{MeOH} ; 2 . \mathrm{SOCl}_{2}, \mathrm{PhH}$, reflux $\left(\mathbf{1 6 5}, 85 \%\right.$; 166, 91\%); i) $\mathrm{NaN}_{3}$, $\mathrm{NH}_{4} \mathrm{Cl}$, LiCl, DMF, reflux, 52h (168, 44\%; 167, 30\%).

Table 3. Complement inhibitory and lytic activities of synthetic CD-ring analogues of K-76

\begin{tabular}{|c|c|c|c|c|}
\hline Compound & $\mathrm{R}_{1}$ & $\mathrm{R}_{2}$ & $\begin{array}{c}\text { Complement Inhibition } \\
\mathrm{IC}_{50}(\mathrm{mM})\end{array}$ & $\begin{array}{c}\text { Lysis } \\
\mathrm{EC}_{50}(\mathrm{mM})\end{array}$ \\
\hline 26 (K-76 COONa) & & & 0.68 & $>0.68$ \\
\hline 159 & $\mathrm{H}$ & $\mathrm{CHO}$ & $>1.56$ & $>1.56$ \\
\hline 162 & $\mathrm{H}$ & $\mathrm{CO}_{2} \mathrm{H}$ & $>1.44$ & $>1.44$ \\
\hline 160 & $\mathrm{Me}$ & $\mathrm{CHO}$ & 1.10 & $>1.46$ \\
\hline 161 & $\mathrm{Ph}$ & $\mathrm{CHO}$ & $>1.12$ & $>1.12$ \\
\hline 163 & $\mathrm{Me}$ & $\mathrm{CO}_{2} \mathrm{H}$ & $>1.35$ & $>1.35$ \\
\hline 164 & $\mathrm{Ph}$ & $\mathrm{CO}_{2} \mathrm{H}$ & $>1.06$ & $>1.06$ \\
\hline 167 & $\mathrm{Ph}$ & Tetrazole-5-yl & 0.20 & 0.65 \\
\hline 168 & $\mathrm{Me}$ & Tetrazole-5-yl & 0.25 & $>1.22$ \\
\hline
\end{tabular}


The acids and the aldehydes were less potent than the natural product; however, potency was significantly improved by the replacing the carboxylic acid functionality with a tetrazole ring. These results suggested that the presence of an ionizable functional group at position 6 is relevant for Complement inhibition.

\subsection{Synthesis and evaluation of BCD-ring analogues}

Bradbury and Sindelar synthesized a series of BCD-ring analogues of $\mathrm{K}-76^{114}$ following a general strategy reminiscent to that employed by Kaufman and Sindelar for the preparation of grisan, using successive regioselective heteroatom-facilitated aromatic lithiation reactions. ${ }^{115}$ This approach allowed the introduction of different substituents at position-7 from a single intermediate, and the regioselective functionalization of the aromatic moiety to give 6,7disubstituted derivatives.

As shown in Scheme 15, cyclohexanone (131) was subjected to the addition of cyanide anion, followed by dehydration of the intermediate cyanohydrin and subsequent Pinner-type acid-catalyzed ethanolysis, furnishing unsaturated ester 169. In turn, this was reduced to the corresponding alcohol with $\mathrm{LiAlH}_{4}$ and further converted to the required allylic bromide 170 with $\mathrm{PBr}_{3}$ in pyridine in $45 \%$ overall yield. On the other side, the aromatic component 172 was prepared in high yield from the commercially available phenol $\mathbf{1 7 1 .}$

Coupling of 170 and 172 was performed in 91\% yield by heteroatom directed orthometallation of the latter with the ${ }^{n}$ BuLI-TMEDA complex, followed by conversion of the organolithium species to the corresponding cuprate with $\mathrm{CuI}$ at low temperature. A second heteroatom facilitated ortho-lithiation followed by quenching the intermediate organolithium species with different electrophiles provided compounds 174a-d in 61-92\% yield. In turn, these were submitted to acid hydrolysis to yield phenols 175, setting the stage for the cyclization step. Interestingly, during the preparation of $\mathbf{1 7 4 d}$ formation of compound $\mathbf{1 7 8}$ could be observed in up to $40 \%$ yield, when the reaction was performed at $0^{\circ} \mathrm{C}$. This resulted from nitrogen-assisted displacement of the methoxy group from the neighbour MOM ether. On the other hand, 174c was highly sensitive to acid media and did not withstand MOM removal conditions.

Submission of the cyclohexenyl phenols 175a,b to Amberlyst-15 mediated cyclization afforded the corresponding tricyclic methyl ether derivatives 176a,b, which were cleaved to the corresponding free phenols $\mathbf{1 7 7 a}, \mathbf{b}$ with lithium tert-butyl mercaptide. ${ }^{116}$

Aldehyde 175b was further functionalized through a third ortho-directed metallation under the conditions initially developed by Comins and Brown, where $N, N^{\prime}, N^{\prime \prime}$ trimethylethylenediamine was used as an amine component for the in situ formation of $\alpha$-amino alkoxides, which served the purposes of protecting the formyl group and directing lithiation. ${ }^{117}$ The reaction furnished a moderate yield of dialdehyde 177a; in turn, this was oxidized to the monocarboxylic acid $\mathbf{1 7 7} \mathbf{c}$ or to the diacid $\mathbf{1 7 7 b}$ with silver(I) reagents under basic conditions. In an analogous fashion, C6 substituted analogues were prepared, as shown in Scheme 16, which were further functionalized to afford 6,7-disubstituted BCD-ring analogues of K-76. ${ }^{118}$ 


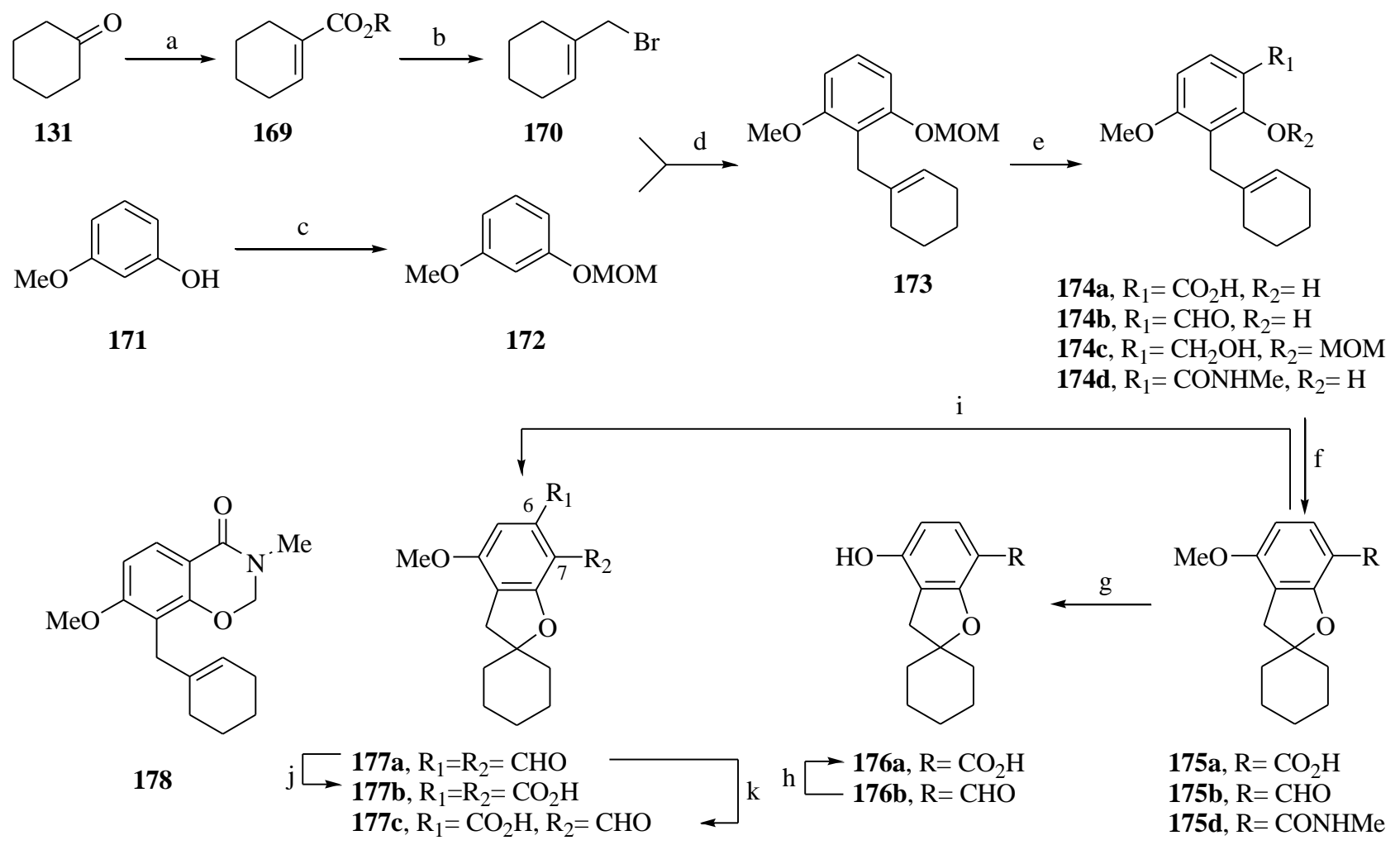

Scheme 15. Reagents and conditions: a) $1 . \mathrm{NaCN}, \mathrm{NaHSO}_{3}, \mathrm{H}_{2} \mathrm{O}, 0^{\circ} \mathrm{C}, 4 \mathrm{~h} ; 2 . \mathrm{POCl}_{3}$, $\mathrm{Pyridine}$, $\mathrm{PhH}$, reflux, $30 \mathrm{~min} ; 3 . \mathrm{H}_{2} \mathrm{SO}_{4}$, EtOH, reflux, 72h (50\% overall); b) 1. $\mathrm{LiAlH}_{4}, \mathrm{Et}_{2} \mathrm{O}$, reflux, 30 min; 2. $\mathrm{PBr}_{3}$, hexanes, $-12^{\circ} \mathrm{C} \rightarrow \mathrm{rt}, 24 \mathrm{~h}(90 \%)$; c) $\mathrm{MOMCl}, \mathrm{K}_{2} \mathrm{CO}_{3}, 18-C r o w n-6, \mathrm{MeCN}, \mathrm{rt}, 10 \mathrm{~h}$ (96\%); d) 1. ${ }^{n} \mathrm{BuLi}$, TMEDA, THF, $0^{\circ} \mathrm{C}, 2 \mathrm{~h}$; 2. CuI, $-40^{\circ} \mathrm{C}, 90 \mathrm{~min} ;-78^{\circ} \mathrm{C} \rightarrow \mathrm{rt}, 16 \mathrm{~h}(91 \%)$; e) 1. ${ }^{n} \mathrm{BuLi}$, TMEDA, Hexane, $0^{\circ} \mathrm{C} \rightarrow \mathrm{rt}, 3 \mathrm{~h} ; 2 . \mathrm{E}^{+},-78^{\circ} \mathrm{C} ; 3 . \mathrm{HCl}, 2-\mathrm{PrOH}$, rt, $16 \mathrm{~h}\left[\mathrm{E}^{+}=\mathrm{CO}_{2}, 174 \mathbf{a}\right.$, 66\%; $\mathrm{E}^{+}=\mathrm{DMF}, \mathbf{1 7 4 b}, 92 \% ; \mathrm{E}^{+}=\left(\mathrm{CH}_{2} \mathrm{O}\right)_{\mathrm{n}}, \mathbf{1 7 4 c}, 64 \%$; $\left.\mathrm{E}^{+}=\mathrm{MeNCO}, 174 \mathrm{~d}, 61 \%\right]$; f) Amberlyst15, PhH, rt, 24h (175a, 85\%; 175b, 83\%; 175d, 94\%); g) ${ }^{t} \mathrm{BuSLi}, \mathrm{HMPA}, 0^{\circ} \mathrm{C}, 12 \mathrm{~h}(\mathbf{1 7 6 a}, 55 \%$; 176b, 93\%; 176d, 94\%); h) $\mathrm{Ag}_{2} \mathrm{O}, \quad \mathrm{NaOH}, \quad \mathrm{H}_{2} \mathrm{O}, \quad 80^{\circ} \mathrm{C}, \quad 72 \mathrm{~h} \quad(50 \%) ;$ i) ${ }^{n} \mathrm{BuLi}$, $\mathrm{Me}_{2} \mathrm{NCH}_{2} \mathrm{CH}_{2} \mathrm{NHMe}$, THF, DMF, $-20^{\circ} \mathrm{C}, 24 \mathrm{~h}\left(34 \%\right.$ ); (j) $\mathrm{AgOH}, \mathrm{AgNO}_{3}, \mathrm{KOH}, \mathrm{EtOH}-\mathrm{H}_{2} \mathrm{O}$, rt, $2 \mathrm{~h}(91 \%) ; \mathrm{k}) \mathrm{AgOH}, \mathrm{Ag}_{2} \mathrm{O}, \mathrm{KOH}, \mathrm{THF}-\mathrm{H}_{2} \mathrm{O}$, rt, $2 \mathrm{~h}(7-14 \%)$.

Benzyl alcohol 179, easily available in $95 \%$ yield from the corresponding ester, by $\mathrm{LiAlH}_{4}$ reduction, was partially oxidized with buffered PCC and acetalized to afford intermediate $\mathbf{1 8 0 .}$ This was coupled with 1-bromomethyl cyclohexene as before, employing organocopper chemistry, to obtain $71 \%$ of aldehyde $\mathbf{1 8 1}$ after acid hydrolysis. Lithium tert-butyl mercaptideassisted cleavage of one of the methyl groups furnished phenol 182, which was uneventfully transformed into tricyclic aldehyde 183 by reaction with Amberlyst-15. Final demethylation yielded $87 \%$ of free phenol 184. When the aldehyde 182 was subjected to a silver oxidemediated oxidation, $94 \%$ of the benzoic acid derivative 185 was isolated; this was easily cyclized with Amberlyst-15, affording 94\% of $\mathbf{1 8 7}$. The related 186 was prepared in $91 \%$ yield by $\operatorname{Ag}_{2} \mathrm{O}-$ oxidation of the corresponding aldehyde 183. 

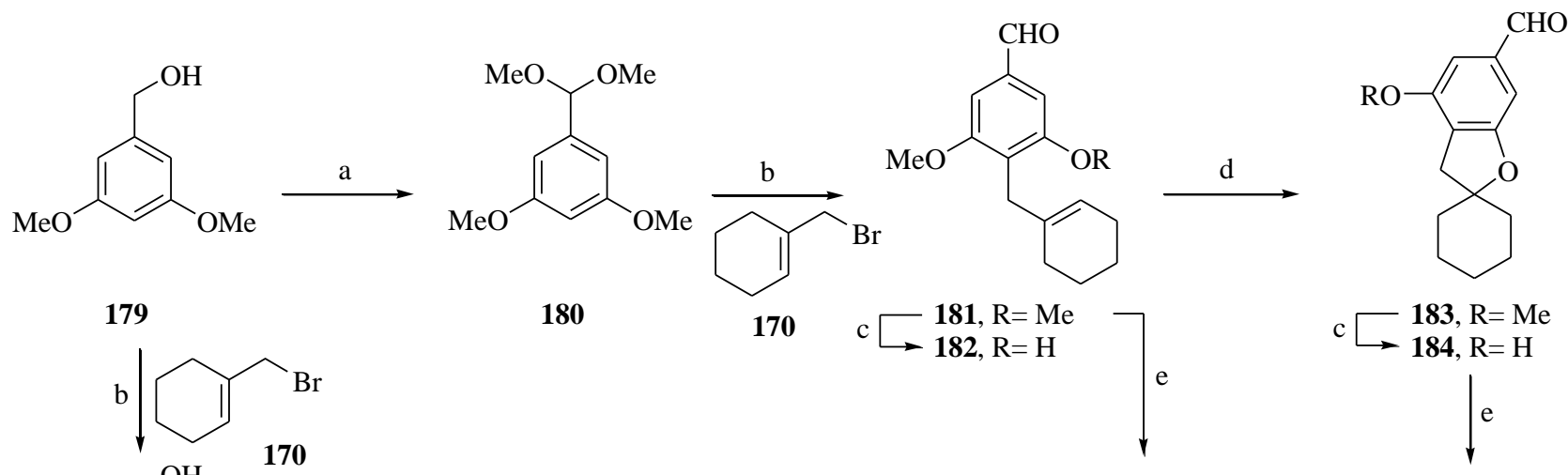

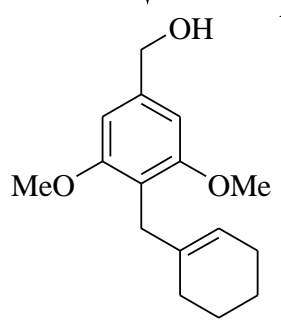

188

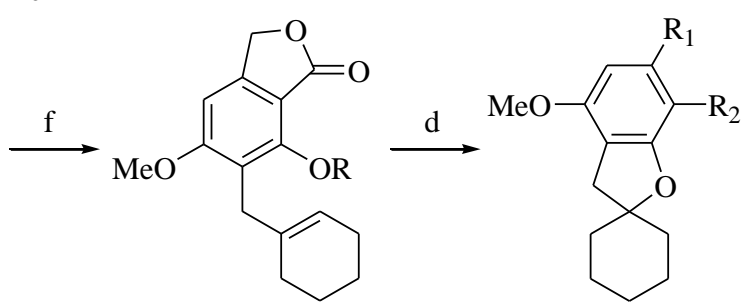

$\begin{aligned} & \mathrm{c} \\ & \mathrm{189}, \mathrm{R}=\mathrm{Me} \\ & \mathrm{190}, \mathrm{R}=\mathrm{H}\end{aligned}$

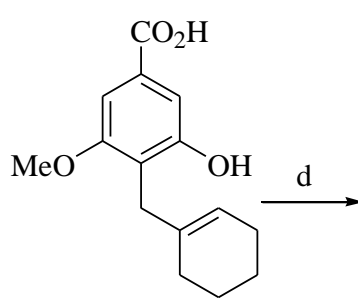

185
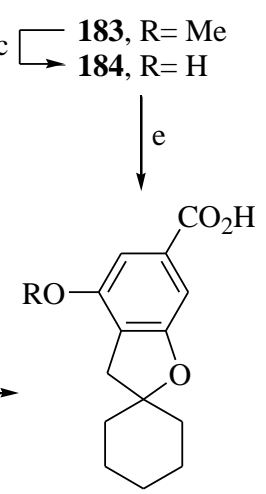

186, $\mathrm{R}=\mathrm{Me}$ 187, $\mathrm{R}=\mathrm{H}$

Scheme 16. Reagents and conditions: a) 1. PCC, $\mathrm{NaOAc}, \mathrm{CH}_{2} \mathrm{Cl}_{2}, \mathrm{rt}, 16 \mathrm{~h}(87 \%)$; 2. TsOH, $\mathrm{CaCl}_{2}, \mathrm{MeOH}$, rt, 3h (84\%); b) 1. ${ }^{n} \mathrm{BuLi}$, TMEDA, THF, rt, 3h; 2. CuI, $-45^{\circ} \mathrm{C}$, 1.5h; 3. 1bromomethylcyclohexene (170), $-70^{\circ} \mathrm{C} \rightarrow \mathrm{rt}, 24 \mathrm{~h} ; 4$. Et $2 \mathrm{O}, 5 \% \mathrm{HCl}, 16 \mathrm{~h}(\mathbf{1 8 0}, 71 \% ; \mathbf{1 8 8}, 77 \%)$; $)$ ${ }^{t}$ BuSLi, HMPA, rt, 48h (182, 93\%; 184, 87\%; 190, 74\%); d) Amberlyst-15, $\mathrm{PhH}$ or $\mathrm{CH}_{2} \mathrm{Cl}_{2}, \mathrm{rt}$, overnight $\left(183,96 \%\right.$; 186, 91\%; 191, 95\%); e) $\mathrm{Ag}_{2} \mathrm{O}, \mathrm{NaOH}, \mathrm{H}_{2} \mathrm{O}, \mathrm{rt}, 16 \mathrm{~h}(\mathbf{1 8 1} \rightarrow \mathbf{1 8 5}, 94 \%$; 184 $\rightarrow 187,96 \%$ ); f) ${ }^{n} \mathrm{BuLi}, \mathrm{TMEDA}, \mathrm{CO}_{2}$, hexanes, $\left.-78^{\circ} \mathrm{C}, 1 \mathrm{~h}(66 \%) \mathrm{g}\right) \mathrm{KMnO}_{4}, \mathrm{TBAF}, \mathrm{NaOH}$, THF- $\mathrm{H}_{2} \mathrm{O}(53 \%)$.

On the other side, coupling the benzylic alcohol 179 with 1-bromomethylcyclohexene (170) yielded symmetric intermediate 188, which was carboxylated with carbon dioxide to phthalide 189 in $66 \%$ yield. ${ }^{119}$ Selective demethylation of the methyl ether located ortho to the carbonyl moiety $(\mathbf{1 9 0}, 74 \%)$ followed by Amberlyst-15 mediated cyclization gave $95 \%$ of tetracyclic lactone 191, the oxidation of which with the $\mathrm{KMnO}_{4}$-TBAF reagent mixture ${ }^{120}$ furnished acidaldehyde 192 in moderate yield.

The synthetic analogues were tested for their ability to inhibit Complement activation in the classical and alternative pathways. Although the natural product is a free phenol, methyl ether derivatives carrying a C6 carboxyl group $\left(\mathbf{1 7 7 b}, \mathbf{1 7 7}\right.$,, 185 and 186) displayed activities ( $\mathrm{IC}_{50}$ values ranged from 0.16 to $0.82 \mathrm{mM})$ comparable to that of $\mathrm{K}-76 \mathrm{COOH}\left(\mathbf{2 8}, \mathrm{IC}_{50}=0.57 \mathrm{mM}\right)$ in the inhibition of total hemolysis. On the other hand, phenol 187 exhibited slightly reduced ability to inhibit total hemolysis $\left(\mathrm{IC}_{50}=1.45 \mathrm{mM}\right)$. A similar effect on Complement activity was observed among the ACD-ring analogues (see below). However, the most potent analogue (177c) was that retaining the carbonyl substitution pattern of the natural product (however, carrying an $O$-methyl ether). 
The ability of the analogues to inhibit the lysis of rabbit red blood cells by the alternative Complement pathway121 was also assessed (Table 4). Since higher concentrations of human serum are required to achieve proper lysis of the rabbit erythrocytes by the alternative pathway than those needed to lyse antibody-sensitized sheep red blood cells, $\mathrm{IC}_{50}$ values by the classical and alternative pathways are not comparable.

Table 4. Complement inhibition ability of BD- and BCD-ring analogues of K-76<smiles>[R]Oc1cc([R])c([R])c(O)c1CC1=CCCCC1</smiles>

$174 a, 185$

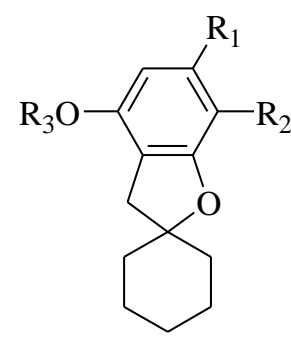

175a, 176a, 177b,c, 186, 187, 192

\begin{tabular}{cccccc}
\hline Compound $\mathrm{N}^{\mathbf{0}}$ & $\mathrm{R}_{1}$ & $\mathrm{R}_{2}$ & $\mathrm{R}_{3}$ & $\begin{array}{c}\text { Total hemolysis } \\
\mathrm{IC}_{50}(\mathrm{mM})\end{array}$ & $\begin{array}{c}\text { Alternative hemolysis } \\
\mathrm{IC}_{50}(\mathrm{mM})\end{array}$ \\
\hline $\mathbf{2 8}$ & $\mathrm{CO}_{2} \mathrm{H}$ & $\mathrm{CHO}$ & $\mathrm{H}$ & 0.57 & 0.33 \\
$\mathbf{1 7 4 a}$ & $\mathrm{H}$ & $\mathrm{CO}_{2} \mathrm{H}$ & $\mathrm{Me}$ & 2.1 & 2.2 \\
$\mathbf{1 7 5 a}$ & $\mathrm{H}$ & $\mathrm{CO}_{2} \mathrm{H}$ & $\mathrm{Me}$ & 1.3 & \\
$\mathbf{1 7 6 a}$ & $\mathrm{H}$ & $\mathrm{CO}_{2} \mathrm{H}$ & $\mathrm{H}$ & 3.0 & 1.2 \\
$\mathbf{1 7 7 b}$ & $\mathrm{CO}_{2} \mathrm{H}$ & $\mathrm{CO}_{2} \mathrm{H}$ & $\mathrm{Me}$ & 0.8 & 0.73 \\
$\mathbf{1 7 7 c}$ & $\mathrm{CO}_{2} \mathrm{H}$ & $\mathrm{CHO}$ & $\mathrm{Me}$ & 0.16 & 3.5 \\
$\mathbf{1 8 5}$ & $\mathrm{CO}_{2} \mathrm{H}$ & $\mathrm{H}$ & $\mathrm{Me}$ & 0.82 & 2.2 \\
$\mathbf{1 8 6}$ & $\mathrm{CO}_{2} \mathrm{H}$ & $\mathrm{H}$ & $\mathrm{Me}$ & 0.53 & 3.8 \\
$\mathbf{1 8 7}$ & $\mathrm{CO}_{2} \mathrm{H}$ & $\mathrm{H}$ & $\mathrm{H}$ & 1.5 & 1.9 \\
$\mathbf{1 9 2}$ & $\mathrm{CHO}^{2}$ & $\mathrm{CO}_{2} \mathrm{H}$ & $\mathrm{Me}$ & 1.7 & \\
\hline
\end{tabular}

However, analogue 177c inhibited hemolysis by the alternative pathway with $\mathrm{IC}_{50}=0.73$ $\mathrm{mM}$, comparable to the activity displayed by the natural product $\left(\mathbf{2 8}, \mathrm{IC}_{50}=0.33 \mathrm{mM}\right)$. The other analogues were slightly less active, with $\mathrm{IC}_{50}$ values ranging between 1.2 and $3.8 \mathrm{mM}$.

\subsection{Synthesis and evaluation of ACD-ring analogues}

The group of Sindelar prepared C6- and C7-substituted ACD ring analogues of K-76 employing both enantiomers of limonene ${ }^{122}$ and $(R)$-carvone as starting materials for building the A-ring moiety. The enantiomers of limonene were individually submitted to metallation at the propenyl side chain ${ }^{123}$ and the resulting species were subjected to treatment with oxygen, leading to hydroperoxydic intermediates, which were reduced in situ to the corresponding allyl alcohols 208. In turn, these were converted into the required allylic chlorides 193 by reaction with the 
$\mathrm{PPh}_{3} / \mathrm{CCl}_{4}$ reagent. ${ }^{124}$

For the preparation of the C7-substituted analogues, allylic chloride 193 was coupled in $93 \%$ yield to resorcinol derivative 194, synthesized in good yields from 3-methoxyphenol (171), employing an heteroatom-facilitated ortho-directed lithiation (Scheme 17), followed by transformation of the lithium species into organocopper intermediates.

A second heteroatom directed ortho lithiation performed on 194 coupled to reaction with $\mathrm{DMF}, \mathrm{CO}_{2}$ and ethyl carbonate furnished carbonyl derivatives 195-197 in 60-64\% yield. Because the direct carboxylation of 194 with $\mathrm{CO}_{2}$ gave no clean products, ester 197 was prepared.

In turn, these intermediates were selectively deprotected under acid conditions (198-199a) and 199a was converted into $199(92 \%)$ by basic hydrolysis. Next, the resulting free phenols were subjected to Amberlyst-15 cyclization, affording dihydrobenzofuran derivatives 200-202 in $73-81 \%$ yield, as diastereomeric mixtures at the quaternary carbon level. Final cleavage of their methyl ether moiety with ${ }^{t} \mathrm{BuSLi}$ in HMPA furnished phenols 203-205 in 95-97\% yield. On the other hand, ester 205 was also transformed into acid 204 (85\%) by $\mathrm{NaOH}$-mediated hydrolysis.

The ability of the synthesized analogues to inhibit Complement activation and production of anaphylatoxins C3a and C5a was assayed. The enantiomers of aldehydes $\mathbf{2 0 0}$ and $\mathbf{2 0 3}$ exhibited poor aqueous solubility, which precluded testing. However, both enantiomers of acid 201 were active ( $\mathrm{IC}_{50}=8 \mathrm{mM}$ and $6 \mathrm{mM}$ ), being the $S$-enantiomer slightly more potent and comparable to $\mathrm{K}-76 \mathrm{COONa}\left(\mathrm{IC}_{50}=3 \mathrm{mM}\right)$, while the corresponding free phenols 204 proved to be essentially inactive at the $\mathrm{C} 5 \mathrm{a}$ and $\mathrm{C} 3 \mathrm{a}$ levels.

The capacity of the compounds to inhibit Complement-mediated erythrocyte lysis (hemolysis) was also assessed. ${ }^{125}$ Both enantiomers of the acids 201 and 204 demonstrated to be active $\left(\mathrm{IC}_{50}=\boldsymbol{R}-\mathbf{2 0 1}, 0.750 \mathrm{mM} ; \boldsymbol{S}-\mathbf{2 0 1}, 0.24 \mathrm{mM} ; \boldsymbol{R}-\mathbf{2 0 4}, 2.15 \mathrm{mM} ; \boldsymbol{S}-\mathbf{2 0 4}, 2.41 \mathrm{mM}\right.$ ) in the same order of magnitude than K-76 COONa $(0.57 \mathrm{mM})$, albeit the free phenols were less potent.

These authors also evaluated the capacity of the acids to inhibit the mitogen-stimulated proliferation of lymphocytes. When the immunosuppressant OKT-3 and phytohemagglutinine were employed as mitogens, the $\mathrm{IC}_{50}$ values of the synthetic inhibitors were slightly higher than those of K-76 COONa.

More functionalized C7 substituted analogues were obtained from $R$-carvone (209). ${ }^{126}$ These were designed with the hope to overcome the problem of diastereomer formation among the ACD-ring analogues derived from the limonene enantiomers. After studying the steric and electronic factors that contribute to the cyclization and analysis of molecular models of the cyclising phenol, it was concluded that provision of interactions between the A and D rings could afford a rigid intermediate and induce a preferred conformation that would allow a preferential side attack of $\mathrm{C} 8$ by the phenolic hydroxyl.

In order to provide such interactions, functionalization of the endocyclic double bond of the alicyclic moiety was proposed with the expectation that regio- and stereospecific hydroxylation would not only provide the proper hydrogen bonding interactions to induce the cyclization, but also generate analogues carrying a cis-diol functionalization similar to that found in the natural product. Following the procedures of Itoh and Royals, $R$-carvone (209) was reduced to the 
corresponding allylic alcohol (210), which was submitted to a TBHP-mediated epoxidation (211) directed and catalyzed by $\mathrm{VO}(\text { Acac })_{2}$ (Scheme 18).

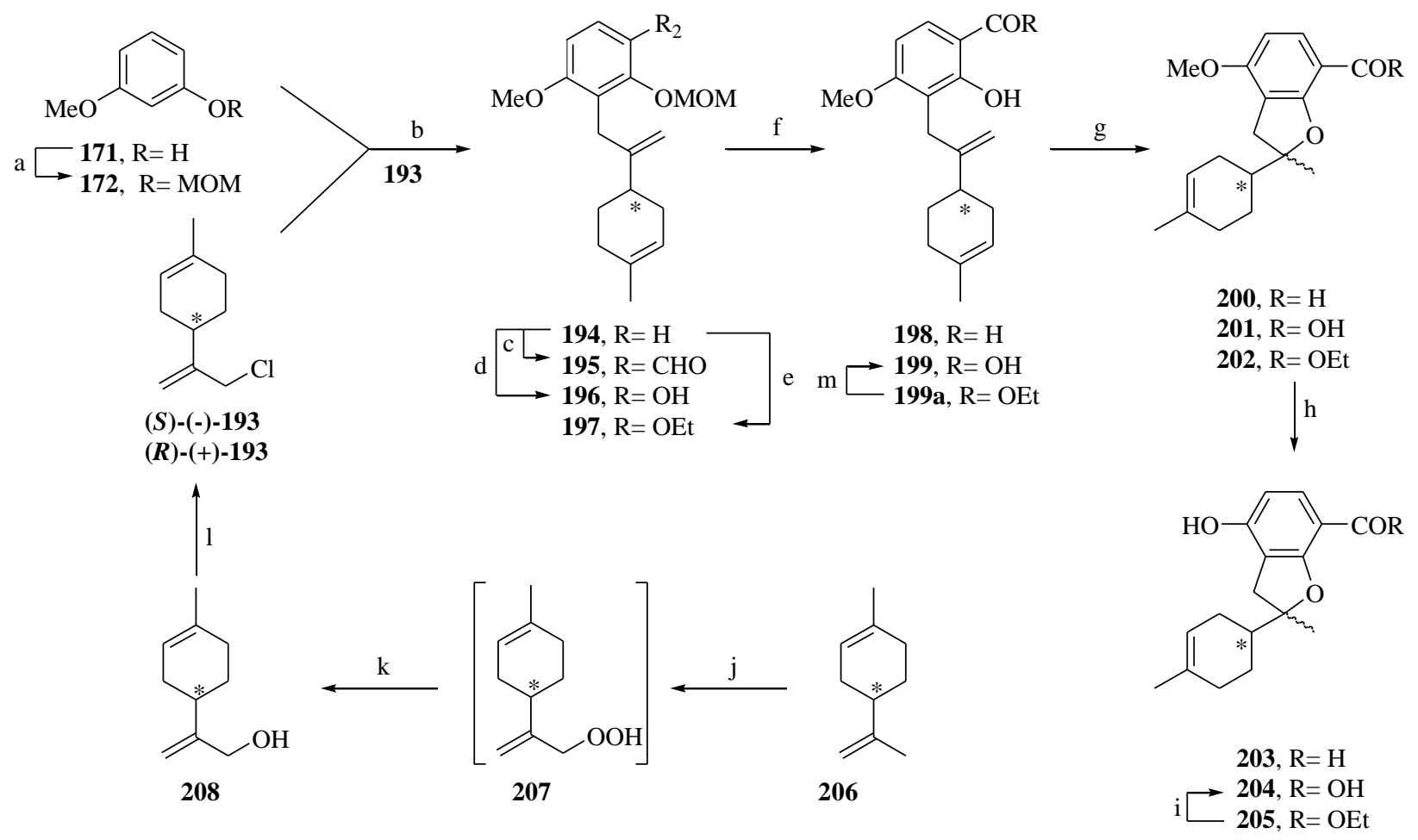

Scheme 17. Reagents and conditions: a) MOMCl, NaH, DMF, rt, overnight (89\%); b) 1. ${ }^{n} \mathrm{BuLi}$, TMEDA, hexane, $0^{\circ} \mathrm{C} ; 2$. CuI, $-45^{\circ} \mathrm{C}, 1 \mathrm{~h} ; 3.193-78^{\circ} \mathrm{C} \rightarrow \mathrm{rt}, 3 \mathrm{~h}(93 \%)$; c) ${ }^{n} \mathrm{BuLi}, \mathrm{TMEDA} \mathrm{Et}_{2} \mathrm{O}$, DMF (64\%); d) ${ }^{n} \mathrm{BuLi}$, TMEDA, Et ${ }_{2} \mathrm{O}, \mathrm{CO}_{2}$; e) ${ }^{n} \mathrm{BuLi}$, TMEDA, Et ${ }_{2} \mathrm{O}, \mathrm{CO}_{3} \mathrm{Et}_{2}$ (60\%); f) $3 \mathrm{~N}$ $\mathrm{HCl}, 2-\mathrm{PrOH}\left(198,92 \%\right.$; 199, 40\% from 194; 199a, 88\%); g) Amberlyst-15, $\mathrm{CH}_{2} \mathrm{Cl}_{2}(\mathbf{2 0 0}, 73 \%$; 201, 77\%; 202, 81\%); h) ${ }^{t} \mathrm{BuSLi}, \mathrm{HMPA}(203,95 \%$; 204, 97\%; 205, 97\%); i) $30 \% \mathrm{NaOH}, \mathrm{EtOH}$, reflux, overnight (85\%); j) 1. ${ }^{n} \mathrm{BuLi}$, TMEDA, rt, 24h; 2. $\mathrm{O}_{2},-35^{\circ} \mathrm{C}$; k) $\left.\mathrm{Na}_{2} \mathrm{SO}_{3} ; 1\right) \mathrm{PPh}_{3}, \mathrm{CCl}_{4}$, $\mathrm{CH}_{2} \mathrm{Cl}_{2}$, reflux (91\% overall); m) $40 \% \mathrm{KOH}$, overnight, rt (92\%).

Reductive opening of the epoxide form the less hindered side afforded cis-diol 212, which was then protected as the acetonide (213) and allylically halogenated with the calcium hypochlorite-dry ice reagent to furnish $\mathbf{2 1 4} .^{127}$

Metallation of 172 initiated the coupling with 214 to afford 68\% of 215. An ortho-directed metallation of 215, followed by treatment of the organometallic intermediates with ethyl formate and ethyl carbonate and mild acid hydrolysis provided $46 \%$ of $\mathbf{2 1 6}$ and 53\% of $\mathbf{2 1 8}$, respectively. Acid 217 was obtained by saponification of the corresponding ester in $96 \%$ yield. Acid hydrolysis of the products caused removal of the MOM ether moiety, leaving phenolic intermediates 219-221 ready for cyclization. 


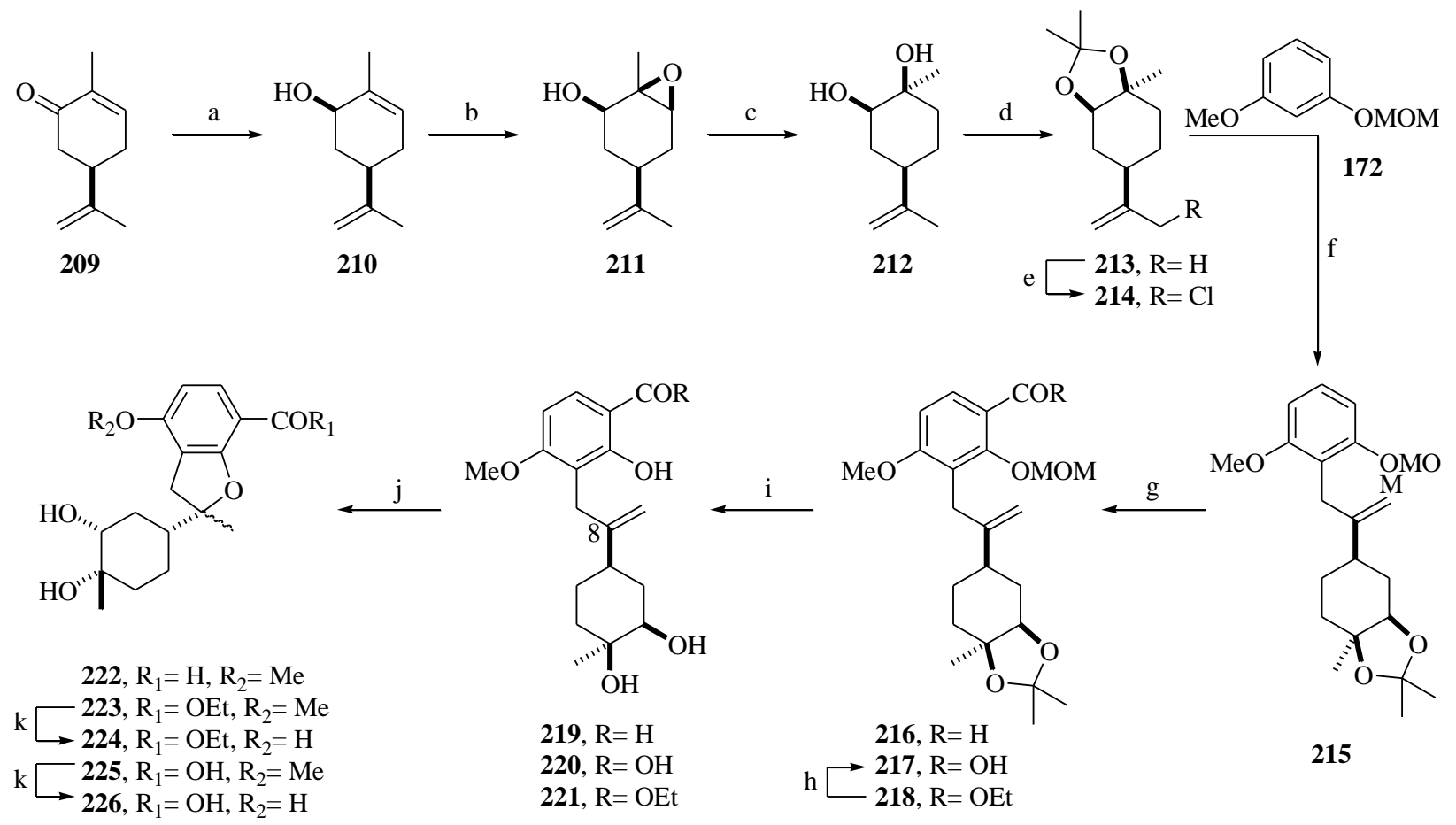

Scheme 18. Reagents and conditions: a) $\mathrm{LiAIH}_{4}, \mathrm{THF}$; b) ${ }^{t} \mathrm{BuOOH}, \mathrm{VO}(\mathrm{Acac})_{2}$; c) $\mathrm{LiAlH}_{4}$, THF, reflux; d) $\mathrm{Me}_{2} \mathrm{C}(\mathrm{OMe})_{2}$, TsOH; e) $\mathrm{Ca}(\mathrm{ClO})_{2}, \mathrm{CO}_{2}, \mathrm{CCl}_{4}$; f) ${ }^{n} \mathrm{BuLi}, \mathrm{TMEDA}, \mathrm{CuI}, 172$ $(88 \%)$; g) $\left.{ }^{n} \mathrm{BuLi}, \mathrm{TMEDA}, \mathrm{HCO}_{2} \mathrm{Et}(\mathrm{R}=\mathrm{H}, 46 \%), \mathrm{CO}_{3} \mathrm{Et}_{2}(\mathrm{R}=\mathrm{OEt}, 53 \%) ; \mathrm{h}\right) 30 \% \mathrm{NaOH}$, EtOH-H $2 \mathrm{O}$, reflux (96\%); i) $\mathrm{SiO}_{2}, 1 \% \mathrm{AcOH}$, EtOAc (79-96\%); j) Amberlyst-15, $\mathrm{CH}_{2} \mathrm{Cl}_{2}$ (91$92 \%)$; k) ${ }^{t} \mathrm{BuSLi}$, HMPA.

This was performed with Amberlyst-15, furnishing 222, 223 and 225 in 91-92\% yield. Among these compounds, it was expected that interaction between the secondary alcohol and the carbonyl moiety would lead preferentially or exclusively to one diastereomer. Finally, cleavage of the methyl ether with ${ }^{t}$ BuSLi in HMPA yielded phenolic analogues 224 and 226.

Evaluation of representative analogues was performed, since compounds 219 and 221-224 exhibited poor aqueous solubility. Therefore, analysis of $\mathbf{2 2 0}$ and $\mathbf{2 2 5}$ was carried out for inhibition of the classical and alternative ${ }^{121}$ Complement pathways, with the results consigned in Table 5. These results suggested that the cis-diol moiety may not be a structural requirement for Complement inhibition.

Next, fluoro-desilylation of the silyl ether was followed by PCC-mediated partial oxidation of the intermediate benzylic alcohol furnished aldehyde (228), which was deprotected with $3 \mathrm{~N}$ $\mathrm{HCl}$ in 2-propanol, yielding a mixture of mono- and bis-deprotected aldehydes 229 and 230.

Upon cyclization with Amberlyst-15, both aldehydes afforded phenolic aldehyde 232; however, the MOM-ether 235 was not isolated. The phenol moiety was protected as methyl (233) and phenyl (234) ethers in 95\% and 75\% yield, respectively, and the three tricyclic aldehydes were subjected to a silver(I)-mediated oxidation to the corresponding carboxylic acids 
(235-237) in good yields. Finally, $\mathbf{2 3 6}$ was dihydroxylated to give 68\% of diol $\mathbf{2 3 8}$.

Table 5. Inhibition of human Complement activation by ACD-ring analogues derived from $R$ carvone

\begin{tabular}{ccc} 
& \\
\hline Compound $\mathrm{N}^{\mathbf{0}}$ & Classical pathway $\mathrm{IC}_{50}(\mathrm{mM})$ & Alternate pathway $\mathrm{IC}_{50}(\mathrm{mM})$ \\
\hline $\mathbf{2 8}, \mathbf{K}-\mathbf{7 6} \mathbf{C O O N a}$ & 0.57 & 0.85 \\
$\mathbf{2 2 5}$ & $24 \%$ at $2.0 \mathrm{mM}$ & - \\
\hline
\end{tabular}

The synthetic analogues were tested for their ability to inhibit activation of the Complement system and for their intrinsic lytic activity (Table 6). The results indicated that compounds $2 \mathbf{2 3 2}$ and 235 display in vitro inhibition of classical human Complement-mediated hemolysis in the same range of concentrations as the natural product. This suggests that the presence of a formyl group in the D-ring may not be an essential requirement for Complement inhibition. In addition, among the carboxylic acids the analogues substituted at C6 were more potent than those functionalized at $\mathrm{C} 7$.

In light of these results, the phenolic hydroxyl also seems to play an important role especially when the carboxyl group is at C6. The phenoxy derivatives $\mathbf{2 3 4}$ and $\mathbf{2 3 7}$ were inactive, while poor activity was observed in case of the methoxy acid derivative 236. Lipophilicity changes in the A- (diols $\mathbf{2 2 6}$ and 238) and/or D-rings affected the intrinsic lytic activity of the analogues.

In view of the compared better potency of the analogues prepared with the $S$-enantiomer of limonene, the $\mathrm{C} 6$ analogues were prepared according to a similar strategy, ${ }^{128}$ as depicted in Scheme 19, employing $S$-193. Therefore, the bis-MOM derivative 155 was submitted to an ortho lithiation and coupled with the $S$-enantiomer of chloride 193, employing organocopper chemistry (227). 


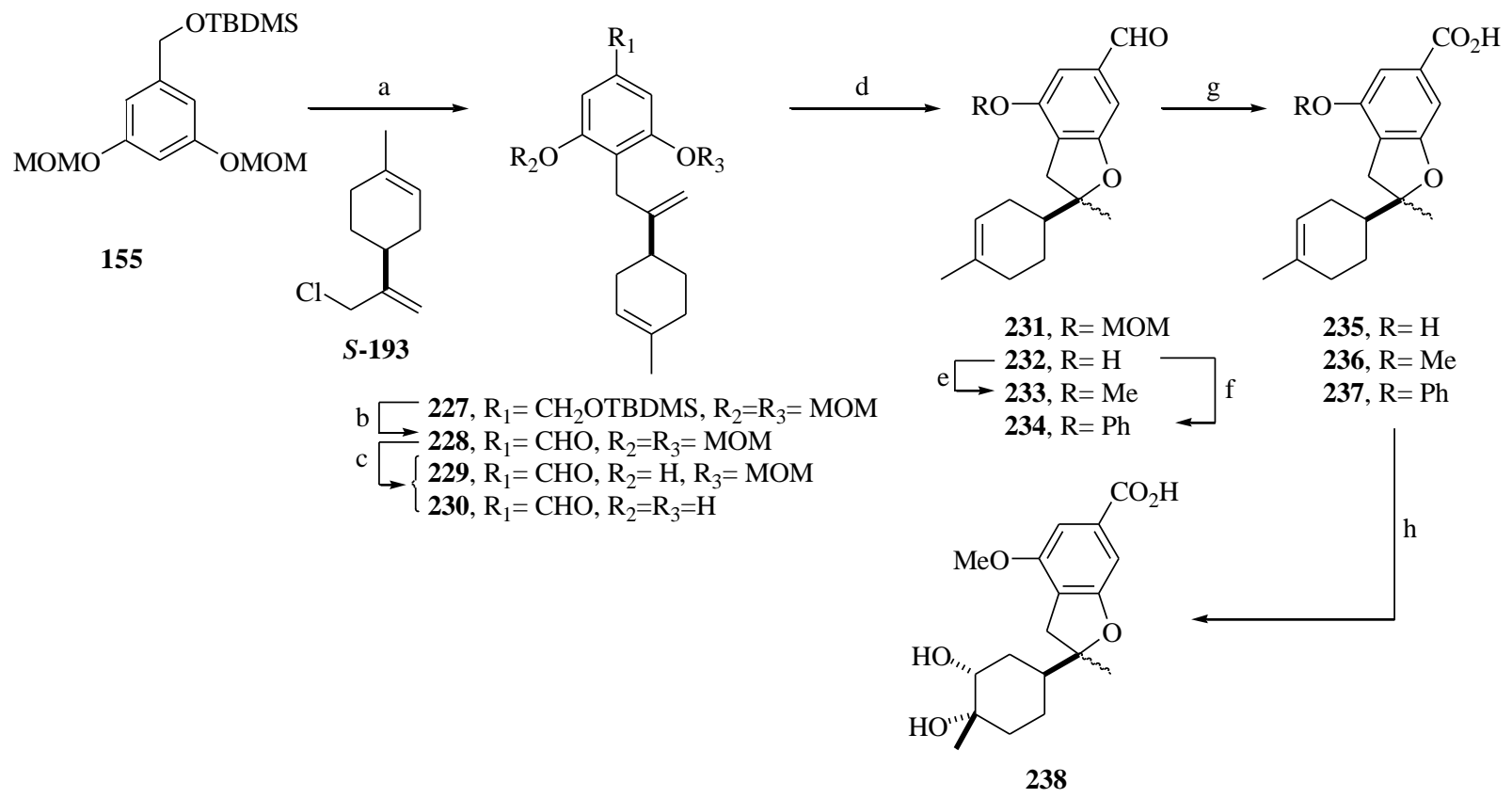

Scheme 19. Reagents and conditions: a) ${ }^{n} \mathrm{BuLi}$, TMEDA, CuI, $S$-193 (82\%); b) 1 . TBAF, THF; 2. PCC, $\mathrm{CH}_{2} \mathrm{Cl}_{2}$ (90\%, overall); c) $3 \mathrm{~N} \mathrm{HCl}, 2-\mathrm{PrOH}, \mathrm{rt}, 8 \mathrm{~h}(\mathbf{2 2 9}, 21 \%$; 230, 52\%); d) Amberlyst15, $\mathrm{CH}_{2} \mathrm{Cl}_{2}$, rt; e) $\mathrm{CH}_{3} \mathrm{I}, \mathrm{Ag}_{2} \mathrm{O}, \mathrm{CHCl}_{3}(95 \%)$; f) $\mathrm{Ph}_{3} \mathrm{Bi}(\mathrm{OAc})_{2}, \mathrm{Cu}^{\circ}, \mathrm{CH}_{2} \mathrm{Cl}_{2}(75 \%)$; g) $\mathrm{AgNO}_{3}$, $\mathrm{KOH}, \mathrm{EtOH}, \mathrm{H}_{2} \mathrm{O}(\mathbf{2 3 5}, 63 \%)$; h) $\mathrm{OsO}_{4}, \mathrm{Me}_{3} \mathrm{NO} .2 \mathrm{H}_{2} \mathrm{O},{ }^{t} \mathrm{BuOH}(68 \%)$.

Table 6. Complement inhibition and lytic activity of synthetic ACD-ring analogues of K-76

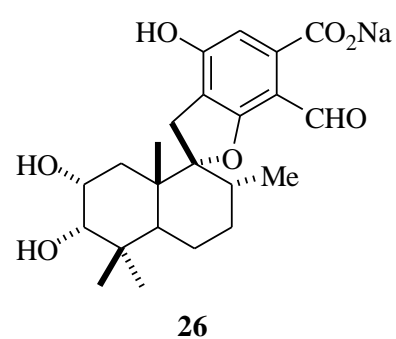

26

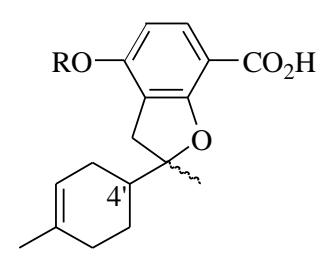

$$
\begin{aligned}
& \boldsymbol{R}-204, \mathrm{R}=\mathrm{H} \\
& S-204, \mathrm{R}=\mathrm{H} \\
& \boldsymbol{R}-170, \mathrm{R}=\mathrm{Me} \\
& S-170, \mathrm{R}=\mathrm{Me}
\end{aligned}
$$

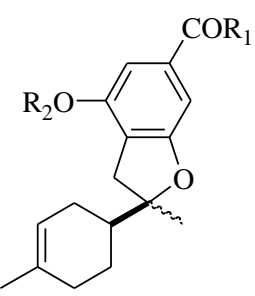

232, $\mathrm{R}_{1}=\mathrm{R}_{2}=\mathrm{H}$

233, $\mathrm{R}_{1}=\mathrm{H}, \mathrm{R}_{2}=\mathrm{Me}$

234, $\mathrm{R}_{1}=\mathrm{H}, \mathrm{R}_{2}=\mathrm{Ph}$

235, $\mathrm{R}_{1}=\mathrm{OH}, \mathrm{R}_{2}=\mathrm{H}$

236, $\mathrm{R}_{1}=\mathrm{OH}, \mathrm{R}_{2}=\mathrm{Me}$

237, $\mathrm{R}_{1}=\mathrm{OH}, \mathrm{R}_{2}=\mathrm{Ph}$<smiles>[R]c1cc(OC)c2c(c1[R])OC(C)(C1CC[C@](C)(O)[C@H](O)C1)C2</smiles>

225, $\mathrm{R}_{1}=\mathrm{H}, \mathrm{R}_{2}=\mathrm{CO}_{2} \mathrm{H}$ 238, $\mathrm{R}_{1}=\mathrm{CO}_{2} \mathrm{H}, \mathrm{R}_{2}=\mathrm{H}$

\begin{tabular}{cccccc}
\hline $\begin{array}{c}\text { Compd. } \\
\mathrm{N}^{\mathbf{0}}\end{array}$ & $\begin{array}{c}\text { Complement inhibition } \\
\mathrm{IC}_{50}(\mathrm{mM})\end{array}$ & $\begin{array}{c}\text { Lysis } \\
\mathrm{EC}_{50}(\mathrm{mM})\end{array}$ & $\begin{array}{c}\text { Compd. } \\
\mathrm{N}^{\mathbf{0}}\end{array}$ & $\begin{array}{c}\text { Complement inhibition } \\
\mathrm{IC}_{50}(\mathrm{mM})\end{array}$ & $\begin{array}{c}\text { Lysis } \\
\mathrm{EC}_{50}(\mathrm{mM})\end{array}$ \\
\hline $\mathbf{2 6}$ & 0.68 & $>0.68$ & $\mathbf{2 3 3}$ & $>1.05$ & $>1.05$ \\
$\boldsymbol{R}-\mathbf{1 7 0}$ & 0.68 & - & $\mathbf{2 3 4}$ & $>0.86$ & $>0.86$ \\
$\boldsymbol{S}-\mathbf{1 7 0}$ & 0.38 & - & $\mathbf{2 3 5}$ & 0.73 & $>1.04$ \\
$\boldsymbol{R}-\mathbf{2 0 4}$ & 2.10 & - & $\mathbf{2 3 6}$ & $>1.00$ & 0.66 \\
$\boldsymbol{S}-\mathbf{2 0 4}$ & 2.10 & - & $\mathbf{2 3 7}$ & $>0.82$ & $<0.20$ \\
$\mathbf{2 2 5}$ & 1.60 & - & $\mathbf{2 3 8}$ & $>0.89$ & $>0.89$ \\
$\mathbf{2 3 2}$ & 0.52 & $<0.28$ & - & - & - \\
\hline
\end{tabular}




\subsection{Semi-synthetic filifolinol derivatives as K-76 COOH analogues. Biological evaluation}

More recently, a new series of $\mathrm{K}-76 \mathrm{COOH}$ analogues was elaborated by the group of Kaufman, ${ }^{129}$ inspired in the similarity between $\mathbf{2 8}$ and filifolinol (31), an abundant naturallyoccurring spiro-benzofuran cyclohexane.

Based on a semi-synthetic approach, systematic studies were conducted in order to identify parts of the basic structure which may lead to more potent Complement inhibitors, as well as to identify structural features responsible of intrinsic hemolytic activity. With this aim, in an initial study, a small collection of compounds was prepared, through modification of the substituents on the aromatic ring (Scheme 20).

Mild hydrolysis of filifolinol (31) with $\mathrm{LiOH}$ in $\mathrm{THF}-\mathrm{H}_{2} \mathrm{O}$ gave $80 \%$ of acid $\mathbf{2 4 0}$. The acidnitrile 244 was prepared by conversion of filifolinol into acetate 239 in $92 \%$ yield and submission of the latter to an electrophilic bromination, which yielded $91 \%$ of bromide $241 a$. This key intermediate was transformed into the corresponding cyanide $\mathbf{2 4 3}$ in $55 \%$ yield, with $\mathrm{Zn}(\mathrm{CN})_{2}$ in DMF under microwave irradiation and $\mathrm{Pd}\left(\mathrm{PPh}_{3}\right)_{4}$ catalysis; this alternative proved to be superior than conventional thermal heating. Basic hydrolysis of $243\left(\mathrm{LiOH}, \mathrm{THF}-\mathrm{H}_{2} \mathrm{O}\right)$ furnished $72 \%$ of the desired acid-nitrile 244 .

The aryl bromide intermediate $\mathbf{2 4 1}$ was hydrolyzed, furnishing $\mathbf{2 4 2}$, which was also obtained by direct bromination of $\mathbf{2 3 9}$ with $\mathrm{Br}_{2}$ in glacial $\mathrm{AcOH}$; however, yields were substantially lower $(<20 \%)$. On the other hand, for the synthesis of phenol 248, filifolinol was reduced to benzylic alcohol 245 with $\mathrm{LiAlH}_{4}$ and this was selectively oxidized $\mathrm{BaMnO}_{4}$ to the corresponding aldehyde 246. In turn, the aldehyde was subjected to a Baeyer-Villiger oxidation with $m$-CPBA, affording formate $\mathbf{2 4 7}$ in $\mathbf{8 5 \%}$ yield; final hydrolysis of the formate $\left(10 \% \mathrm{NaHCO}_{3}, \mathrm{THF}-\mathrm{H}_{2} \mathrm{O}\right)$ afforded $80 \%$ of $\mathbf{2 4 8 .}$

Transesterification of $\mathbf{2 4 7}$ with the $\mathrm{Ac}_{2} \mathrm{O}$-pyridine reagent furnished $75 \%$ of the diacetate 249, which upon irradiation with UV-light at $254 \mathrm{~nm}$ suffered a photo-Fries rearrangement, providing a 2:1 mixture of ortho-hydroxy acetophenones $\mathbf{2 5 0}$ and $\mathbf{2 5 1}$ in $63 \%$ combined yield. Quantitative hydrolysis of the latter $\left(\mathrm{NaOH}, \mathrm{THF}-\mathrm{H}_{2} \mathrm{O}\right)$ to $\mathbf{2 5 2}$ and 253, respectively, gave the required final products. The Complement inhibitory activity of this series of semi-synthetic analogues was tested and compared with literature data for $\mathrm{K}-76 \mathrm{COOH}$ and partial analogues (Table 7).

From analysis of this first approach, it was concluded that the novel and easily available acids 240, 242 and 244 as well as phenol 248 and acetophenone 253 displayed comparable activity to that of $\mathrm{K} 76-\mathrm{COOH}$ analogues, such as $\mathbf{1 8 6}$, being their potencies of the same order of magnitude of 28. On the other hand, acetophenone 252 was active but exhibited solubility problems. Quite interestingly, functionalization of C7 (242 and 244 vs. 240) decreased $\mathrm{IC}_{50}$ among the acids, while surprisingly phenol $\mathbf{2 4 8}$ displayed remarkable potency, exhibiting an $\mathrm{IC}_{50}$ value slightly lower than that of $\mathrm{K} 76-\mathrm{COOH}$.

Previous findings had shown that a phenolic hydroxyl group was important for the activity of ACD-ring acid analogues of K-76 $(\mathbf{2 2 5}, \mathbf{2 2 6})^{104,128}$ and that methyl ethers were more active than 
their corresponding free phenols among the BCD-ring analogues $(\mathbf{1 7 5}, \mathbf{1 7 7 c}, \mathbf{1 8 6}) .{ }^{104,112,118} \mathrm{In}$ the present case, however, the acids 240, 242 and 244 were active despite the absence of methyl ether or free phenol moieties.

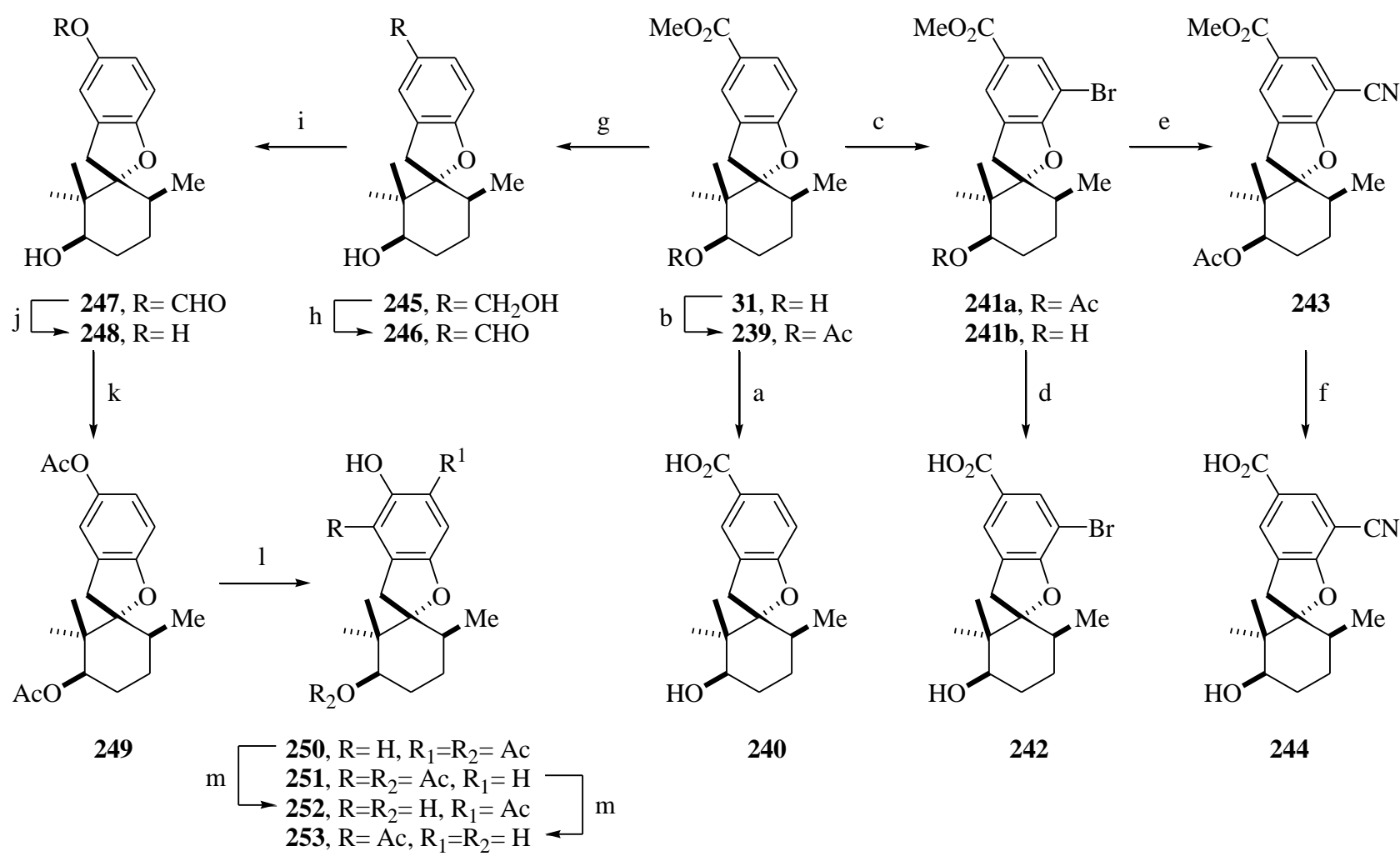

Scheme 20. Reagents and conditions: a) $\mathrm{LiOH}, \mathrm{THF}-\mathrm{H}_{2} \mathrm{O}, \mathrm{rt}, 2 \mathrm{~h}(80 \%)$; b) $\mathrm{Ac}_{2} \mathrm{O}, \mathrm{Et}_{3} \mathrm{~N}, \mathrm{CH}_{2} \mathrm{Cl}_{2}$, $\mathrm{rt}$, overnight (92\%); c) $\mathrm{Br}_{2}, \mathrm{AcOH}, 0^{\circ} \mathrm{C} \rightarrow \mathrm{rt}$, overnight (239 $\left.\rightarrow \mathbf{2 4 1 a}, 91 \%\right)$; d) LiOH, THF- $\mathrm{H}_{2} \mathrm{O}, \mathrm{rt}$ $(82 \%)$; e) $\mathrm{Zn}(\mathrm{CN})_{2}, \mathrm{Pd}\left(\mathrm{PPh}_{3}\right)_{4}(5 \mathrm{~mol} \%)$, DMF, MW (400 W), $55 \mathrm{~min}(55 \%)$; f) LiOH, THF$\mathrm{H}_{2} \mathrm{O}$, rt, 2h (72\%); g) $\mathrm{LiAlH}_{4}$, THF, rt, 3h (95\%); h) $\mathrm{BaMnO}_{4}, \mathrm{CH}_{2} \mathrm{Cl}_{2}$, reflux, 48h (91\%); i) mCPBA, $\mathrm{CHCl}_{3}, 55^{\circ} \mathrm{C}, 1.5 \mathrm{~h}(85 \%)$; ) $10 \% \mathrm{NaHCO}_{3}, \mathrm{THF}_{-} \mathrm{H}_{2} \mathrm{O}$, rt, $4 \mathrm{~h}(80 \%)$; k) $\mathrm{Ac}_{2} \mathrm{O}$, Pyridine, DMAP, $\mathrm{CH}_{2} \mathrm{Cl}_{2}$, rt, overnight (75\%); l) Hexane, hv (254 nm), rt, 2h (63\%); m) NaOH, THF$\mathrm{H}_{2} \mathrm{O}, 2 \mathrm{~h}, \mathrm{rt}(100 \%)$.

In addition, the compounds retained activity regardless of the fact that the carboxyl group was attached to the aromatic ring para to the benzofuran oxygen instead of meta as in 28 . Other interesting findings from this series of compounds were that, as observed in the cases of $\mathbf{2 5 / 2 8 b}$ and their lower analogues, ${ }^{126}$ the carboxylic acid moiety conveniently imparted better solubility to the compounds. However, results of $\mathbf{2 4 8}$ and $\mathbf{2 5 3}$ also suggested that a carboxyl group may not be essential for the analogues to display biological activity.

In a second approach, and based on these previous results, Larghi and co-workers ${ }^{130}$ systematically explored the effects of modifying C3'. In order to prepare the proposed analogues with alcohol or diol-bearing chains, the secondary alcohol of the natural product was submitted 
to an $O$-allylation (Scheme 21), which gave equal amounts of the expected compound 254 and the related acid $\mathbf{2 5 5}$ in $89 \%$ overall yield.

Table 7. Classical Complement pathway inhibition mediated by filifolinol derivatives

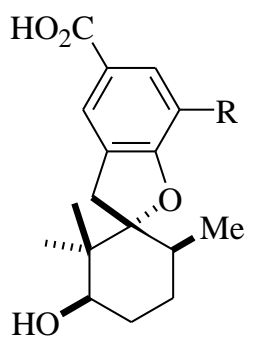

240, $\mathrm{R}=\mathrm{H}$

242, $\mathrm{R}=\mathrm{Br}$

244, $\mathrm{R}=\mathrm{CN}$

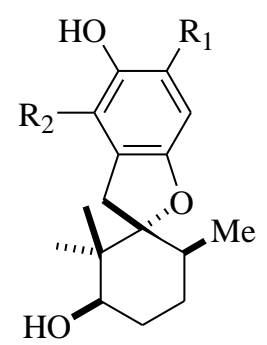

248, $\mathrm{R}_{1}=\mathrm{R}_{2}=\mathrm{H}$ 252, $\mathrm{R}_{1}=\mathrm{Ac}, \mathrm{R}_{2}=\mathrm{H}$ 253, $\mathrm{R}_{1}=\mathrm{H}, \mathrm{R}_{2}=\mathrm{Ac}$

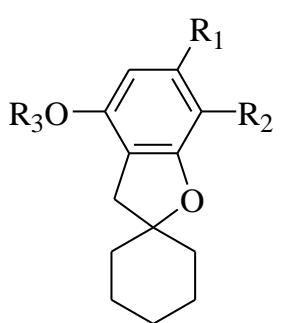

175a, $\mathrm{R}_{1}=\mathrm{H}, \mathrm{R}_{2}=\mathrm{CO}_{2} \mathrm{H}$

177c, $\mathrm{R}_{1}=\mathrm{CO}_{2} \mathrm{H}, \mathrm{R}_{2}=\mathrm{CHO}$

186, $\mathrm{R}_{1}=\mathrm{CO}_{2} \mathrm{H}, \mathrm{R}_{2}=\mathrm{H}$<smiles>COc1ccc(C(=O)O)c2c1C[C@](C)([C@H]1CC[C@@](C)(O)[C@H](O)C1)O2</smiles>

225

\begin{tabular}{cccc}
\hline Entry $\mathrm{N}^{\mathbf{o}}$ & Compound $\mathrm{N}^{\mathrm{o}}$ & $\mathrm{IC}_{50}(\mathrm{mM})^{\mathrm{a}}$ & $\mathrm{IC}_{50}(\mathrm{mg} / \mathrm{mL})^{\mathrm{a}}$ \\
\hline 1 & $\mathbf{2 4 0}$ & 2.00 & 0.58 \\
2 & $\mathbf{2 4 2}$ & 0.95 & 0.35 \\
3 & $\mathbf{2 4 4}$ & 1.32 & 0.42 \\
4 & $\mathbf{2 4 8}$ & 0.46 & 0.26 \\
5 & $\mathbf{2 5 2}$ & $-{ }^{\mathrm{b}}$ & 0.32 \\
6 & $\mathbf{2 5 3}$ & 1.07 & 0.24 \\
$7^{126}$ & $\mathbf{2 8 ,} \mathbf{K - 7 6} \mathbf{C O O H}$ & 0.57 & 0.34 \\
$8^{118}$ & $\mathbf{1 7 5 a}$ & 1.30 & 0.044 \\
$9^{118}$ & $\mathbf{1 7 7}$ & 0.16 & 0.21 \\
$10^{118}$ & $\mathbf{1 8 6}$ & 0.82 & 0.52 \\
$11^{126}$ & $\mathbf{2 2 5}$ & 1.60 & \\
\hline
\end{tabular}

${ }^{a}$ Concentration required to inhibit Complement induced hemolysis by 50\% compared to the control (without test compound). Values reported were obtained by interpolation in the corresponding concentration/inhibition (\%) plots. Samples were run in duplicate. Results are within the $\pm 5 \%$ error. ${ }^{b}$ At a concentration of $253 \mu \mathrm{g} / \mathrm{mL}$, acetophenone 252 produced $17 \pm 5 \%$ inhibition. Poor solubility of the compound precluded testing more concentrated solutions.

Allyl ether $\mathbf{2 5 4}$ was subjected to an osmium tetraoxide-catalyzed dihydroxylation, furnishing diols 256 as a diastereomeric mixture. The latter was further oxidatively cleavaged in $78 \%$ yield with the $\mathrm{OsO}_{4}-\mathrm{KIO}_{4}$ reagent system, ${ }^{131}$ yielding $82 \%$ of the mono-protected ethylene-glycol derivative 257 after a $\mathrm{NaBH}_{4}$ reductive step.

For the sake of comparison, 255 was catalytically hydrogenated $(\mathrm{Pd} / \mathrm{C}, \mathrm{EtOH})$ to acid $\mathbf{2 5 8}$ (98\% yield) and $\mathbf{3 1}$ was deoxygenated in $74 \%$ overall yield by means of a three-step process involving a chlorodehydroxylation followed by in situ hydrogen chloride elimination and final 
catalytic hydrogenation to $\mathbf{2 5 9}$. For testing purposes, the corresponding acids $\mathbf{2 4 0}, \mathbf{2 5 5}, \mathbf{2 5 6}, 257$ and $\mathbf{2 5 8}$ were obtained by basic hydrolysis.
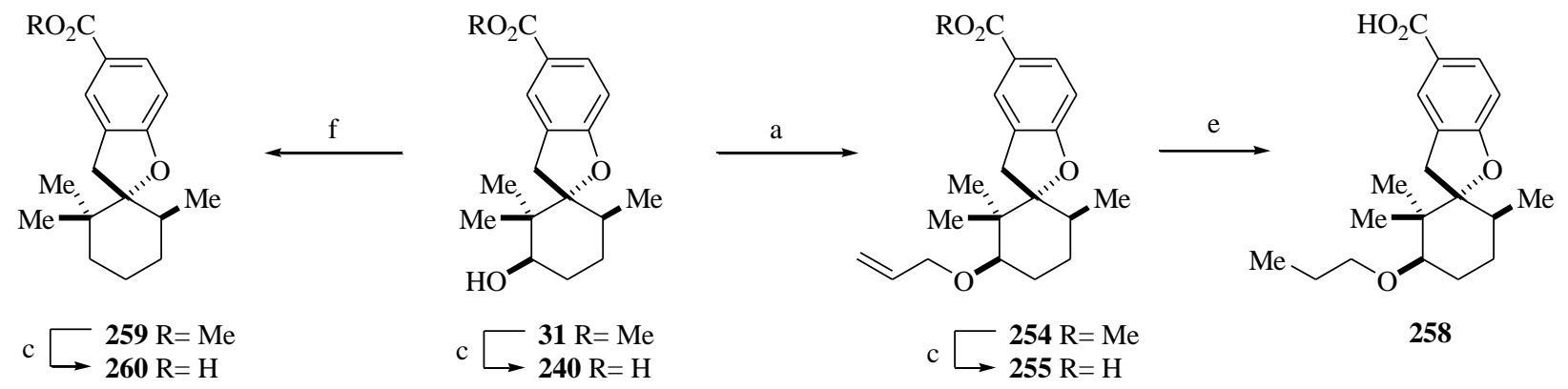

258

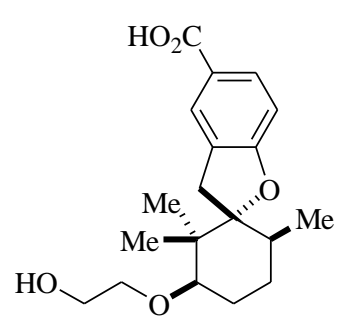

257

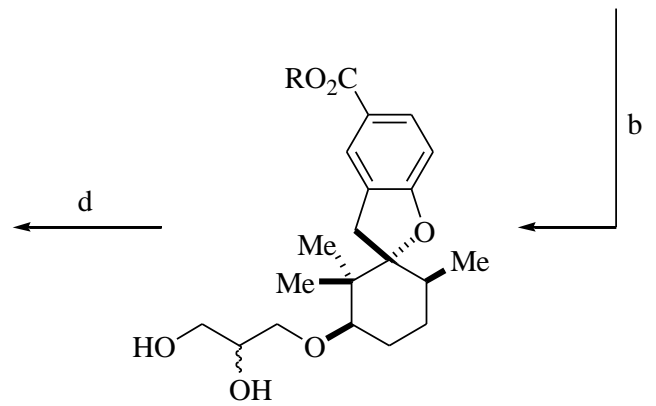

$256 \mathrm{R}=\mathrm{H}$

Scheme 21. Reagents and conditions: a) $\mathrm{NaH}, \mathrm{BrCH}_{2} \mathrm{CH}=\mathrm{CH}_{2}$, THF-DMF, rt, 25h (89\% 254/255 1); b) $\mathrm{OsO}_{4}$ (cat.), $\mathrm{K}_{3} \mathrm{Fe}(\mathrm{CN})_{6}, \mathrm{~K}_{2} \mathrm{CO}_{3},{ }^{t} \mathrm{BuOH}-\mathrm{H}_{2} \mathrm{O}$, rt, $21 \mathrm{~h}$ (78\%); c) $\mathrm{NaOH}$, Dioxane, $60^{\circ} \mathrm{C}\left(\mathbf{2 4 0}, 85 \%\right.$; 255, 59\%; 260, 99\%); d) $1 . \mathrm{KIO}_{4}$, Acetone, rt, 2.5h, 2. $\mathrm{NaBH}_{4}, 2-\mathrm{PrOH}, \mathrm{rt}, 20 \mathrm{~h}$ (82\%); e) $\mathrm{H}_{2}$ (1 atm.), $10 \% \mathrm{Pd} / \mathrm{C}, \mathrm{EtOH}, \mathrm{rt}, 5 \mathrm{~h}(98 \%)$; f) $1 . \mathrm{SOCl}_{2}$, DMF (cat.), $\mathrm{CHCl}_{3}$, reflux, $1.1 \mathrm{~h}(74 \%) ; 2 . \mathrm{H}_{2}$ (1 atm.), 10\% Pd/C, MeOH, rt, 2.45h (99\%).

Another group of derivatives carrying C3' modifications was prepared by amination and Grignard addition reactions (Scheme 22). To that end, filifolinol was first oxidized to filifolinone $(\mathbf{2 6 1})^{69 b}$ in $90-92 \%$ yield and this was reacted with allyl Grignard, furnishing $62 \%$ of tertiary alcohol 263 as a sole diastereomer.

Next, osmium-mediated catalytic dihydroxylation of $\mathbf{2 6 3}$ gave $87 \%$ of diols $\mathbf{2 6 4}$. On the other hand, $\mathrm{NaBH}_{4}$-mediated reduction of filifolinone provided $60 \%$ of 3'-epifilifolinol (266), while base-catalyzed transesterification of $\mathbf{2 6 1}$ to $\mathbf{2 6 2}$ followed by a reductive amination of the ketone $^{132}$ with allylamine furnished amines $\mathbf{2 6 8}$ as a separable mixture of diastereomers in $74 \%$ overall yield. Upon catalytic hydrogenation, $3^{\prime} R-268$ and $3^{\prime} S-268$ conveniently provided the free $N-{ }^{n}$ propylamino acids $3^{\prime} \boldsymbol{R}-269$ and $3^{\prime} S-269$, respectively. The congener acids $260,265 \mathbf{a}, \mathbf{b}$ and 267 were obtained by saponification of the corresponding esters.

The activity of the synthetic analogues as inhibitors of Complement classical pathway activation was tested and compared with literature data (Table 8). The introduction of diversity at the $\mathrm{C}^{3}$ ' position generated derivatives showing broadly different inhibitory profiles. From the results of this structure-activity study it was deduced that introduction of a three-carbon chain at 
the C3' carbinol moiety $(\mathbf{2 5 5}, \mathbf{2 5 8})$ did not improve the Complement inhibitory activity; moreover, introduction of alcohol or diol functionalities in the side chain to mimic the diol moiety of $\mathrm{K} 76-\mathrm{COOH}(\mathbf{2 5 6}, \mathbf{2 5 7})^{133}$ surprisingly lead to less active compounds, perhaps because they were laid in a different conformational space. In fact, the activity of the parent compound was restored in 265a,b, where the hydroxyl groups exhibit good superimposition with the diol moiety of the natural product. On the other hand, removal of the $\mathrm{C} 3$ ' hydroxyl group furnished analogue 260, which behave as a hemolytic agent.

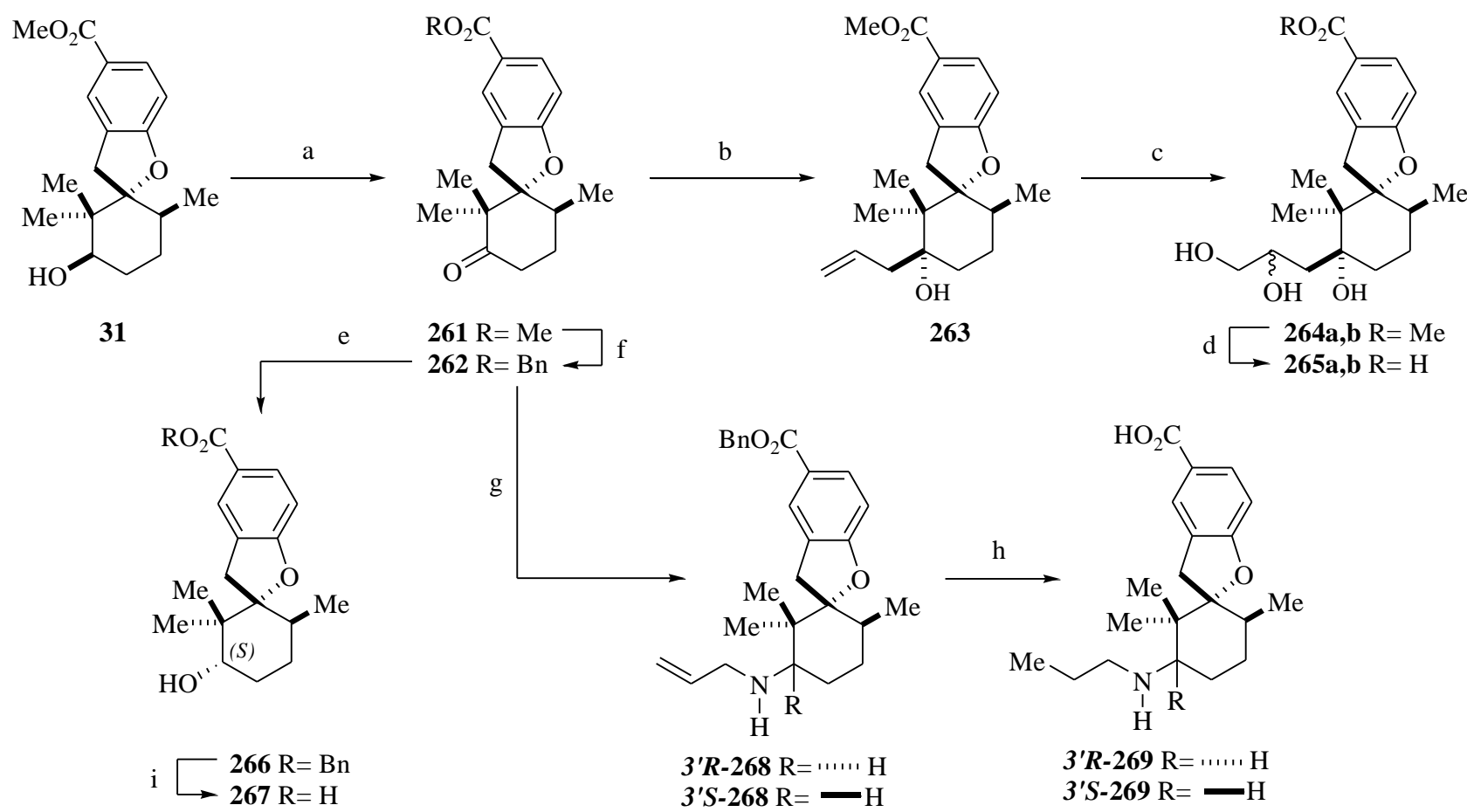

Scheme 22. Reagents and conditions: a) 1. DMSO, TFAA, $\mathrm{CH}_{2} \mathrm{Cl}_{2},-60^{\circ} \mathrm{C}, 2$. TEA, $0^{\circ} \mathrm{C} \rightarrow \mathrm{rt}$, 35min. (90\%) or $\mathrm{PCC} \mathrm{Al}_{2} \mathrm{O}_{3}, \mathrm{CH}_{2} \mathrm{Cl}_{2}$, rt, 23h (95\%); b) $\mathrm{BrMgCH}_{2} \mathrm{CH}=\mathrm{CH}_{2}, \mathrm{Et}_{2} \mathrm{O}, 0^{\circ} \mathrm{C}, 2.5 \mathrm{~h}$ (62\%); c) $\mathrm{OsO}_{4}$ (cat.), $\mathrm{K}_{3} \mathrm{Fe}(\mathrm{CN})_{6}, \mathrm{~K}_{2} \mathrm{CO}_{3},{ }^{t} \mathrm{BuOH}-\mathrm{H}_{2} \mathrm{O}, \mathrm{rt}, 23 \mathrm{~h}(87 \%, \alpha / \beta \approx 1.5)$; d) $\mathrm{NaOH}$, Dioxane, $60^{\circ} \mathrm{C}, 22 \mathrm{~h}(92 \%)$; e) $\mathrm{NaBH}_{4}, \mathrm{EtOH}, 0^{\circ} \mathrm{C}, 3 \mathrm{~h}(60 \%)$; f) $\mathrm{BnOH}, \mathrm{NaH}$ (cat.), $\mathrm{PhMe}, 70^{\circ} \mathrm{C}$, 2.5h (65\%); g) 1. $\mathrm{H}_{2} \mathrm{NCH}_{2} \mathrm{CH}=\mathrm{CH}_{2}, \mathrm{AcOH}, \mathrm{MgSO}_{4}, 4 \AA \mathrm{MS}$, EtOH, reflux, 19h; 2. $\mathrm{NaCNBH}_{3}$, EtOH, rt, 22h (74\%, 3'R-268/3'S-268 $\approx 3: 1)$; h) $\mathrm{H}_{2}$ (1 atm.), 10\% Pd/C, MeOH, rt, 4h (3'R-268, 90\%; 3 'S-268, 90\%); i) $\mathrm{H}_{2}$ (1 atm.), 10\% Pd/C, MeOH, rt, 2.1h (83\%).

In addition, it was observed that the stereochemistry of the C3' functionality is relevant to activity, being acid 240 near 24 times more active than acid 267, its C3' epimer carrying the 3'S configuration. The same trend was observed among the nitrogen-containing analogues 269, where the $3^{\prime} R$ isomer was approximately 13 times more potent than its $3 S$ congener. 
Table 8. Classical Complement pathway inhibition by filifolinol derivatives carrying C3' modifications

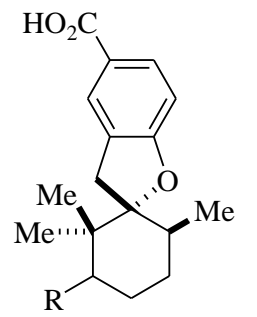

240, $\mathrm{R}=-\mathrm{OH}$

260, $\mathrm{R}=\mathrm{H}$

267, $\mathrm{R}=\cdots \cdots \cdot \cdot \mathrm{OH}$

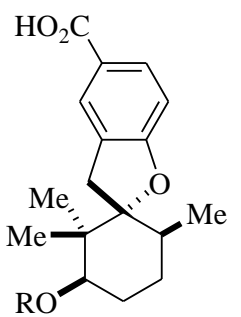

255, $\mathrm{R}=\mathrm{CH}_{2} \mathrm{CH}=\mathrm{CH}_{2}$ 257, $\mathrm{R}=\mathrm{CH}_{2} \mathrm{CH}_{2} \mathrm{OH}$ 258, $\mathrm{R}=\mathrm{CH}_{2} \mathrm{CH}_{2} \mathrm{Me}$

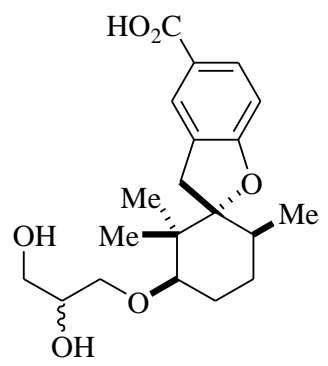

256

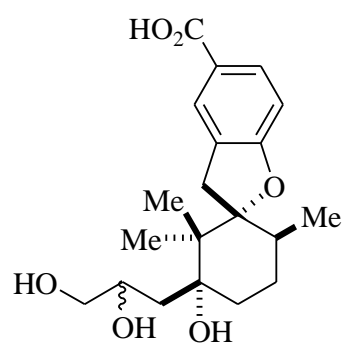

265a,b

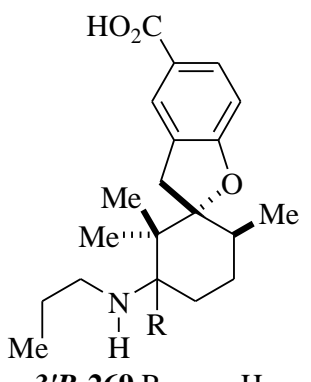

3'R-269 $\mathrm{R}=\ldots \ldots \mathrm{H}$ 3'S-269 $\mathrm{R}==\mathrm{H}$

\begin{tabular}{cccccc}
\hline Compd. $^{\mathbf{o}}$ & \multicolumn{2}{c}{ Complement inhibition $^{\mathrm{a}}$} & Compd. $^{\mathbf{o}}$ & \multicolumn{2}{c}{ Complement Inhibition $^{\mathrm{a}}$} \\
& $\mathrm{IC}_{50}, \mathrm{mM}$ & $\mathrm{IC}_{50}, \mathrm{mg} / \mathrm{mL}$ & & $\mathrm{IC}_{50}, \mathrm{mM}$ & $\mathrm{IC}_{50}, \mathrm{mg} / \mathrm{mL}$ \\
\hline $\mathbf{2 4 0}$ & 0.52 & 0.15 & $\mathbf{2 6 5 a}$ & 0.48 & 0.18 \\
$\mathbf{2 5 5}$ & 3.08 & 1.01 & $\mathbf{2 6 5 b}$ & 3.29 & 1.20 \\
$\mathbf{2 5 6}$ & 4.72 & 1.72 & $\mathbf{2 6 7}$ & 12.1 & 3.52 \\
$\mathbf{2 5 7}$ & 4.40 & 1.47 & $\mathbf{3}^{\prime} \boldsymbol{R}-\mathbf{2 6 9}$ & 0.21 & 0.07 \\
$\mathbf{2 5 8}$ & 0.55 & 0.19 & $\mathbf{3}^{\prime} \boldsymbol{S}-\mathbf{2 6 9}$ & 2.75 & 0.91 \\
$\mathbf{2 6 0}$ & \multicolumn{2}{c}{ Hemolytic } & $\mathbf{2 8 ,} \mathbf{K}-\mathbf{7 6} \mathbf{C O O H}$ & 0.57 & 0.24 \\
$\boldsymbol{S} \mathbf{- 2 0 4}^{122}$ & 2.15 & & $\boldsymbol{S}-\mathbf{- 1 7 0}^{118}$ & 0.38 & \\
$\mathbf{2 2 5}^{118}$ & 1.60 & & & & \\
\hline
\end{tabular}

\section{Conclusions}

Complement activation has several benefits, including provision of resistance towards infectious agents, processing naturally generated immune complexes and developing an optimal humoral immune response. However, under certain circumstances and conditions, the Complement system may become activated and, as part of its complex functions, yield undesirable results, including injury, deepening or worsening of a disease.

The artificial manipulation of the balance between Complement activation and inhibition represents a very interesting therapeutic opportunity to ameliorate the negative effects of abnormal Complement activation and lessen pathological events in disease states and interventional conditions.

The desirable properties of a broadly applicable anticomplement therapeutic agent, useful in acute and chronic conditions include inexpensiveness, high specificity and very long plasma half-life. It should be active orally and block pathological activation of Complement while causing minimal disruption of the systemic Complement function. None of the currently available agents fit all these characteristics, but this unmet need has driven research over the last 
three decades and substantial progress has been made. However, there are no currently available low molecular weight oral therapies for temporally targeting undesirable or abnormal Complement system activation without negatively affecting the beneficial functions of Complement or interfering with other complex cascades that Complement is linked to.

$\mathrm{K} 76-\mathrm{COOH}$, the partial oxidation derivative of the naturally-occurring $\mathrm{K}-76$, demonstrated to be influential under different conditions involving the Complement system and the immune system, and the source of inspiration for the development of new molecular entities capable of inhibiting the Complement system.

Although there is much room left to improve, interesting progress has been observed. The development of more effective and specific Complement inhibitors will provide potential therapeutic agents for diseases in which this pathway is determined to be critical, and powerful new tools with which to dissect the role of Complement in various diseases and at different points during the evolution of tissue injury. Moreover, it can be anticipated that, analogous to the utility of pharmaceutically useful inhibitors of the coagulation cascade, Complement inhibitors will find an important niche in the pharmacologic arsenal to reduce undesirable inflammatory reactions. It is not unlikely to expect that in another two decades or so humankind will have agents that meet most of the desirable properties of an ideal oral Complement inhibitor, enabling effective control of this system in humans.

\section{Acknowledgements}

The authors gratefully acknowledge CONICET, ANPCyT and SECyT-UNR for financial support.

\section{References}

1. (a) Zarkadis, I. K.; Mastellos, D.; Lambris, J. D. Dev. Comp. Immunol. 2001, 25, 745. (b) Endo, Y.; Takahashi, M.; Fujita, T. Immunobiology 2006, 211, 283. (c) Sompayrac, L. How the Immune System Works; Wiley-Blackwell: New York, 2000.

2. (a) Makrides, S. C. Pharmacol. Rev. 1998, 50, 59. (b) Mollnes, T. E.; Song, W. C.; Lambris, J. D. Trends Immunol. 2002, 23, 61.

3. Flierman, R.; Daha, M. R. Immunobiology 2007, 212, 363.

4. (a) Mollnes, T. E.; Song, W.-C.; Lambris, J. D. Trends Immunol. 2002, 23, 61. (b) Hyde, R. M. Immunology; Lippincott, Williams \& Wilkins: Philadelphia, 2000. (c) Benjamini, E.; Leskowitz, S. Complement. In: Immunology, A Short Course; Benjamini, E.; Leskowitz, S. Eds.; Alan R. Liss: New York, 1988; pp 121-133. (d) Goldsby, R. A.; Kindt, T. J.; Osborne, 
B. A. The Complement System. In: Immunology; Kuby, J. Ed.; W. H. Freeman and Company: New York, 2000; pp 329-350.

5. (a) DeAngelis, R. A.; Markiewski, M. M.; Lambris, J. D. Adv. Exp. Med. Biol. 2006, 586, 17. (b) Markiewski, M. M.; DeAngelis, R. A.; Benencia, F.; Ricklin-Lichtsteiner, S. K.; Koutoulaki, A.; Gerard, C.; Coukos, G.; Lambris, J. D. Nature Immunol. 2008, 9, 1225.

6. Leinhase, I.; Rozanski, M.; Harhausen, D.; Thurman, J. M.; Schmidt, O. I.; Hossini, A. M.; Taha, M. E.; Rittirsch, D.; Ward, P. A.; Holers, V. M.; Ertel, W.; Stahel, P. F. J. Neuroinflammation 2007, 4, 13.

7. (a) Holers, V. M. Immunol. Rev. 2008, 223, 300. (b) Harboe, M.; Mollnes, T. E. J. Cell. Mol. Med. 2008, 12, 1074.

8. Thrane, A. S.; Skehan, J. D.; Thrane, P. S. Med. Hypotheses 2007, 68, 1363.

9. (a) Amara, U.; Rittirsch, D.; Flierl, M.; Bruckner, U.; Klos, A.; Gebhard, F.; Lambris, J. D.; Huber-Lang, M. Adv. Exp. Med. Biol. 2008, 632, 71. (b) Clark, A.; Weymann, A.; Hartman, E.; Turmelle, Y.; Carroll, M.; Thurman, J. M.; Holers, V. M.; Hourcade, D. E.; Rudnick, D. A. Mol. Immunol. 2008, 45, 3125.

10. Gorbet, M. B.; Sefton, M. V. Biomaterials 2004, 25, 5681.

11. (a) Kirschfink, M. Immunol. Rev. 2001, 180, 177. (b) Caliezi, C.; Wuillemin, W. A.; Zeerleder, S.; Redondo, M.; Eisele, B.; Hack, C. E. Pharmacol. Rev. 2000, 52, 91.

12. Pascual, M. A.; Crespo, M.; Tolkoff-Rubin, N. Nefrologia 2001, 21, 327.

13. D’Ambrosio, A. L.; Pinsky, D. J.; Connolly, E. S. Mol. Med. 2001, 7, 367.

14. Carugati, A.; Pappalardo, E.; Zingale, L. C.; Cicardi, M. Mol. Immunol. 2001, 38, 161.

15. Lissoni, P.; Barni, S.; Cattaneo, G.; Archili, C.; Crispino, S.; Tancini, G.; D’Angelo, L.; Magni, S.; Fiorelli, G. Int. J. Biol. Markers 1990, 5, 195.

16. Langlois, P. F.; Gawryl, M. S. Clin. Immunol. Immunopathol. 1988, 47, 152.

17. (a) Pruitt, S. K.; Bollinger, R. R. J. Surg. Res. 1991, 50, 350. (b) Spirig, R.; Gajanayake, T.; Korsgren, O.; Nilsson, B.; Rieben, R. Mol. Immunol. 2008, 45, 4084; see also: (c) Tanaka, M.; Murase, N.; Miyazawa, H.; Ye, Q.; Manez, R.; Todo, S.; Demetris, A. J.; Nomoto, M.; Miyazaki, W.; Starzl, T. E. Transplant. Proc. 1995, 27, 275.

18. Mollnes, T. E.; Fiane, A. E. Mol. Immunol. 2003, 40, 135.

19. (a) Arumugam, T. V.; Magnus, T.; Woodruff, T. M.; Proctor, L. M.; Shiels, I. A.; Taylor, S. M. Clin. Chim. Acta 2006, 374, 33. (b) Costa, C.; Zhao, L.; Shen, Y.; Su, X.; Hao, L.; Colgan, S. P.; Stahl, G. L.; Zhou, T.; Wang, Y. Brain Res. 2006, 1100, 142. (c) Murata, K.; Baldwin III, W. M. Transplantation Rev. 2009, 23, 139. (d) The Complement System: Novel Roles in Health and Disease; Szebenis, J. Ed.; Kluwer: New York, 2004.

20. (a) Frangogiannis, N. G. Pharmacol. Res. 2008, 58, 88. (b) Proctor, L. M.; Strachan, A. J.; Woodruff, T. M.; Mahadevan, I. B.; Williams, H. M.; Shiels, I. A.; Taylor, S. M. Int. Immunopharmacol. 2006, 6, 1224. (c) Arumugam, T. V.; Woodruff, T. M.; Lathia, J. D.; Selvaraj, P. K.; Mattson, M. P.; Taylor, S. M. Neuroscience 2009, 158, 1074. (d) Current Topics in Complement II; Lambris, J. D. Ed.; Springer: New York, 2008. 
21. Holers, M. V. Clin. Immunol. 2003, 107, 140.

22. (a) Ricklin, D.; Lambris, J. D. Nature Biotechnol. 2007, 25, 1265. (b) Ratner, M. Nature Biotechnol. 2006, 24, 371.

23. Morgan, B. P. Eur. J. Clin. Invest. 1994, 24, 219.

24. Bureeva, S.; Andia-Pravdivy, J.; Kaplun, A. Drug Discov. Today 2005, 10, 1535.

25. (a) Asghar, S. S. Pharmacol. Rev. 1984, 36, 223. (b) Sahul, A.; Lambris, J. D. Immunopharmacology 2000, 49, 133.

26. (a) Hagmann, W. K.; Sindelar, R. D. Potential Therapeutic Modifiers of the Complement Cascade. In: Annual Reports in Medicinal Chemistry; Bristol, J. A., Ed.; Academic Press: San Diego, CA, 1992; pp 199-208. (b) Sjöberg, A. P.; Trouw, L. A.; Blom, A. M. Trends Immunol. 2009, 30, 84.

27. (a) Kulkarni, P. A.; Afshar-Kharghan, V. Biologics: Targets Ther. 2008, 2, 671. (b) Zacharia, B. E.; Hickman, Z. L.; Grobelny, B. T.; DeRosa, P. A.; Ducruet, A. F.; Connolly, S. E. Mediat. Inflammat. 2009, 12, 4384. (c) Trendelenburg, M. Swiss Med. Weekly 2007, 137, 413. (d) La Bonte, L. R.; Davis-Gorman, G.; Stahl, G. L.; McDonagh, P. F. Am. J. Physiol. Heart Circ. Physiol. 2008, 294, H1282. (e) Quigg, R. J. Trends Mol. Med. 2002, 8, 430. (f) Liszewski, M. K.; Subramanian, V. B.; Atkinson, J. P. Clin. Immunol. 1997, 17, 168. (g) Holers, V. M.; Thurman, J. M. Mol. Immunol. 2004, 41, 147.

28. Morikis, D.; Lambris, J. D. Biochem. Soc. Trans. 2002, 30, 1026.

29. (a) Mollnes, T. E.; Kirschfink, M. Mol. Immunol. 2006, 43, 107. (b) Sahu, A.; Lambris, J. D. Immunopharmacology 2000, 49, 133. (c) Therapeutic Interventions in the Complement System; Lambris, J. D.; Holers, V. M. Eds.; Humana Press: Totowa, 2000; Vol. 9. (d) Morgan, B. P.; Harris, C. L. Mol. Immunol. 2003, 40, 159.

30. (a) Ducruet, A. F.; Mocco, J.; Mack, W. J.; Coon, A. L.; Marsh Jr., H. C.; Pinsky, D. J.; Hickman, Z. L.; Kim, G. H.; Connolly, E. S. J. Med. Primatol. 2007, 36, 375. (b) Thurman, J. M.; Kraus, D. M.; Girardi, G.; Hourcade, D.; Kang, H. J.; Royer, P. A.; Mitchell, L. M.; Giclas, P. C.; Salmon, J.; Gilkeson, G.; Holers, V. M. Mol. Immunol. 2005, 42, 87. (c) Banz, Y.; Hess, O. M.; Robson, S. C.; Csizmadia, E.; Mettler, D.; Meier, P.; Haeberli, A.; Shawa, S.; Smith, R. A.; Rieben, R. Mol. Immunol. 2007, 44, 147. (d) De Silva, R. J.; Vuylsteke, A.; Fritchley, S. J.; Trull, A. K.; Dunning, J. J.; Wallwork, J. Eur. J. Cardio-thor. Surg. 2006 , 30, 72. (e) Rooijakkers, S. H. M.; Milder, F. J.; Bardoel, B. W.; Ruyken, M.; van Strijp, J. A. G.; Gros, P. J. Immunol. 2007, 179, 2989.

31. Roos, A.; Nauta, A. J.; Broers, D.; Faber-Krol, M. C.; Trouw, L. A.; Drijfhout, J. W.; Daha, M. R. J. Immunol. 2001, 167, 7052.

32. Weisman, H. F.; Bartow, T.; Leppo, M. K.; Boyle, M. P.; Marsh Jr., H. C.; Carson, G. R.; Roux, K. H.; Weisfeldt, M. L.; Fearon, D. T. Trans. Assoc. Am. Phys. 1990, 103, 64.

33. (a) Lauenstein, K.; Siedensropf, H. G.; Fischer, H. Z. Naturforsch. 1965, 20b, 575. (b) Raepple, E.; Hill, H.-U.; Loos, M. Immunochemistry 1976, 13, 251.

34. Ricklin, D.; Lambris, J. D. Adv. Exp. Med. Biol. 2008, 632, 273. 
35. Lambris, J. D.; Becherer, J. D.; Servis, C.; Alsenz, J. Use of Synthetic Peptides in Exploring and Modifying Complement Reactivities. In: Activators and Inhibitors of Complement Activation; Sim, R. B. Ed.; Kluwer Academic Publishers: Netherlands, 1993, pp. 201-232.

36. Armstrong, P. W.; Granger, C. B.; Adams, P. X.; Hamm, C.; Holmes Jr., D.; O’Neill, W. W.; Todaro, T. G.; Vahanian, A.; Van de Werf, F. JAMA 2007, 297, 43.

37. Qu, H.; Ricklin, D.; Lambris, J. D. Mol. Immunol. 2009, 47, 185.

38. (a) Holland, M. C.; Morikis, D.; Lambris, J. D. Curr. Opin. Invest. Drugs 2004, 5, 1164. (b) Andersson, M.; Hanson, I. A.; Englund, G.; Dahlbiick, B. Eur. J. Clin. Pharmacol. 1991, 40, 261.

39. Becker, E. L. In: Synthetic Inhibitors of Complement in Inflammation: Mechanisms and Control; Lepow, I. H.; Ward, P. A. Eds.; Academic Press: New York, 1972; pp 281-299.

40. (a) Taylor, S. M.; Fairlie, D. P. Expert Opin. Ther. Patents 2000, 10, 1. (b) Kozlov, L. V.; Burdelev, O. O.; Bureeva, S. V.; Kaplun, A. P. Russ. J. Bioorg. Chem. 2007, 33, 449.

41. (a) Mulakala, C.; Lambris, J. D.; Kaznessis, Y. Bioorg. Med. Chem. 2007, 15, 1638. (b) Magotti, P.; Ricklin, D.; Qu, H.; Wu, Y.-Q.; Kaznessis, Y. N.; Lambris, J. D. J. Mol. Recogn. 2009, 22, 495.

42. Assefa, H.; Nimrod, A.; Walker, L.; Sindelar, R. D. Bioorg. Med. Chem. Lett. 1999, 9, 1889.

43. Sahu, A.; Rawal, N.; Pangburn, M. K. Biochem. Pharmacol. 1999, 57, 1439.

44. (a) Thorgersen, E. B.; Ghebremariam, Y. T.; Thurman, J. M.; Fung, M.; Nielsen, E. W.; Holers, V. M.; Kotwal, G. J.; Mollnes, T. I. Mol. Immunol. 2007, 44, 1827. (b) Schwertz, H.; Carter, J. M.; Russ, M.; Schubert, S.; Schlitt, A.; Buerke, U.; Schmidt, M.; Hillen, H.; Werdan, K.; Buerke, M. J. Cardiovasc. Pharmacol. 2008, 52, 151.

45. (a) Szalai, A. J.; Digerness, S. B.; Agrawal, A.; Kearney, J. F.; Bucy, R. P.; Niwas, S.; Kilpatrick, J. M.; Babu, Y. S.; Volanakis, J. E. J. Immunol. 2000, 164, 463. (b) Pugsley, M. K.; Abramova, M.; Cole, T.; Yang, X.; Ammons, W. S. Cardiovasc. Toxicol. 2003, 3, 43. (c) Romano, C. Patent WO 2008137236, 2008.

46. (a) Subasinghe, N. L.; Ali, F.; Illig, C. R.; Rudolph, M. J.; Klein, S.; Khalil, E.; Soll, R. M.; Bone, R. F.; Spurlino, J. C.; DesJarlais, R. L.; Crysler, C. S.; Cummings, M. D.; Morris Jr., P. E.; Kilpatrick, J. M.; Sudhakara Babu, Y. Bioorg. Med. Chem. Lett. 2004, 14, 3043. (b) Subasinghe, N. L.; Travins, J. M.; Ali, F.; Huang, H.; Ballentine, S. K.; Marugan, J. J.; Khalil, E.; Hufnagel, H. R.; Bone, R. F.; DesJarlais, R. L.; Crysler, C. S.; Ninan, N.; Cummings, M. D.; Molloy, C. J.; Tomczuk, B. E. Bioorg. Med. Chem. Lett. 2006, 16, 2200.

47. Ueda, N.; Midorikawa, A.; Ino, Y.; Oda, M.; Nakamura, K.; Suzuki, S.; Kurumi, M. Inflamm. Res. 2000, 49, 42.

48. (a) Gerard, N. P.; Gerard, C. Curr. Opin. Immunol. 2002, 14, 705. (b) Hawlisch, H.; WillsKarp, M.; Karp, C. L.; Kohl, J. Mol. Immunol. 2004, 41, 123. (c) Mocco, J.; Mack, W. J.; Ducruet, A. F.; Sosunov, S. A.; Sughrue, M. E.; Hassid, B. G.; Nair, M. N.; Laufer, I.; Komotar, R. J.; Claire, M.; Holland, H.; Pinsky, D. J.; Connolly Jr., E. S. Circ. Res. 2006, 99, 209. 
49. Wang, X.; Zhao, G.; Chen, Y.; Xu, X.; Zhong, W.; Wang, L.; Li, L. Bioorg. Med. Chem. Lett. 2009, 19, 770.

50. Master, H. E.; Khan, S. I.; Poojari, K. A. Bioorg. Med. Chem. 2005, 13, 4891.

51. (a) Drag, M.; Grzywa, R.; Oleksyszyn, J. Bioorg. Med. Chem. Lett. 2007, 17, 1516. (b) Kapil, A.; Sharma, S. J. Pharm. Pharmacol. 1994, 46, 922. (c) Kapil, A.; Sharma, S. J. Pharm. Pharmacol. 1995, 47, 585. (d) Lauver, D. A.; Lockwood, S. F.; Lucchesi, B. R. J. Pharm. Exp. Ther. 2005, 314, 686.

52. Kinoshita, T.; Warizaya, M.; Ohori, M.; Sato, K.; Neya, M.; Fujii, T. Bioorg. Med. Chem. Lett. 2006, 16, 55.

53. Zhang, W.; Richardson, R. D.; Chamni, S.; Smith, J. W.; Romo, D. Bioorg. Med. Chem. Lett. 2008, 18, 2491.

54. Hansch, C.; Yoshimoto, M. J. Med. Chem. 1974, 17, 1160.

55. Hansch, C.; Yoshimoto, M.; Doll, M. H. J. Med. Chem. 1976, 19, 1089.

56. Bureeva, S.; Pravdivy, J. A.; Petrov, G.; Igumnov, M.; Romanov, S.; Kolesnikova, E.; Kapluna, A.; Kozlov, L. Bioorg. Med. Chem. 2005, 13, 1045.

57. Furuta, T.; Hirooka, Y.; Abe, A.; Sugata, Y.; Ueda, M.; Murakami, K.; Suzuki, T.; Tanaka, K.; Kan, T. Bioorg. Med. Chem. Lett. 2007, 17, 3095

58. (a) Burger, A. Systematic Drug Development and Rational Research Methods. In: A Guide to the Chemical Basis of Drug Design; John Wiley \& Sons: New York, 1983, pp. 15-16. (b) Eisen, V.; Loveday, C. Br. J. Pharmacol. 1973, 49, 678. (c) Guckian, J. C.; Christensen, W. D.; Fine, D. P. J. Immunol. 1978, 120, 1580. (d) Conrow, R. B.; Bauman, N.; Brockman, J. A.; Bernstein, S. J. Med. Chem. 1980, 23, 240.

59. Packard, B. D.; Weiler, J. M. Infect. Immun. 1983, 40, 1011.

60. Bureeva, S.; Pravdivy, J. A.; Symon, A.; Bichucher, A.; Moskaleva, V.; Popenko, V.; Shpak, A.; Shvets, V.; Kozlov, L.; Kaplun, A. Bioorg. Med. Chem. Lett. 2007, 15, 3489.

61. Assefa, H.; Nimrod, A.; Walker, L.; Sindelar, R. Bioorg. Med. Chem. Lett. 2001, 11, 1619.

62. Master, H. E.; Khan, S. I.; Poojari, K. A. Bioorg. Med. Chem. Lett. 2003, 13, 1249.

63. Cerqueira, F.; Watanadilok, R.; Sonchaeng, P.; Kijjoa, A.; Pinto, M. Planta Med. 2003, 69, 174.

64. (a) Miyazaki, W.; Izawa, T.; Shinohara, M.; Nakano, Y.; Kaise, H.; Oshiro, Y.; Tamaoka, H.; Inoue, K.; Kinoshita, T.; Hong, K. The 15th Japanese Complement Symposium, Shigisan, Nara, Japan, August 11, 1978: Abstract No 24. (b) Miyazaki, W.; Tomaoka, H.; Shinohara, M.; Kaise, H.; Izawa, T.; Nakano, Y.; Kinoshita, T.; Hong, K.; Inoue, K. Microbiol. Immunol. 1980, 24, 1091.

65. Kaise, H.; Shinohara, M.; Miyazaki, W.; Izawa, T.; Nakano, Y.; Sugawara, M.; Sugiura, K. Sasaki, K. J. Chem. Soc. D. Chem. Commun. 1979, 726.

66. Harada, N.; Nakanishi, K. Acc. Chem. Res. 1972, 5, 257.

67. Hong, K.; Kinoshita, T.; Miyazaki, W.; Izawa, T.; Inoue, K. J. Immunol. 1979, 122, 2418. 
68. Rønnest, M. H.; Rebacz, B.; Markworth, L.; Terp, A. H.; Larsen, T. O.; Krämer, A.; Clausen, M. H. J. Med. Chem. 2009, 52, 3342.

69. (a) Torres, R.; Virrarroel, L.; Urzúa, A.; Delle Monache, F.; Delle Monache, G.; Gacs-Baitz, E. Phytochemistry 1994, 36, 249. (b) Torres, R.; Modak, B.; Urzúa, A.; Delle Monache, F.; Damonte, E.; Pujol, C. A. Bol. Soc. Chil. Quím. 2002, 47, 259. (c) Modak, B.; Rojas, M.; Torres, R. Molecules 2009, 14, 1980. (d) Mendoza, L.; Modak, B.; Torres, R.; Cotoras, M. J. Chil. Chem. Soc. 2008, 53, 1447. (e) Modak, B.; Sandino, A. M.; Arata, L.; Cárdenas-Jirón, G.; Torres, R. Vet. Microbiol. 2010, 141, 53. (f) Modak, B.; Salina, M.; Rodilla, J.; Torres, R. Molecules 2009, 14, 4625.

70. (a) Dave, M.-N.; Kusumi, T.; Ishitsuka, M.; Iwashita, T.; Kakisawa, H. Heterocycles 1984, 22, 2301. (b) Fenical, W.; McConnell, O. Experientia 1975, 31, 1004. (c) Marcos, I. S.; Conde, A.; Moro, R. F.; Basabe, P.; Diez, D.; Urones, J. G. Mini-Rev. Org. Chem. 2010, 7, 230.

71. (a) Gerwick, W. H.; Fenical, W.; Fritsch, N.; Clardy, J. Tetrahedron Lett. 1979, 145. (b) Gerwick, W. H.; Fenical, W. J. Org. Chem. 1981, 46, 22. (c) Rovirosa, J.; Sepúlveda, M.; Quezada, E.; San-Martín, A. Phytochemistry 1992, 31, 2679. (d) Gerwick, W. H.; Fenical, W.; Norris, J. Phytochemistry 1985, 24, 1279. (e) Gerwick, W. H.; Whatley, G. J. J. Chem. Ecol. 1989, 15, 677.

72. (a) Abad, A.; Agulló, C.; Arnó, M.; Cuñat, A. C.; Meseguer, B.; Zaragozá, R. J. J. Org. Chem. 1998, 63, 5100. (b) Mori, K.; Koga, Y. Bioorg. Med. Chem. Lett. 1992, 2, 391. (c) Mori, K.; Koga, Y. Liebigs Ann. Chem. 1991, 769. (d) Mori, K.; Koga, Y. Liebigs Ann. Chem. 1995, 1755. (e) Falck, J. R.; Chandrasekhar, S.; Manna, S.; Chiu, C.-C. J. Am. Chem. Soc. 1993, 115, 11606.

73. (a) Joh, T.; Ikai, M.; Oshima, T.; Kurokawa, T.; Seno, K.; Yokoyama, Y.; Okada, N.; Ito, M. Life Sci. 2001, 70, 109. (b) Kimura, T.; Andoh, A.; Fujiyama, Y.; Saotome, T.; Bamba, T. Clin. Exp. Immunol. 1998, 111, 484.

74. (a) Kaji, H.; Platt, J. L.; Sutherland, D. E. R.; Inoue, K.; Maria, C.; Shiota, K.; Imamura, M. Transplant Immunol. 1997, 5, 70. (b) Blum, M. G.; Collins, B. J.; Chang, A. C.; Zhang, J. P.; Knaus, S. A.; Pierson III, R. N. Xenotransplantation 1998, 5, 35.

75. Roos, A.; Ramwadhdoebé, T. H.; Nauta, A. J.; Hack, E.; Daha, M. R. Immunobiology 2002, $205,595$.

76. Hudig, D.; Redelman, D.; Minning, L.; Carine, K. J. Immunol. 1984, 133, 408.

77. Pachter, J. A. Mol. Pharmacol. 1991, 40, 107.

78. (a) Kawabata, Y.; Yang, S.; Yokochi, T.; Matsushita, M.; Fujita, T.; Shibazaki, M.; Noikura, T.; Endo, Y.; Takada, H. Shock 2000, 14, 572. (b) Endo, Y.; Yokochi, T.; Matsushita, M.; Fujita, T.; Takada, H. Innate Immun. 2001, 7, 451.

79. Endo, Y.; Yokochi, T.; Matsushita, M.; Fujita, T.; Takada, H. J. Endotoxin Res. 2001, 7, 451. 
80. (a) Jarvis, B. B.; Salemme, J.; Morais, A. Nat. Toxins 1995, 3, 10. For other papers about fungal metabolites from Stachybotrys, see: (b) Kamalov, S.; Aripova, S. F.; Isaev, M. I. Chem. Nat. Comp. 1997, 33, 462. (c) Kamalov, L. S.; Aripova, S. F.; Isaev, M. I. Chem. Nat. Compd. 1999, 35, 82. (d) Kaneto, R.; Dobashi, K.; Kojima, I.; Sakai, K.; Shibamoto, N.; Yoshioka, T.; Nishida, H.; Okamoto, R.; Akagawa, H.; Mizuno, S. J. Antibiot. 1994, 47, 727.

81. (a) Nakamura, M.; Ito, Y.; Ogawa, K.; Michisuj, Y.; Sato, S.-I.; Takada, M.; Hayashi, M.; Yaginuma, S.; Yamamoto, S. J. Antibiot. 1995, 48, 1389. (b) Ogawa, K.; Nakamura, M.; Hayashi, M.; Yaginuma, S.; Yamamoto, S.; Furihata, K.; Shin-ya, K.; Seto, H. J. Antibiot. 1995, 48, 1396. (c) Roggo, B. E.; Petersen, F.; Sills, M.; Roesel, J. L.; Moerker, T.; Peter, H. H. J. Antibiot. 1996, 49, 13. (d) Roggo, B. E.; Hug, P.; Moss, S.; Stampfli, A.; Kriemler, H.P.; Peter, H. H. J. Antibiot. 1996, 49, 374.

82. (a) Piettre, S. R.; Ganzhorn, A.; Hoflack, J.; Islam, K.; Hornsperger, J.-M. J. Am. Chem. Soc. 1997, 119, 3201 and references cited therein. (b) For the synthesis and structure revision of L-671,776, see: (c) Falck, J. R.; Reddy, K. K.; Chandrasekhar, S. Tetrahedron Lett. 1997, 38, 5245. (d) Lam, Y. K. T.; Wichmann, C. F.; Meinz, M. S.; Guariglia, L.; Glacobbe, R. A.; Mochales, S.; Kong, L.; Honeycutt, S. S.; Zink, D.; Bills, G. E.; Huang, L.; Burg, R. W.; Monaghan, R. L.; Jackson, R.; Reid, G.; Maguire, J. J.; Mcknight, A. T.; Ragan, C. I. J. Antibiot. 1992, 45, 1397.

83. (a) Ayer, W. A.; Miao, S. Can. J. Chem. 1994, 71, 487. (b) Lin, T.-W.; Chang, W.-W.; Chen, C.-C.; Tsai, Y.-C. Biochem. Biophys. Res. Commun. 2005, 331, 953.

84. Sakai, K.; Watanabe, K.; Masuda, K.; Tsuji, M.; Hasumi, K.; Endo, A. J. Antibiot. 1995, 48, 447.

85. Vázquez, M. J.; Vega, A.; Rivera-Sagredo, A.; Jiménez-Alfaro, M. D.; Díez, E.; HuesoRodríguez, J. A. Tetrahedron 2004, 60, 2379.

86. (a) Xu, X.; de Guzman, F. S.; Gloer, J. B. J. Org. Chem. 1992, 57, 6700. (b) Nozawa, Y.; Ito, M.; Sugawara, K.; Hanada, K.; Mizoue, K. J. Antibiot. 1997, 50, 641. (c) Kohyama, T.; Hasumi, K.; Hamanaka, A.; Endo, A. J. Antibiot. 1997, 50, 172. (d) Hu, W.; Ohyama, S.; Hasumi, K. J. Antibiot. 2000, 53, 241. (e) Hu, W.; Narasaki, R.; Ohyama, S.; Hasumi, K. J. Antibiot. 2001, 54, 962. (f) Hasumi, K.; Hasegawa, K.; Kitano, Y. J. Antibiot. 2007, 60, 463.

87. (a) Minagawa, K.; Kouzuki, S.; Yoshimoto, J.; Kawamura, Y.; Tani, H.; Iwata, T.; Terui, Y.; Nakai, H.; Yagi, S.; Hattori, N.; Fujiwara, T.; Kamigauchi, T. J. Antibiot. 2002, 55, 155. (b) Minagawa, K.; Kouzuki, S.; Kamigauchi, T. J. Antibiot. 2002, 55, 165. (c) Minagawa, K.; Kouzuki, S.; Tani, H.; Ishii, K.; Tanimoto, T.; Terui, Y.; Kamigauchi, T. J. Antibiot. 2002, 55, 239 and references cited therein. (d) For the first total synthesis of racemic stachyflin, see: Taishi, T.; Takechi, S.; Mori, S. Tetrahedron Lett. 1998, 39, 4347. (e) Kamigauchi, T.; Fujiwara, T.; Tani, H.; Kawamura, Y.; Horibe, I. Patent WO 9711947, 1997.

88. Corey, E. J.; Das, J. J. Am. Chem. Soc. 1982, 104, 5552. 
89. (a) Corey, E. J.; Tius, M. A.; Das, J. J. Am. Chem. Soc. 1980, 102, 1742. (b) Corey, E. J.; Tius, M. A.; Das, J. J. Am. Chem. Soc. 1980, 102, 7612. (c) Sum, F.-W.; Weiler, L. Can. J. Chem. 1979, 57, 1431.

90. McMurry, J. E.; Erion, M. D. J. Am. Chem. Soc. 1985, 107, 2712.

91. (a) Singh, S. B.; Zink, D. L.; Williams, M.; Polishook, J. D.; Sanchez, M.; Silverman, K. C.; Lingham, R. B. Bioorg. Med. Chem. Lett. 1998, 8, 2071. (b) Iwasaki, K.; Nakatani, M.; Inoue, I.; Katoh, T. Tetrahedron Lett. 2002, 43, 7937. (c) Iwasaki, K.; Nakatani, M.; Inoue, I.; Katoh, T. Tetrahedron 2003, 59, 8763.

92. Estrada, E.; Uriarte, E.; Montero, A.; Teijeira, M.; Santana, L.; De Clercq, E. J. Med. Chem. 2000, 43, 1975.

93. Dethoup, T.; Manoch, L.; Kijjoa, A.; Pinto, M.; Gales, L.; Damas, A. M.; Silva, A. M. S.; Eaton, G.; Herz, W. J. Nat. Prod. 2007, 70, 1200.

94. Mori, K.; Komatsu, M. Liebigs Ann. Chem. 1988, 107.

95. Mori, K.; Mori, H. Tetrahedron 1985, 41, 5487.

96. Mori, K.; Mori, H.; Yanai, M. Tetrahedron 1986, 42, 291.

97. Reich, H. J.; Renga, J. M.; Reich, I. L. J. Am. Chem. Soc. 1975, 97, 5434.

98. (a) Mori, K.; Watanabe, H. Tetrahedron 1986, 42, 273. (b) Hollingshead, D. N.; Howell, S. C.; Ley, S. V.; Nahon, N.; Ratcliffe, N. N.; Worthington, P. J. Chem. Soc., Perkin Trans. 1 1983, 1579.

99. Ohsuka, A. Nippon Kagaku Zasshi 1963, 84, 748 [Chem. Abstr. 1964, 60, 132771].

100.Lombardo, L.; Mander, L. N.; Turner, J. V. J. Am. Chem. Soc. 1986, 102, 6626.

101.Grove, J. F.; MacMillan, J.; Mulholland, T. P. C.; Rogers, M. A. Th. J. Chem. Soc. 1952, 3977.

102.Danishefsky, S.; Walker, F. J. J. Am. Chem. Soc. 1979, 101, 7018.

103.Antus, S.; Baits-Gacs, E.; Snatzke, G.; Vas, J. Tetrahedron 1986, 42, 5637.

104. (a) Kaufman, T. S.; Sindelar, R. D. J. Heterocyclic Chem. 1989, 26, 879. (b) Kaufman, T. S. J. Chem. Soc., Perkin Trans. 1 1993, 403. (c) Kaufman, T. S. J. Chem. Soc., Perkin Trans. 1 1996, 2497.

105.Franck, X.; Figadére, B.; Cavé, A. Tetrahedron Lett. 1997, 38, 1413.

106.(a) Williams, G. J.; Hunter, N. R. Can. J. Chem. 1976, 54, 3830. (b) Dunlap, N. K.; Sabol, M. R.; Watt, D. S. Tetrahedron Lett. 1984, 25, 5839. (c) Demir, A. S.; Jeganathan, A. Synthesis 1992, 235.

107.Snider, B. B.; Kiselgof, E. Y. Tetrahedron 1996, 52, 6073.

108.Snider, B. B.; Han, L.; Xie, C. J. Org. Chem. 1997, 62, 6978.

109. Snider, B. B. Chem. Rev. 1996, 96, 339.

110.Fristad, W. E.; Peterson, J. R.; Ernst, A. B.; Urbi, G. B. Tetrahedron 1986, 42, 3429.

111.Srivastava, R. P.; Zhu, X.; Walker, L. A.; Sindelar, R. D. Bioorg. Med. Chem. Lett. 1995, 5, 1751. 
112.Lipinski, C. A. In Annual Reports in Medicinal Chemistry; Bailey, D. M. Ed.; Academic Press: Orlando, Florida, 1986; pp. 283-291.

113. Weisman, H. F.; Batow, T.; Leppo, M. K.; Marsh Jr., H. C.; Carson, G. R.; Concino, M. F.; Boyle, M. P.; Roux, K. H.; Weisfeldt, M. L.; Fearon, D. T. Science 1990, 249, 146.

114.Bradbury, B. J.; Sindelar, R. D. J. Heterocyclic Chem. 1989, 26, 1827.

115.(a) Narasimhan, N. S.; Mali, R. S. Synthesis 1983, 957. (b) Gschwend, H. W.; Rodríguez, H. R. Org. React. 1979, 26, 1.

116.(a) Welch, S. C.; Prakasa Rao, A. S. C. J. Org. Chem. 1978, 43, 1957. (b) Weissman, S. A.; Zewge, D. Tetrahedron 2005, 61, 7833. (c) Bianchi, D. A.; Brambilla, L.; Gattuso, M. A.; Kaufman, T. S. J. Plant Growth. Regul. 2006, 25, 332.

117. (a) Comins, D. L.; Brown, J. D. J. Org. Chem. 1984, 49, 1078. (b) Larsen, R. D.; Corley, E. G.; King, A. O.; Carroll, J. D.; Davis, P.; Verhoeven, T. R.; Reider, P. J. J. Org. Chem. 1996, 61, 3398. (c) Grig-Alexa, I. C.; Finaru, A. L.; Caubère, P.; Guillaumet, G. Org. Lett. 2006, 8, 4187.

118. Bradbury, B. J.; Bartyzel, P.; Kaufman, T. S.; Nieto, M. J.; Sindelar, R. D.; Scesney, S. M.; Gaumond, B. R.; Marsh Jr., H. C. J. Med. Chem. 2003, 46, 2697.

119.(a) Orito, K.; Miyazawa, M.; Suginome, H. Tetrahedron 1995, 51, 2489. (b) Uemura, M.; Nishikawa, N.; Tokuyama, S.; Hayashi, Y. Bull. Chem. Soc. Japan 1980, 53, 293.

120.(a) Deng, X.; Stefanick, S.; Pippel, M. C. W.; Mani, N. S. Org. Proc. Res. Dev. 2006, 10, 1287. (b) Srinivasan, N.; Ramadas, K. Tetrahedron Lett. 2001, 42, 2001. (c) Nakayama, H.; Bull. Chem. Soc. Japan 1983, 56, 877. (d) Soldatenkov, A. T.; Temesgen, A. V.; Kolyadina, N. M. Chem. Heterocyclic Comp. 2004, 40, 537.

121.Platts-Mills, T. A. E.; Ishizaka, K. J. Immunol. 1974, 113, 348.

122.Kaufman, T. S.; Srivastava, R. P.; Sindelar, R. D.; Scesney, S. M.; Marsh Jr., H. C. J. Med. Chem. 1995, 38, 1437.

123. Crawford, R. L.; Erman, W. F.; Broaddus, C. D. J. Am. Chem. Soc. 1972, 94, 4298.

124.Kaufman, T. S.; Srivastava, R. P.; Sindelar, R. D. Org. Prep. Proc. Int. 1994, 26, 557.

125. Yeh, C. G.; Marsh Jr., H. C.; Carson, G. R.; Berman, L.; Concino, M. F.; Scesney, S. M.; Kuestner, R. E.; Skibbens, R., Donahue, K. A.; Ip, S. H. J. Immunol. 1991, 146, 250.

126. Kaufman, T. S.; Srivastava, R. P.; Sindelar, R. D. Bioorg. Med. Chem. Lett. 1995, 5, 501.

127.(a) Hegde, S. G.; Vogel, M. K.; Saddler, J.; Hrinyo, T.; Rockwell, N.; Haynes, R.; Oliver, M.; Wolinsky, J. Tetrahedron Lett. 1980, 21, 441. (b) Baccelli, C.; Navarro, I.; Block, S.; Abad, A.; Morel, N.; Quetin-Leclercq, J. J. Nat. Prod. 2007, 70, 910.

128. Srivastava, R. P.; Zhu, X.; Walker, L: A.; Sindelar, R. D. Bioorg. Med. Chem. Lett. 1995, 5, 2429.

129.Useglio, M.; Castellano, P. M.; Operto, M. A.; Torres, R.; Kaufman, T. S. Bioorg. Med. Chem. Lett. 2006, 16, 5097.

130.Larghi, E. L.; Operto, M. A.; Torres, R.; Kaufman, T. S. Bioorg. Med. Chem. Lett. 2009, 19, 6172. 
131.Bianchi, D. A.; Bracca, A. B. J.; Schmeda Hirschmann, G.; Theoduloz, C.; Kaufman, T. S. Bioorg. Med. Chem. Lett. 2005, 15, 2711.

132. (a) Larghi, E. L.; Obrist, B. V.; Kaufman, T. S. Tetrahedron 2008, 64, 5236. (b) Tetrahedron Lett. 1997, 38, 3159.

133.(a) Ponzo, V. L.; Kaufman, T. S. Synlett 1995, 1149. (b) Bianchi, D. A.; Kaufman, T. S. Can. J. Chem. 2000, 78, 1165. (c) Bianchi, D. A.; Cipulli, M. A.; Kaufman, T. S. Eur. J. Org. Chem. 2003, 4701. 